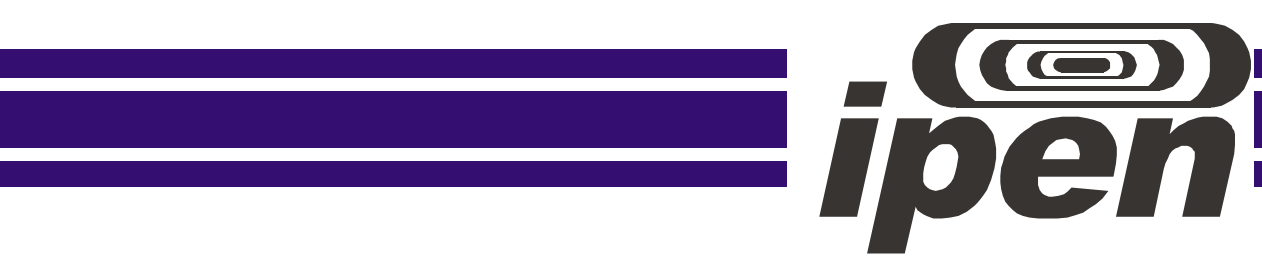

AUTARQUIA ASSOCIADA À UNIVERSIDADE DE SÃO PAULO

\title{
ESTUDO DA INFLUÊNCIA DE PARTÍCULAS DE OURO NA DOSE ABSORVIDA EM TECIDO MOLE UTILIZANDO DOSIMETRIA COM GEL POLIMÉRICO
}

\author{
Luciana Caminha Afonso
}

Tese apresentada como parte

dos requisitos para obtenção do Grau de Doutor em Ciências na Área de Tecnologia Nuclear - Aplicações

Orientadora:

Profa. Dra. Linda V. E. Caldas 
INSTITUTO DE PESQUISAS ENERGÉTICAS E NUCLEARES

Autarquia associada à Universidade de São Paulo

\title{
ESTUDO DA INFLUÊNCIA DE PARTÍCULAS DE OURO NA DOSE ABSORVIDA EM TECIDO MOLE UTILIZANDO DOSIMETRIA COM GEL POLIMÉRICO
}

\author{
LUCIANA CAMINHA AFONSO
}

Tese apresentada como parte dos requisitos para obtenção do Grau de Doutor em Ciências na Área de Tecnologia Nuclear - Aplicações.

Orientadora:

Profa. Dra. LINDA V.E. CALDAS

SÃO PAULO

2011 


\section{AGRADECIMENTOS}

À Dra. Linda V. E. Caldas, pela orientação nesta jornada acadêmica desde a Iniciação Científica e pelos conselhos e incentivos tanto na vida profissional como na vida pessoal.

À Dra. Maria da Penha Albuquerque Potiens e ao Dr. Vitor Vivolo, pelas discussões e sugestões desde o início da minha vida acadêmica.

À Sra. Donata C. O. Zanin, pela assistência nos assuntos administrativos.

Ao Conselho Nacional de Desenvolvimento Científico e Tecnológico e à Coordenação de Aperfeiçoamento de Pessoal de Nível Superior, pelo auxílio financeiro durante o desenvolvimento deste trabalho.

À Comissão de Pós-Graduação do IPEN, por possibilitar o desenvolvimento deste projeto.

Ao Helmholtz Center Munich, pela infra-estrutura oferecida para o desenvolvimento deste projeto de cooperação.

Ao Dr. Christoph Hoeschen, ao Dr. Uwe Oeh e ao Dr. Felix Schöfer, pela co-orientação no desenvolvimento deste trabalho.

Aos colegas do Helmholtz Center Munich, pelo companheirismo e discussões científicas durante a execução deste trabalho.

Aos velhos amigos e aos amigos que se revelaram ao longo dos últimos anos: Alessio Mangiarotti, Aline Rodrigues Ajala, Anahí Philippart, Daniele Nogueira Milani, Diana Renata Gonçalves Gama, Elisângela Moura Linares, Fernanda Yamashitafuji, João Pedro Kerr Catunda, Leandro Gibelli Molon, Lélia Maria Luzia, Maria Antonia Gibelli Molon, Marilia Gabriela Oséas Quadrado, Monika Keusch e Thyago Fressati Mangueira.

Aos meus familiares, João Afonso, Vera Lucia Caminha Afonso e Guilherme Caminha Afonso, pelo amor e carinho durante o percurso da vida e pelo suporte emocional e financeiro durante a construção da carreira acadêmica.

Ao meu namorado, Thomas Wieser, pelo amor, paciência, dedicação e companheirismo mesmo nos momentos mais estressantes. 


\title{
ESTUDO DA INFLUÊNCIA DE PARTÍCULAS DE OURO NA DOSE ABSORVIDA EM TECIDO MOLE UTILIZANDO DOSIMETRIA COM GEL POLIMÉRICO
}

\author{
Luciana Caminha Afonso
}

\begin{abstract}
RESUMO
A presença de material de alto número atômico adjacente ao tecido mole aumenta localmente a dose absorvida pelo tecido quando submetido à radiação. Este efeito ocorre devido aos fotoelétrons ejetados do material de alto número atômico. Dosímetros de gel polimérico com partículas de ouro foram utilizados para investigar este efeito. Foram realizados cálculos analíticos para estimar o aumento de dose e simulações com o método de Monte Carlo. A irradiação de amostras de gel polimérico (GP) puro e com 0,005 gAu/gGP utilizando um feixe de raios $X$ produzido por um potencial de $150 \mathrm{kV}$ filtrado com $4 \mathrm{mmAl}$ e $5 \mathrm{mmCu}$ resultou em uma dose absorvida pelas amostras com ouro aproximadamente $20 \%$ maior que a dose absorvida pelas amostras de gel polimérico puro. Os cálculos analíticos e a simulação com o método de Monte Carlo resultaram em um aumento de aproximadamente $30 \%$ na dose absorvida.
\end{abstract}




\title{
STUDY OF THE INFLUENCE OF GOLD PARTICLES ON THE ABSORBED DOSE IN SOFT TISSUE USING POLYMER GEL DOSIMETRY
}

\author{
Luciana Caminha Afonso
}

\begin{abstract}
The presence of high- $Z$ material adjacent to soft tissue, when submitted to irradiation, enhances locally the absorbed dose in these soft tissues. Such effect occurs due to the outscattering of photoelectrons from the high- $Z$ material. Polymer gel dosimeters have been used to investigate this effect. Analytic calculations to estimate the dose enhancement and Monte Carlo simulations have been performed. Samples containing polymer gel (PG) with $0.005 \mathrm{gAu} / \mathrm{gPG}$ and pure polymer gel have been irradiated using an X-rays beam produced by $150 \mathrm{kV}$, filtered with $4 \mathrm{~mm} \mathrm{Al}$ and $5 \mathrm{~mm} \mathrm{Cu}$, which resulted in an approximately $20 \%$ higher absorbed dose in the samples with gold in comparison to those with pure polymer gel. The analytic calculations and the Monte Carlo simulation resulted in a dose enhancement factor of approximately $30 \%$.
\end{abstract}




\section{SUMÁRIO}

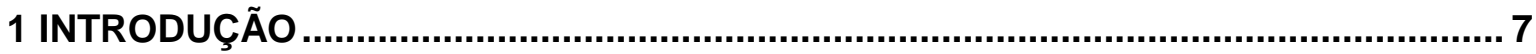

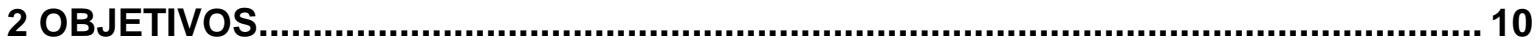

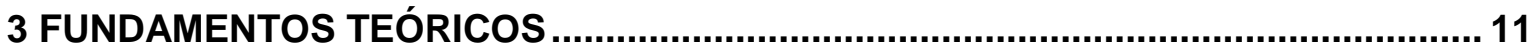

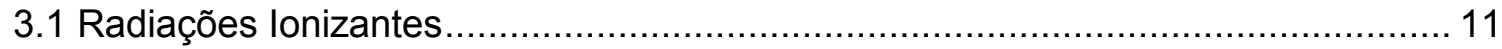

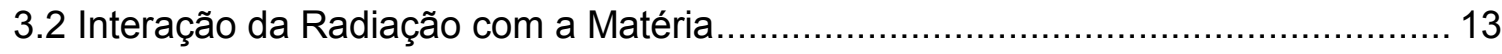

3.2.1 Interação de Fótons com a Matéria .......................................................... 13

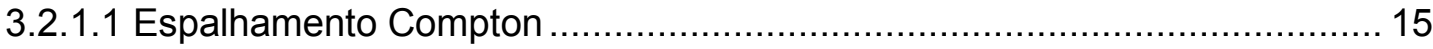

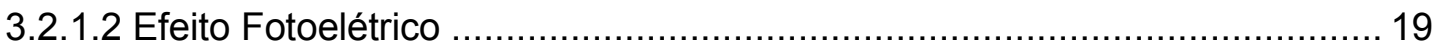

3.2.1.3 Coeficientes de Transferência de Energia e de Absorção de Energia ......... 25

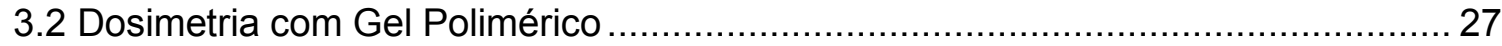

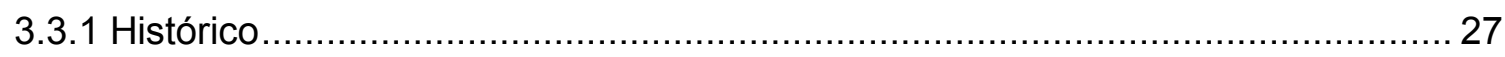

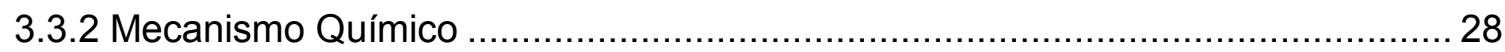

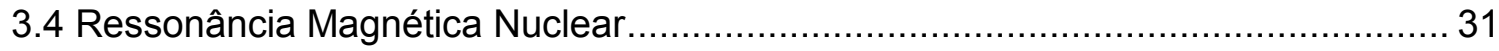

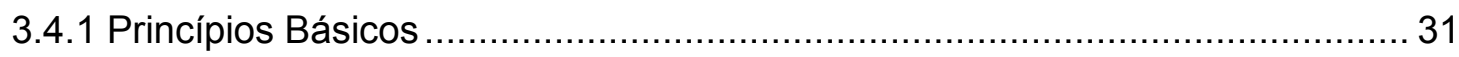

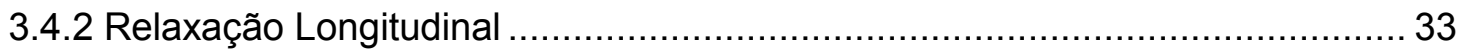

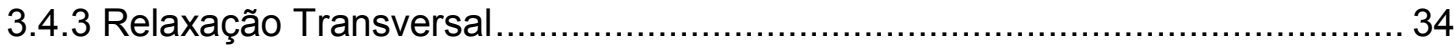

3.4.4 Avaliação dos Dosímetros de Gel Polimérico utilizando Ressonância Magnética

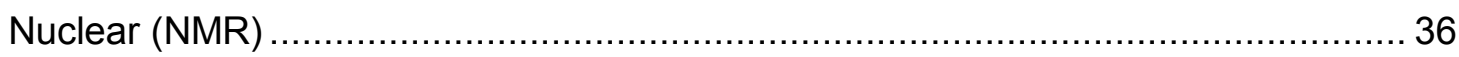

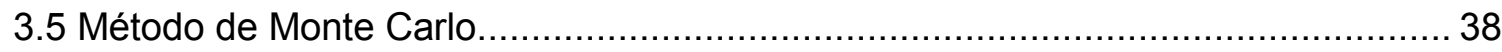

3.5.1 Números Aleatórios Uniformimente Distribuídos ....................................... 38

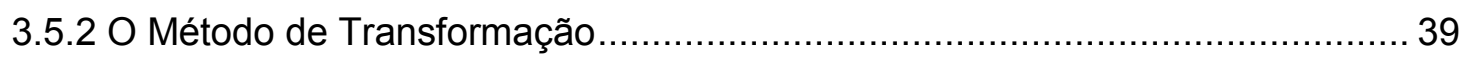

3.5.3 O Método de Aceitação-Rejeição ............................................................. 40

3.5.4 Aplicações do Método de Monte Carlo .................................................... 41

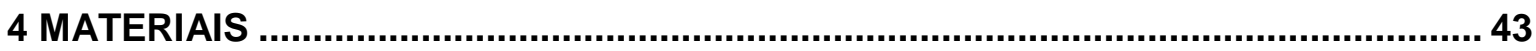

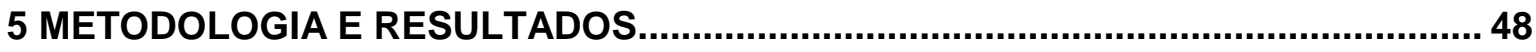

5.1 Caracterização do Dosímetro de Gel Polimérico................................................ 48

5.1.1 Produção do Dosímetro de Gel Polimérico.................................................. 48

5.1.2 Avaliação do Gel Polimérico com Ressonância Magnética Nuclear ................ 49 
5.1.3 Dependência do Dosímetro em Relação aos Intervalos Produção-Irradiação e Irradiação-Avaliação 53

5.1.4 Comportamento Dosimétrico para Fótons ............................................. 57

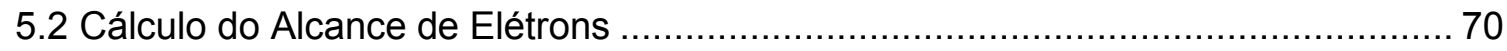

5.3 Experimentos Preliminares com Folhas de Ouro …......................................... 72

5.4 Feixes de Raios X que aumentam o Efeito Fotoelétrico ........................................ 78

5.5 Cálculo dos Coeficientes de Absorção Mássica de Energia .................................. 85

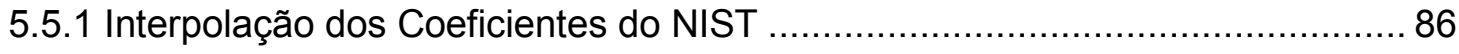

5.5.2 Cálculo dos Coeficientes de Absorção Mássica de Energia para o Gel

Polimérico Puro e para o Gel Polimérico com Ouro .................................................. 90

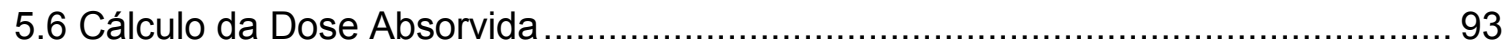

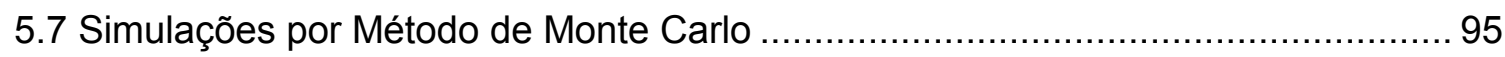

$5.8 \mathrm{Gel}$ Polimérico com Microesferas de Ouro ........................................................ 102

5.8.1 Irradiação com o Espectro de Raios X do Feixe 50*................................. 102

5.8.2 Irradiação com o Espectro de Raios X do Feixe 150*................................ 105

6 CONCLUSÕES E CONSIDERAÇÕES FINAIS ........................................................ 109

7 REFERÊNCIAS .............................................................................................. 112

Anexo: Trabalhos publicados em anais de congressos ......................................... 116 


\section{INTRODUÇÃo}

A Radioterapia está entre os três principais métodos de tratamento de câncer, sendo os outros dois a cirurgia e quimioterapia. Muitas especialidades médicas contam principalmente com o conhecimento clínico e a experiência dos especialistas; entretanto, a radioterapia, devido à utilização da radiação ionizante no tratamento do câncer, depende fortemente da tecnologia e do empenho dos diversos profissionais envolvidos no entendimento da física subjacente. Os avanços da radioterapia são baseados essencialmente na física da interação da radiação com a matéria e no desenvolvimento tecnológico de equipamentos.

Desde a descoberta dos raios X por Whilhelm C. Roentgen em 1895, os raios $X$ começaram a ser utilizados em medicina diagnóstica e terapêutica, tendo Emil A. Grubbe como pioneiro em 1896. No mesmo ano, Pierre e Marie Curie descobriram o Rádio 226, introduzindo-o em terapia. Nesta época, os cirurgiões passaram a utilizar as radiações no tratamento de tumores malignos, acreditando atuarem por ação cáustica nos tecidos. A falta de conhecimentos técnicos e científicos levou ao aparecimento de inúmeras e graves complicações levando as aplicações terapêuticas ao descrédito.

Os progressos da Física Médica na década de 30 permitiram quantificar as doses de radiação e estabelecer comparações entre quantidade de radiação e efeito biológico. Essas comparações eram provenientes de observações clínicas que relacionavam o efeito das radiações sobre os tecidos com o tempo de administração.

A radioterapia é um método capaz de destruir células tumorais, empregando feixes de radiações ionizantes. Uma dose pré-calculada de radiação é aplicada a um volume de tecido que engloba o tumor, buscando erradicar todas as células tumorais, com o menor dano possível às células sadias circunvizinhas, à custa das quais se fará a regeneração da área irradiada. Portanto, o principal desafio em radioterapia é depositar uma alta dose de radiação no tumor sem exceder a tolerância do tecido saudável. 
A resposta dos tecidos às radiações depende de diversos fatores, tais como a sensibilidade do tecido à radiação, sua localização e oxigenação, assim como a qualidade e a quantidade da radiação e o tempo total em que ela é administrada. A velocidade da regressão tumoral é proporcional ao grau de radiossensibilidade do tecido onde o tumor está localizado. A maioria dos tumores radiossensíveis são radiocuráveis. Entretanto, alguns tumores se disseminam independentemente do controle local; outros apresentam sensibilidade tão próxima à dos tecidos normais, que esta impede a aplicação da dose de erradicação, originando, então, uma limitação em radioterapia. Os esforços para superar esta limitação focam em métodos capazes de "moldar" a distribuição de dose em torno do volume tumoral por meio de aperfeiçoamento das técnicas de imagem e planejamento do tratamento, aproveitando a flexibilidade de técnicas avançadas como IMRT (Intensity Modulated Radiation Therapy). A curabilidade local só é atingida quando a dose de radiação aplicada é letal para todas as células tumorais; sem ultrapassar, entretanto, a tolerância dos tecidos sadios.

Tratamentos em radioterapia são baseados na emissão de radiação ionizante por meio de equipamentos de raios $X$, aceleradores de elétrons $\mathrm{e}$ irradiadores gama e beta com fontes radioativas. Esses equipamentos são usados como fontes externas, mantendo distâncias da pele que variam de 1 centímetro a 1 metro (teleterapia). Estas técnicas constituem a radioterapia clínica e se prestam para tratamento de lesões superficiais, semi-profundas ou profundas, dependendo da qualidade da radiação gerada pelo equipamento.

Os isótopos radioativos (cobalto, césio, irídio etc.) ou sais de rádio são utilizados sob a forma de tubos, agulhas, fios, sementes ou placas e geram radiações, habitualmente gama, de diferentes energias, dependendo do elemento radioativo empregado.

O tratamento radioterápico apresenta efeitos colaterais, que são normalmente bem tolerados, desde que as doses pré-calculadas de radiação aplicadas ao tumor sejam eficientemente atingidas.

Os efeitos colaterais do tratamento radioterápico podem ser classificados em imediatos e tardios. Os efeitos imediatos são observados nos tecidos que apresentam maior capacidade proliferativa, como as gônadas, a epiderme, as mucosas dos tratos digestivo, urinário e genital, e a medula óssea. 
Eles ocorrem somente se estes tecidos estiverem incluídos no campo de irradiação e podem ser potencializados pela administração simultânea de medicamentos quimioterápicos. Já os efeitos tardios são raros e ocorrem quando as doses de tolerância dos tecidos sadios são ultrapassadas. Os efeitos tardios manifestam-se por atrofias e fibroses. Menos frequentemente, são observadas também alterações de caráter genético e o desenvolvimento de outros tumores malignos.

O desenvolvimento da Física e da Engenharia Nuclear proporcionaram um grande avanço na produção de materiais radioativos obtidos artificialmente, propiciando novas fontes (entre elas o cobalto 60) com diferentes características para uso em terapias.

No caso da radioterapia com fótons, por exemplo, a dose é concebida a partir da energia depositada por elétrons originados de interações físicas variadas entre os fótons e o tecido tumoral. A compreensão mais aprofundada destas interações trouxe as bases teóricas para o desenvolvimento de sistemas de planejamento de tratamentos capazes de concentrar grandes doses de radiação em um determinado volume alvo, protegendo os tecidos sadios e lesando ao máximo os tumorais. (INCA website; Schaberle \& Silva website; Podgorsak, 2005)

Uma alternativa seria "ajustar" a probabilidade de interação do fóton com o tumor, possibilitando um aumento seletivo da dose no volume do tumor durante a irradiação. Levando em consideração que a probabilidade de ocorrer a absorção de um fóton por efeito fotoelétrico aumenta drasticamente com o número atômico do meio, a inserção de uma substância de alto número atômico no tumor resultaria no aumento da fração de energia transmitida do fóton incidente para o tumor, sem aumentar o dano no tecido saudável próximo ao tumor.

Esta alternativa poderia ser explorada por meio da introdução de contrastes, que é um conceito muito bem estabelecido há muitos anos no campo de diagnóstico por imagem. Agentes de contraste são amplamente utilizados em combinação com técnicas como Tomografia Computadorizada (CT) e Ressonância Magnética Nuclear (NMR). Contudo, estudos acerca dos riscos na utilização destes contrastes encontraram danos maiores nos tecidos após procedimentos de diagnóstico por imagem utilizando contrastes (Norman et al, 
1978), indicando que pode haver um risco aumentado de dano radiológico associado com uma maior absorção. (McMahon, 2008; Jones, 2010)

Ao mesmo tempo em que este fato é um problema para aplições em radiodiagnóstico, também indica o potencial destes contrastes para aprimorar o dano provocado por uma dose no contexto de radioterapia. Os estudos baseados nesta idéia, utilizando contrastes tradicionais, como contraste iodado e gadolínio; agentes quimioterápicos carregados de elementos pesados; e novos materiais, como ouro, indicaram uma vantagem na aplicação terapêutica destes contrastes, embora com diferentes graus de eficácia (McMahon, 2008).

O conceito primário deste efeito é derivado do aumento radical da seção de choque para interação fotoelétrica em materiais de número atômico alto, que, consequentemente, aumenta o coeficiente de absorção mássica de energia, aumentando, por sua vez, a dose na vizinhança (tecido mole tumoral) destes elementos de alto número atômico.

\section{OBJETIVOS}

Com base na possibilidade da aplicação em radioterapia do efeito de aumento de dose causado pela presença de materiais de alto número atômico em tecido mole, o objetivo principal deste trabalho foi mensurar o aumento da dose absorvida causado pela presença de ouro em tecido mole. Para tanto, a técnica de dosimetria por gel polimérico foi utilizada, uma vez que sua principal característica é a de tecido-equivalência; supostamente os fotoelétrons ejetados pelo ouro causam o mesmo efeito que em tecido mole. Outros objetivos deste trabalho consistiram em estudar o comportamento dosimétrico do gel polimérico para utilizá-lo na medição do aumento de dose causado pela presença de ouro durante a irradiação; avaliar a dimensão do efeito em questão por meio de cálculos analíticos e, posteriormente, por simulações pelo método de Monte Carlo. 


\section{FUNDAMENTOS TEÓRICOS}

\subsection{Radiações lonizantes}

As radiações ionizantes são caracterizadas pela capacidade de excitar e ionizar átomos de materiais com os quais elas interagem. A energia mínima necessária para provocar o escape de um elétron de valência de um átomo é da ordem de poucas dezenas de elétrons-volt, portanto as radiações devem transportar energia cinética ou quântica acima deste limiar para ser considerada "ionizante". Este critério poderia incluir radiação eletromagnética com comprimentos de onda de até $320 \mathrm{~nm}$, o que incluiria uma grande parte da banda ultravioleta do espectro eletromagnético; no entanto, por motivos práticos, a radiação ultravioleta não é considerada no contexto da física radiológica, uma vez que a sua capacidade de penetração é ainda menor que a da luz visível, enquanto outras radiações ionizantes são geralmente mais penetrantes.

Os tipos mais importantes de radiação ionizante são:

- Raios gama $(y)$ : radiação eletromagnética emitida de um núcleo ou em processos de aniquilação entre matéria e antimatéria. A faixa de energia destes fótons emitidos de átomos radioativos varia de 2,6 keV a 7,1 MeV.

- Raios X: radiação eletromagnética emitida por partículas carregadas (geralmente elétrons) durante a mudança entre níveis atômicos de energia (chamado raio $X$ característico) ou durante a desaceleração da partícula carregada ao atravessar um campo de força coulombiana (radiação contínua ou de freamento, Bremsstrahlung). A faixa de energia destes fótons varia de poucos keV até $\mathrm{MeV}$.

Os fótons de raios gama e fótons de raios $X$ de mesma energia possuem exatamente as mesmas propriedades, diferindo apenas por suas origens.

- Elétrons rápidos: se carregados positivamente, são chamados pósitrons. Se eles forem emitidos por um núcleo, são chamados de raios beta $(\beta)$. Se resultam de uma colisão entre partículas carregadas, são chamados de raios 
delta $(\delta)$. Feixes contínuos de elétrons chegam a $12 \mathrm{MeV}$, enquanto feixes pulsados atingem energias muito mais altas.

- Partículas carregadas pesadas: são partículas com massa maior ou igual a uma unidade de massa atômica. Podem ser partículas alfa ( $\alpha$ ), prótons, dêuterons, fragmentos de fissão e outras partículas geralmente produzidas em aceleradores.

- Nêutrons: partículas neutras obtidas de reações nucleares, uma vez que não possuem carga para serem aceleradas eletrostaticamente.

A faixa de energia cinética ou de energia de fótons geralmente de aplicações das radiações ionizantes varia de $10 \mathrm{keV}$ a $10 \mathrm{MeV}$ e os principais dados sobre a interação dessas radiações com a matéria enfatizam justamente esta faixa de energias.

A International Commission on Radiation Units and Measurements (ICRU, 2007) recomendou terminologias que distinguem as radiações ionizantos de acordo com as diferenças entre as radiações carregadas e as não-carregadas.

- Radiação diretamente ionizante: partículas rápidas carregadas, que depositam suas energias na matéria de forma direta, por meio de várias pequenas interações de força coulombiana ao longo do seu trajeto.

- Radiação indiretamente ionizante: fótons de raios X ou gama e nêutrons, que transferem suas energias para as partículas carregadas presentes na matéria, por meio de poucas, porém energeticamente intensas, interações. Então, estas partículas carregadas e aceleradas passam a depositar a energia na matéria, como a radiação diretamente ionizante. Portanto, no caso da radiação indiretamente ionizante, o processo de deposição de energia se dá em dois passos.

A radiação ionizante produz efeitos únicos na matéria com a qual interage, especialmente em sistemas biológicos, que são particularmente susceptíveis aos danos causados pela radiação. A radiação ionizante tem a capacidade de transferir sua energia para átomos individuais, moléculas e células de sistemas biológicos. O resultado de uma concentração alta de energia absorvida pode matar uma célula tanto diretamente quanto por meio da formação de espécies químicas altamente reativas, como radicais livres em meios aquosos que constituem grande parte dos materiais biológicos. A radiação ionizante 
também pode causar grandes alterações em compostos orgânicos pela quebra de ligações moleculares, ou em materiais cristalinos por causar defeitos na estrutura reticular (Attix, 2005; Podgorsak, 2005).

\subsection{Interação da Radiação com a Matéria}

Para a radiação ionizante, a matéria é como um agregado de elétrons e núcleos. Dependendo do tipo de radiação, da sua energia e do tipo de material, as reações com os átomos ou com os núcleos podem ocorrer através de qualquer via possível. Uma partícula alfa atravessando uma folha de ouro, por exemplo, pode sofrer espalhamento elástico por força coulombiana proveniente de um núcleo, ou pode colidir eletromagneticamente com um elétron orbial, ou pode ser absorvida em uma reação nuclear para produzir outros tipos de radiação, através de outros processos. Esses processos ocorrem com uma certa probabilidade, que é regida pelas leis da mecânica quântica e pelas intensidades relativas de cada interação básica envolvida. Para partículas carregadas e fótons, os processos mais frequentes são interações eletromagnéticas, em particular colisões inelásticas com os elétrons orbitais dos átomos, devido à força e ao longo alcance da força coulombiana em relação a outras interações. No caso dos nêutrons, os processos envolvendo interações fortes têm preferência de ocorrer, embora a interação também esteja sujeita a processos eletromagnéticos.

Os processos permitidos para cada tipo de radiação possibilitam a caracterização da capacidade de penetração da radiação na matéria, sua dificuldade de detecção, e seu risco para organismos biológicos, entre outros. (Attix, 2005; Podgorsak, 2005; Turner, 2007)

Neste texto serão desenvolvidos apenas os conceitos de interação da radiação com a matéria relevantes para o desenvolvimento deste trabalho.

\subsubsection{Interação de Fótons com a Matéria}

Os fótons são eletricamente neutros e não perdem energia continuamente conforme penetram na matéria. Contrariamente, eles podem viajar alguma distância antes de interagir com um átomo. A profundidade penetrada por um determinado fóton é regida estatisticamente por uma probabilidade de interação por unidade de distância viajada, que depende do meio atravessado e 
da energia do fóton. Quando interage com um átomo, ele pode ser absorvido e, assim, desaparecer ou pode ser espalhado, modificando a sua direção, com ou sem perda de energia.

Espalhamentos Thomson e Rayleigh são dois processos através dos quais os fótons interagem com a matéria sem considerável transferência de energia. No espalhamento Thomson um elétron livre oscila classicamente em resposta ao vetor elétrico resultante da passagem de uma onda eletromagnética. O elétron oscilante emite radiação (fótons) de mesma frequência que a onda incidente. Esse efeito no sistema é elástico e consiste no redirecionamento de alguns fótons incidentes, sem transferência de energia para o meio.

O espalhamento Rayleigh de um fóton é o resultado da combinação da ação de um átomo como um todo. O ângulo de espalhamento normalmente é muito pequeno. Não há uma transferência de energia relevante do fóton para o átomo, o qual se movimenta o suficiente para conservar o momento. $O$ espalhamento Rayleigh não contribui para o kerma ou para a dose, uma vez que nenhuma energia é transferida para qualquer partícula carregada; portanto, nem ionização nem excitação são produzidas. O espalhamento Rayleigh possui alguma relevância apenas em energias baixas, para as quais os ângulos de espalhamento são maiores.

Como os espalhamentos Thomson e Rayleigh não depositam energia na matéria, estes não serão discutidos em detalhes. Os principais mecanismos de deposição de energia por um fóton na matéria são: o espalhamento Compton, absorção fotoelétrica, produção de pares e reações fotonucleares.

Na produção de pares, o fóton desaparece e um par elétron-pósitron é produzido no campo coulombiano do núcleo, ambos com energia cinética igual a $h v-2 m_{e} c^{2}$ (em que $h v$ é a energia do fóton, $m_{e}$ é a massa do elétron em repouso e $c$ é a velocidade da luz no vácuo). Como há produção de massa a partir da energia de um fóton, este efeito só pode ocorrer a partir de um limite mínimo de energia do fóton, 1,02 MeV. Como as energias dos fótons utilizados neste trabalho estão abaixo deste limite, este mecanismo não será abordado em detalhes.

As reações fotonucleares (também conhecidas como reações de fotodesintegração) ocorrem quando um fóton de alta energia é absorvido pelo 
núcleo de um átomo, resultando na emissão de um nêutron (reação $(x, n)$ ) ou de um próton (reação $(x, p)$ ) e na transformação do núcleo em um produto radioativo. O limite mínimo para a ocorrência deste mecanismo é da ordem de $10 \mathrm{MeV}$, portanto este mecanismo também não será abordado em detalhes (Attix, 2005; Leo, 1987; Podgorsak, 2005; Turner, 2007).

\subsubsection{Espalhamento Compton}

O efeito Compton é convenientemente subdividido em dois aspectos: cinemática e seção de choque. A cinemática relaciona as energias e os ângulos das partículas envolvidas quando um evento do tipo Compton ocorre. A seção de choque prevê a probabilidade de acontecer uma interação do tipo Compton. Em ambos aspectos considera-se que o elétron atingido pelo fóton incidente não está ligado e é estacionário. Estas suposições não são rigorosas, dado que os elétrons ocupam diversos níveis atômicos de energia, estando, portanto, em movimento e ligados ao núcleo. No entanto, se a energia do fóton é alta em relação à energia de ligação, esta pode ser desprezada e os elétrons podem ser considerados como livres. Os erros resultantes não trazem consequências para aplicações em física radiológica.

Do ponto de vista cinemático, o espalhamento Compton está representado esquematicamente na Figura 3.1, em que um fóton de energia $h v \mathrm{e}$ momento $h v / c$ interage com um elétron livre em repouso com energia total $m_{e} c^{2}$. Como resultado da colisão, o fóton é espalhado com um ângulo $\theta$, energia reduzida a $h v^{\prime}$ e momento $h v^{\prime} / c$; o elétron recua com um ângulo $\varphi$, energia total $E^{\prime}$ e momento $P^{\prime}$. 


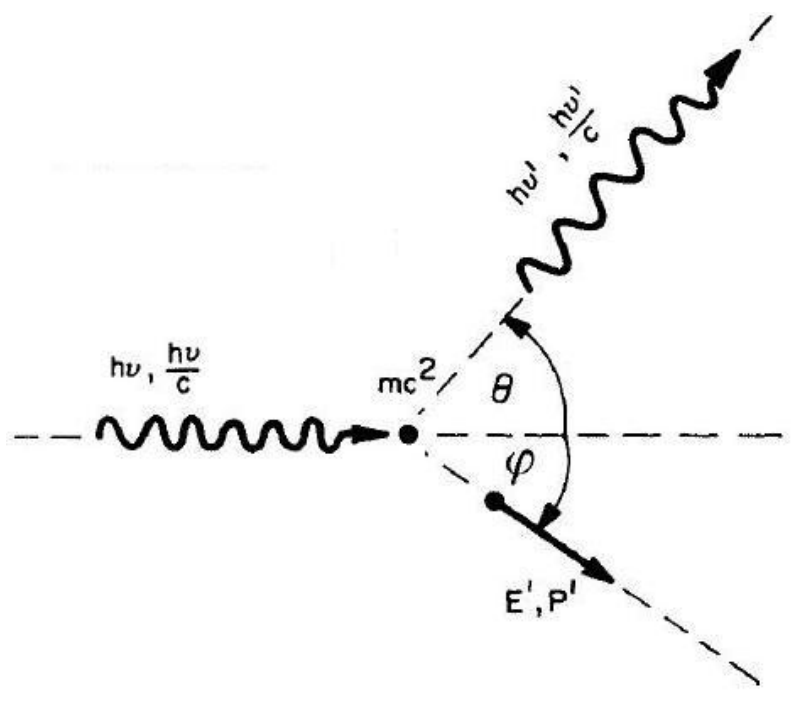

Figura 3.1 - Esquema de interação por espalhamento Compton (Figura extraída e adaptada de Attix, 2005).

Aplicando as leis de conservação de energia:

$$
h v+m c^{2}=h v^{\prime}+E
$$

e de momento:

$$
\frac{h v}{c}=\frac{h v^{\prime}}{c} \cos \theta+P^{\prime} \cos \varphi
$$

e

$$
\frac{h v^{\prime}}{c} \operatorname{sen} \theta=P^{\prime} \operatorname{sen} \varphi
$$

Eliminando $P^{\prime}$ e $\varphi$ destas equações e resolvendo para $v^{\prime}$, resulta:

$$
h v^{\prime}=\frac{h v}{1+\gamma(1-\cos \theta)},
$$

em que $\gamma=\frac{h v}{m c^{2}}$.

Até agora foi discutido como o espalhamento Compton se comporta cinematicamente, a partir das leis de conservação de energia e de momento. No entanto, nada foi dito sobre como a interação entre o fóton e o elétron ocorre ou sobre a probabilidade de um fóton ser espalhado na direção $\theta$. A teoria quântica do espalhamento Compton, baseada na interação específica fóton-elétron, fornece a fórmula de Klein-Nishina para a distribuição angular dos fótons espalhados: 


$$
\frac{d \sigma}{d \Omega}=\frac{r_{e}^{2}}{2} \frac{1}{[1+\gamma(1-\cos \theta)]^{2}}\left(1+\cos ^{2} \theta+\frac{\gamma^{2}(1-\cos \theta)^{2}}{1+\gamma(1-\cos \theta)}\right),
$$

em que $r_{e}$ é o raio do elétron.

A seção de choque de espalhamento diferencial, dada por $d \sigma / d \Omega$, é a probabilidade por unidade de ângulo sólido (em esferorradianos) de um fóton, atravessando um material contendo um elétron por metro quadrado, ser espalhado em um ângulo sólido $d \Omega$ com um ângulo $\theta$. A integral da seção de choque diferencial sobre todos os ângulos sólidos, $d \Omega=2 \pi$. $\operatorname{sen} \theta d \theta$, é chamada de seção de choque para colisão Compton. É a probabilidade $\sigma$ de um fóton ter uma interação Compton por elétron por metro quadrado.

$$
\sigma=2 \pi \int \frac{d \sigma}{d \Omega} \operatorname{sen} \theta d \theta
$$

A seção de choque de Compton, $\sigma$, pode ser interpretada como a área de cruzamento transversal, como em um alvo, apresentada a um fóton para interação por um elétron por metro quadrado. Com isso, a probabilidade de interação está rigorosamente estabelecida. Entretanto, é importante frisar que a área $\sigma$ depende da energia do fóton e não corresponde ao tamanho físico do elétron.

A fórmula de Klein-Nishina pode ser combinada com as equações cinemáticas, levando ao cálculo de diversas grandezas de interesse em física das radiações. Particularmente em dosimetria, alguns conceitos são originados inicialmente pela energia média de recuo dos elétrons Compton ( $\left.T_{\text {avg }}\right)$.

Para fótons de energia $h v$, é possível definir a seção de choque de transferência de energia diferencial Klein-Nishina (por elétron por metro quadrado) como:

$$
\frac{d \sigma_{t r}}{d \Omega}=\frac{T}{h v} \frac{d \sigma}{d \Omega}
$$

A energia média de recuo $T$ é dada por:

$$
T_{\text {avg }}=h v \frac{\sigma_{t r}}{\sigma},
$$

em que $\sigma_{t r}$ é a seção de choque de transferência de energia por Compton (por elétron, por metro quadrado).

Esta seção de choque fornece a fração da energia do fóton incidente que é transferida para os elétrons Compton, por elétron, por metro quadrado no 
material atravessado. A Figura 3.2 mostra a fração da energia do fóton incidente convertida em energia cinética dos elétrons Compton.

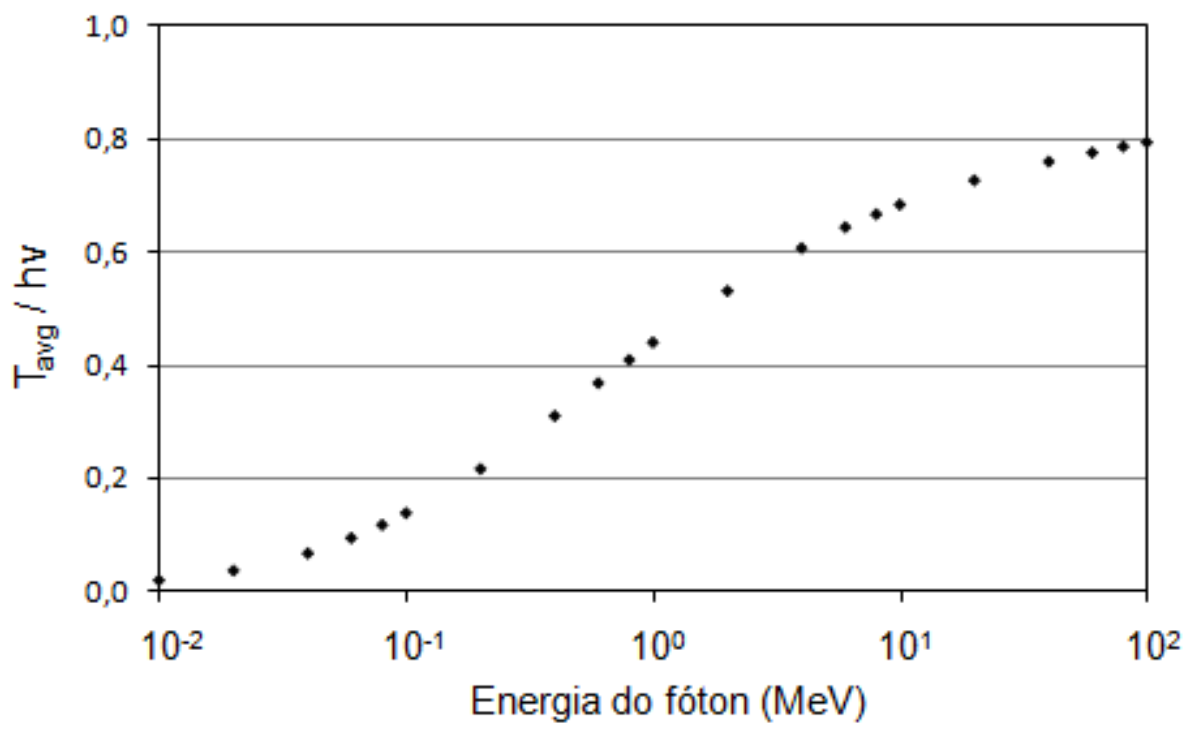

Figura 3.2 - Fração da energia do fóton incidente convertida em energia cinética dos elétrons Compton (Baseada na tabela de Turner, 2007).

Esta fração aumenta continuamente com o aumento da energia do fóton incidente. De modo semelhante, a seção de choque diferencial para espalhamento da energia (i.e., energia transportada pelos fótons espalhados) é definida por:

$$
\frac{d \sigma_{s}}{d \Omega}=\frac{v^{\prime}}{v} \frac{d \sigma}{d \Omega}
$$

A energia média dos fótons espalhados pelos fótons incidentes de energia $h v$ é

$$
\left(h v^{\prime}\right)_{a v g}=h v \frac{\sigma_{s}}{\sigma}
$$

A razão $\sigma_{s}$, obtida a partir da integração sobre $d \Omega$ de ambos lados da Eq. 3.9, e $\sigma$ fornece a fração da energia do fóton incidente que é espalhada (por elétron por metro quadrado). Tomando:

$$
\frac{T_{\text {avg }}}{h v}+\frac{\left(h v^{\prime}\right)_{a v g}}{h v}=1
$$

a seção de choque para colisão Compton é a soma das seções de choque para transferência de energia e para espalhamento de energia, resultando: 


$$
\sigma=\sigma\left[\frac{T_{a v g}}{h v}+\frac{\left(h v^{\prime}\right)_{a v g}}{h v}\right]=\sigma\left[\frac{\sigma_{t r}}{\sigma}+\frac{\sigma_{s}}{\sigma}\right]=\sigma_{t r}+\sigma_{s}
$$

Se o material atravessado é composto por $N$ átomos de um elemento de número atômico $Z$ por metro cúbico, o número de elétrons por metro cúbico será $n=N Z$. A probabilidade de interação Compton por unidade de distância viajada por fóton no material será:

$$
\sigma=N Z \sigma=n \sigma
$$

A grandeza Z $\sigma$ é a seção de choque de colisão Compton por átomo, e $\sigma$ é a seção de choque macroscópica, ou coeficiente de atenuação, tendo o inverso de distância como dimensão. Se o material é um composto ou uma mistura, a seção de choque de cada elemento contribui aditivamente com $\sigma$ como $N Z \sigma$. Esta propriedade aditiva será de grande importância no desenvolvimento deste trabalho.

Os coeficientes de atenuação linear por efeito Compton para transferência de energia e para espalhamento de energia podem ser obtidos das Eq. 8 e Eq. 10 após a multiplicação pela densidade de elétrons.

$$
\sigma_{t r}=\sigma \frac{T_{a v g}}{h v}
$$

e

$$
\sigma_{s}=\sigma \frac{\left(h v^{\prime}\right)_{a v g}}{h v}
$$

O coeficiente de atenuação total por efeito Compton pode ser escrito como:

$$
\sigma=\sigma_{t r}+\sigma_{s}
$$

(Attix, 2005; Leo, 1987; Podgorsak, 2005; Turner, 2007)

\subsubsection{Efeito Fotoelétrico}

O efeito fotoelétrico envolve a absorção de um fóton por um elétron atômico com a subsequente ejeção de um elétron do átomo. O fóton interage com um elétron orbital fortemente ligado do absorvedor e desaparece, enquanto o elétron orbital (chamado fotoelétron) é ejetado do átomo. A energia cinética do fotoelétron é dada por:

$$
E_{k}=h v-E_{b},
$$


em que $E_{b}$ é a energia de ligação do elétron.

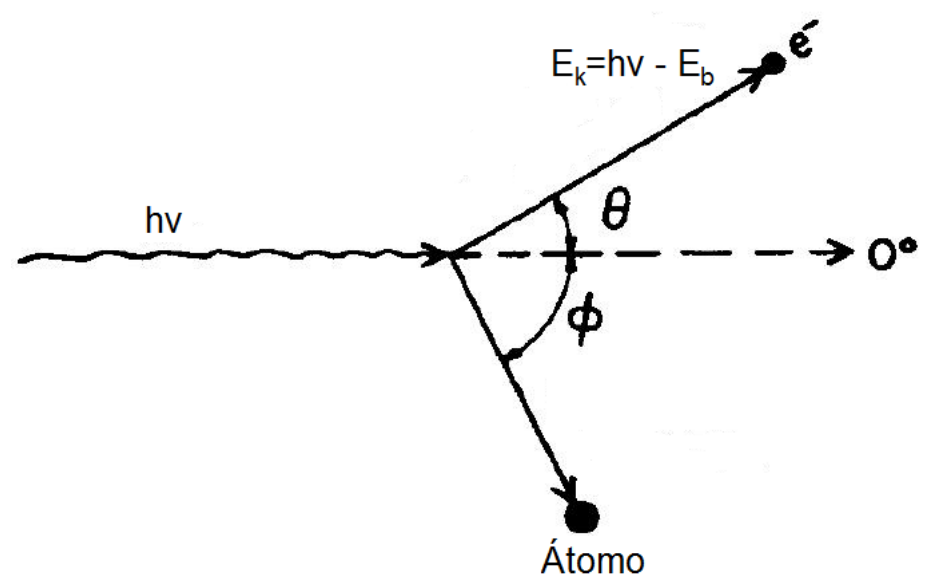

Figura 3.3 - Representação esquemática do efeito fotoelétrico. Um fóton de energia $h v$ atinge um elétron ligado a um átomo com uma energia de ligação $E_{b}$. O fóton é absorvido, fornecendo energia cinética ao elétron e causando um suave recuo do átomo para conservar o momento (Extraída e adaptada de Attix, 2005).

Quando a energia transferida de um fóton para um elétron atômico é muito maior que a energia de ligação deste elétron, este elétron pode ser tratado como livre e em repouso (como no caso do efeito Compton). Porém, a conservação de energia e momento impede a absorção de um fóton por um elétron sob estas condições. Portanto, a ligação de um elétron e sua interação com o resto do átomo são essenciais para a ocorrência do efeito fotoelétrico. Quando o efeito fotoelétrico ocorre, o elétron em questão interage com o núcleo e com os outros elétrons do átomo para que haja conservação de energia e de momento de todas as partes envolvidas neste processo (Figura 3.3).

O efeito fotoelétrico é a interação mais importante para fótons de energias baixas. A Figura 3.4 mostra um comportamento típico da seção de choque para efeito fotoelétrico em relação à energia do fóton incidente. Observase que o coeficiente de atenuação para o efeito fotoelétrico decresce com o aumento da energia $h v$. Adicionalmente a este decréscimo contínuo, a Figura 3.4 também mostra descontinuidades abruptas quando $h v$ se iguala à energia de ligação para uma determinada camada eletrônica de um dado absorvedor. 


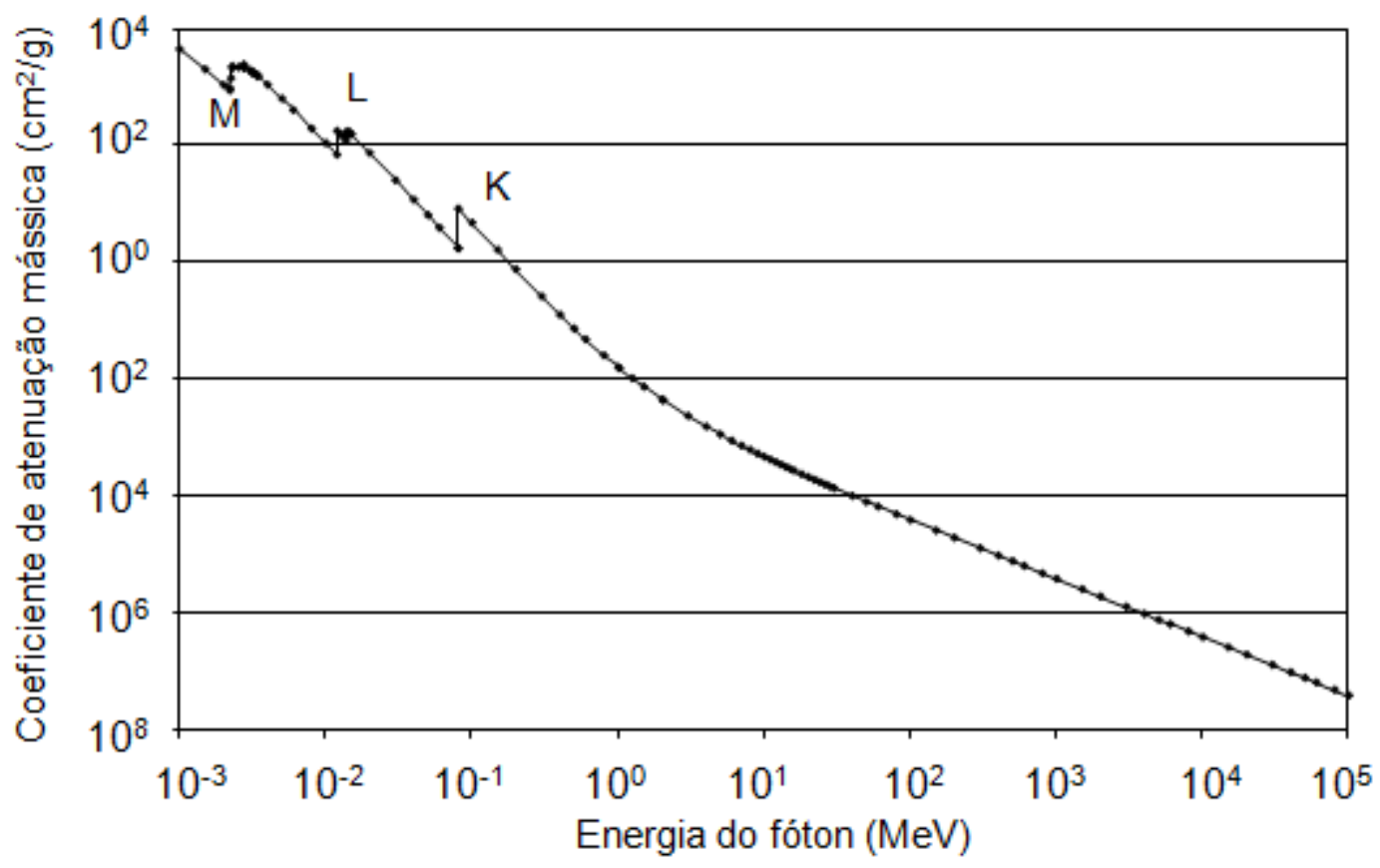

Figura 3.4 - Coeficiente de atenuação mássica para efeito fotoelétrico em relação à energia do fóton incidente. Elemento: ouro. Bordas de absorção: $\mathrm{K}$ ( $\sim 81 \mathrm{keV}$ ), L (três níveis entre $\sim 12 \mathrm{keV}$ e $\sim 14 \mathrm{keV}$ ) e M (cinco níveis entre $\sim 2 \mathrm{keV}$ e $\sim 3 \mathrm{keV}$ ) (a partir de dados do website do NIST, National Institute of Standards and Technology, 1998).

Estas descontinuidades são chamadas de bordas de absorção; os fótons que incidem com energia abaixo da energia de ligação dos elétrons de determinada camada não são capazes de desencadear o efeito fotoelétrico naquela camada. Apenas fótons incidentes com energia igual ou maior à energia de ligação da camada são capazes de desencadear o efeito fotoelétrico.

Assim como para o efeito Compton, a probabilidade de ocorrência da absorção por efeito fotoelétrico é determinada pela chamada seção de choque para efeito fotoelétrico. Entretanto, uma descrição teórica do comportamento da seção de choque para efeito fotoelétrico é mais complexa que para o efeito Compton, pois há a complicação proveniente da ligação do elétron. Não há uma equação simples para a seção de choque diferencial para efeito fotoelétrico que corresponda à fórmula de Klein-Nishina da seção de choque diferencial para efeito Compton. Soluções satisfatórias para diversas faixas de energia já foram publicadas na forma de tabelas. Em geral estas tabelas foram baseadas em 
resultados experimentais, complementados por interpolações auxiliadas por princípios teóricos para outras faixas de energia e outros materiais diferentes daqueles medidos experimentalmente. A compilação de tabelas utilizadas para o desenvolvimento deste trabalho está disponível no website do NIST (National Institute of Standards and Technology, 1998).

A seção de choque para interação por efeito fotoelétrico por átomo é dada por:

$$
\mu \cong k \frac{Z^{n}}{(h v)^{m}}\left(\mathrm{~cm}^{2} \text { látomo }\right)
$$

em que $k$ é constante, $n \cong 4$ para $h v=0,1 \mathrm{MeV}$, aumentando gradativamente para $\sim 4,6$ a $3 \mathrm{MeV}$ e $m \cong 3$ para $h v=0,1 \mathrm{MeV}$, reduzindo gradativamente para $\sim 1$ a $5 \mathrm{MeV}$.

Para energias baixas, como $h v \cong 0,1 \mathrm{MeV}$ e abaixo, em que o efeito fotoelétrico é predominante, a seção de choque é dada por:

$$
\mu \propto \frac{Z^{4}}{(h v)^{3}}\left(\mathrm{~cm}^{2} / \text { atom }\right)
$$

O coeficiente de atenuação mássica é dado por:

$$
\frac{\mu}{\rho} \propto\left(\frac{Z}{h v}\right)^{3}\left(\mathrm{~cm}^{2} / \mathrm{g}\right)
$$

Retornando ao exemplo do gráfico representado na Figura 3.4, a magnitude do degrau do borda $\mathrm{K}$ (de 1,75 a $8,51 \mathrm{~cm}^{2} / \mathrm{g}$ ) mostra a importância da contribuição dos elétrons da camada $\mathrm{K}$ para a seção de choque para efeito fotoelétrico, em comparação com os outros 77 elétrons do átomo de ouro. A camada $\mathrm{K}$ contribui com cerca de $80 \%$ devido à alta energia de ligação destes dois elétrons e à forte dependência do efeito fotoelétrico na energia de ligação. Um efeito semelhante ocorre nos três degraus da camada $L$, que correspondem aos três níveis de energia desta camada. No entanto, a combinação dos degraus da camada $L$ é bem menor que o degrau do borda $K$, porque as energias de ligação da camada $L$ são menores.

Tomando a equação de conservação de energia (Eq. 3.17) para o efeito fotoelétrico, a fração de $h v$ transferida para o fotoelétron é dada por:

$$
\frac{E_{k}}{h v}=\frac{h v-E_{B}}{h v}
$$


No entanto, esta é apenas uma primeira aproximação da fração total de $h v$ transferida para todos os elétrons. A energia de ligação, $E_{B}$, deve ser levada em consideração, pois parte desta energia (ou toda) é convertida em energia cinética do elétron por meio do efeito Auger.

Quando um elétron é removido de um nível interno por qualquer processo de interação da radiação com a matéria, por exemplo do nível $\mathrm{K}$, o átomo pode regressar ao estado fundamental por meio de dois processos: transição radiativa ou não radiativa (Figura 3.5).

No processo de transição radiativa ocorre a transição de um elétron de um nível exterior, que irá ocupar a lacuna do nível $\mathrm{K}$ e assim sucessivamente até a lacuna ficar na camada mais externa do átomo. A lacuna é finalmente neutralizada por um elétron da banda de condução, acompanhado pela emissão de um fóton de raios $X$, cuja energia é igual à diferença de energia potencial entre o nível doador e o nível receptor.

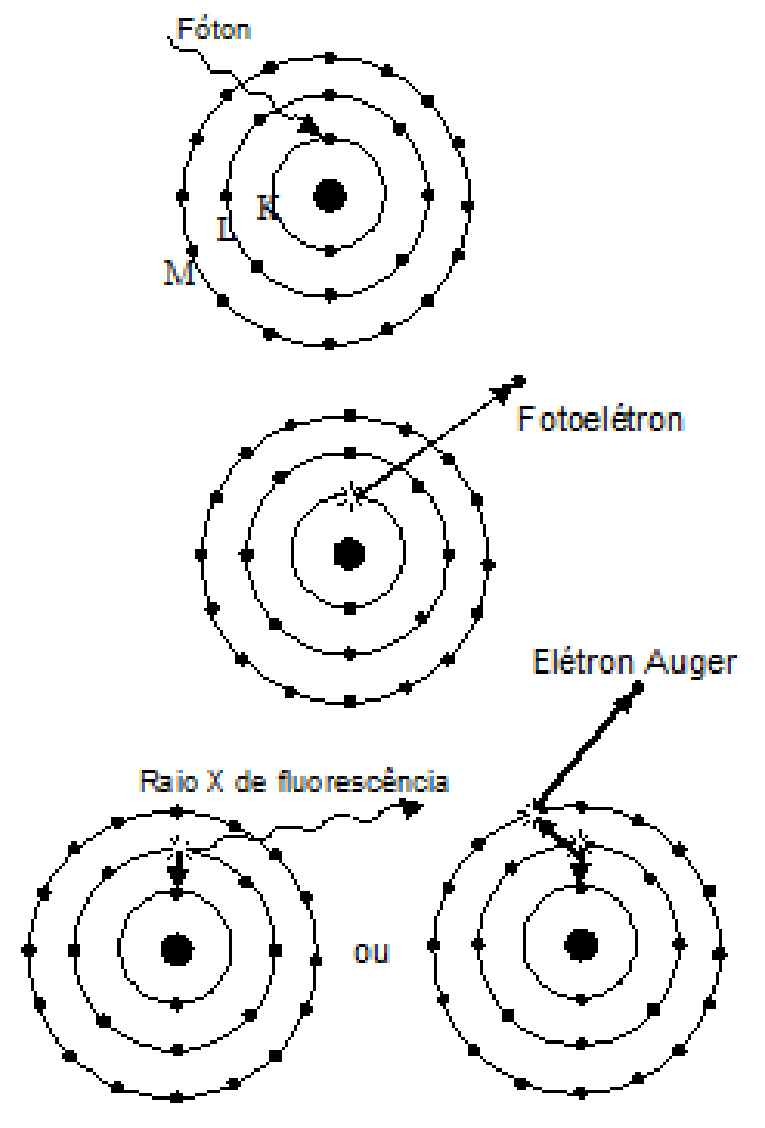

Figura 3.5 - Diagrama dos processos de reorganização atômica após ionização de um nível eletrônico interno. 
Já o processo de transição não radiativa é caracterizado por uma reorganização da distribuição eletrônica sem emissão de radiação $X$, mas com a emissão de um outro elétron, o elétron Auger. Este recebe o excesso de energia do átomo transferido sob a forma de energia cinética. Assim, o efeito Auger provoca uma nova lacuna no átomo, deixando-o duplamente ionizado.

As probabilidades destes processos ocorrerem são chamadas de rendimento de fluorescência e rendimento de Auger e estão representados em função do número atômico, $Z$, na Figura 3.6. O rendimento de fluorescência do nível $\mathrm{K}, \omega_{\mathrm{K}}$, corresponde à probabilidade de que o átomo se reorganize por meio da emissão de um fóton de radiação $X$, enquanto o rendimento de Auger, $a_{K}$, corresponde à probabilidade de reorganização por meio da emissão de um elétron Auger, processo não radiativo.

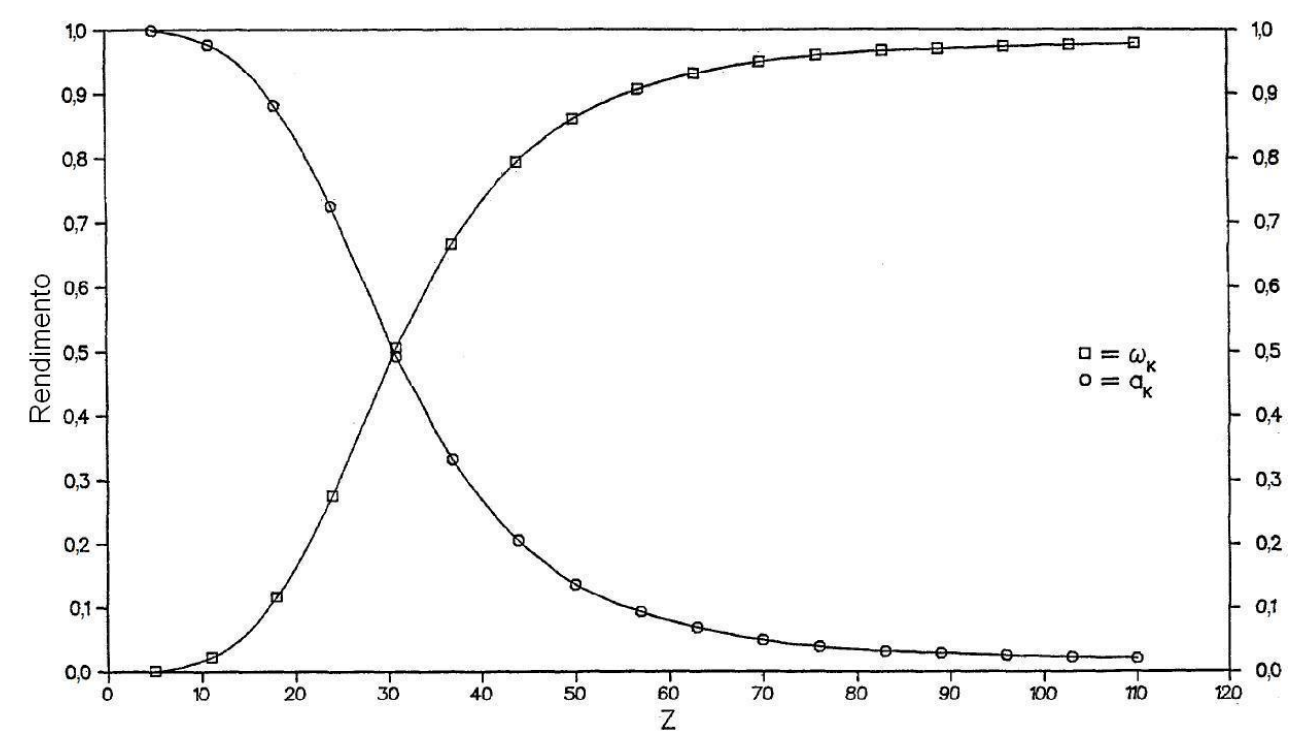

Figura 3.6 - Rendimento de fluorescência para a camada $\mathrm{K}$, $\omega_{\mathrm{K}}$, e rendimendo de Auger para a camada $\mathrm{K}, \mathrm{a}_{\mathrm{K}}$, em função do número atômico, $\mathrm{Z}$. (Figura extraída e adaptada de Krause, 1979).

O fenômeno não radiativo é predominante para elementos de baixos números atômicos, enquanto o processo radiativo predomina para números atómicos elevados. Estes são os únicos processos pelos quais um átomo pode voltar ao estado fundamental.

$\omega_{\mathrm{K}}+\mathrm{a}_{\mathrm{K}}=1$

As transições radiativas provenientes de transições de elétrons para a camada $L$ são muito mais complexas, pois a camada $L$ possui três subníveis, 
sendo o rendimento de fluorescência uma média do comportamento dos diferentes subníveis.

O papel do efeito Auger é permitir um mecanismo alternativo pelo qual o átomo possa transferir qualquer parte da energia de ligação $E_{B}$ que não tenha sido removida por um raio $X$ de fluorescência. Se não houver emissão de raios $X$, toda energia $E_{B}$ será transferida por efeito Auger. Como no efeito Auger o átomo ejeta um ou mais elétrons com energia cinética suficiente para ser relevante em relação à energia coletiva, esta energia transferida aos elétrons Auger contribuem para o kerma (Attix, 2005; Krause, 1979; Leo, 1987; NIST, 1998; Podgorsak, 2005; Turner, 2007).

\subsubsection{Coeficientes de transferência de energia e de absorção de energia}

O coeficiente de transferência mássica de energia, $\mu_{t t} / \rho$, é dado pela combinação dos diversos processos de interação da radiação com a matéria. As parcelas mais relevantes neste trabalho são correspondentes ao efeito fotoelétrico e ao efeito Compton.

$$
\frac{\mu_{t r}}{\rho}=\left(\sigma_{p e}(1-X / E)+\sigma_{C o m p}(1-(E+X) / E) / M_{A}\right.
$$

em que $\sigma_{p e}$ é a seção de choque para o efeito fotoelétrico, $\sigma_{\text {Comp }}$ é a seção de choque para efeito Compton, $X$ é a energia média da radiação de fluorescência emitida por fóton absorvido, $E$ é a energia do fóton incidente, $E$ ' é a energia do fóton Compton e $M_{A}$ é a massa atômica do absorvedor.

A energia de fluorescência, $X$, depende da distribuição entre os elétrons atômicos das lacunas produzidas no processo de absorção fotoelétrica, incluindo a possibilidade de emissão em cascatas de raios $X$ de fluorescência associada ao processo de neutralização do átomo iniciado pela lacuna primária.

Quando multiplicado pela fluência de energia dos fótons, ou intensidade, ( $\psi=\Phi E$, em que $\Phi$ é a fluência de fótons e $E$ a energia do fóton incidente), o coeficiente de transferência mássica de energia, $\mu_{t} / \rho$, fornece a grandeza dosimétrica conhecida como kerma. O kerma é definido como a soma das energias cinéticas de todas as partículas carregadas primárias depositadas por partículas não-carregadas por unidade de massa. 


$$
K=\psi \frac{\mu_{t r}}{\rho}
$$

Outra grandeza importante para fins de dosimetria é o coeficiente de absorção mássica de energia, $\mu_{e} / \rho$, que inclui as demais emissões de radiação produzidas pelas partículas carregadas através do meio, permitindo o cálculo da dose absorvida.

$$
\frac{\mu_{\text {en }}}{\rho}=(1-g) \frac{\mu_{t r}}{\rho}
$$

em que $g$ representa a fração da energia cinética de partículas carregadas secundárias que é depositada em processos radiativos de perda de energia (emissão de fóton).

A dose absorvida, definida como infinitésimo de energia $d \varepsilon$ depositado em um infinitésimo da massa $d m$, é dada por:

$$
D=\frac{d \varepsilon}{d m}=\frac{\psi\left(1-e^{-\frac{\mu_{e n}}{\rho} \cdot \rho \cdot x}\right)}{\rho . A . x}
$$

em que $\rho$ é a densidade do absorvedor, $x$ é a espessura do absorvedor e $A$ a área irradiada do absorvedor (Attix, 2005; Leo, 1987; NIST, 1998; Turner, 2007). 


\subsection{Dosimetria com Gel Polimérico}

\subsubsection{Histórico}

Os sistemas poliméricos começaram a ser estudados em relação à capacidade dosimétrica na década de 50 por Alexander et al (1954), que avaliou os efeitos em polimetilmetacrilato, causados pela radiação. Hoecker \& Watkins (1958) estudaram a polimerização radioinduzida em líquidos. Com o passar do tempo, foram realizados estudos que combinavam estas propriedades, como o primeiro gel polimérico, desenvolvido por Maryanski et al (1992, 1993), cuja formulação era composta por monômeros de acrilamida e N,N'-metileno-bisacrilamida (bis) diluídos em uma matriz aquosa de agarose (gelatina de algas). Este dosímetro recebeu o acrônimo de BANANA devido a seus componentes químicos (bis, acrilamida, óxido nitroso e agarose). Verificou-se que o gel apresentava uma distribuição de dose pós-irradiação relativamente estável.

A reação de polimerização neste gel ocorria devido ao processo de reticulação dos monômeros induzida pelos produtos de radical livre da radiólise da água. Maryanski et al (1994a) refinaram a formulação, substituindo a agarose por gelatina, surgindo o BANG (bis, acrilamida, óxido nitroso e gelatina aquosa), que foi patenteado em 1994 (Maryanski et al, 1994b). Devido à patente, as formulações desenvolvidas subsequentemente passaram a ser chamadas de PAG (poliacrilamida gel) por diversos pesquisadores (Baldock et al, 1998).

Embora os dosímetros de gel polimérico apresentassem uma distribuição de dose relativamente estável, havia uma limitação significativa para sua utilização. Por se basearem em química de radicais livres, os dosímetros de gel polimérico eram suscetíveis à inibição do processo de polimerização devido ao oxigênio atmosférico. Então, a produção deles precisava ser realizada em ambiente livre de oxigênio, como em caixas de luvas (gloveboxes) bombeadas com gás nitrogênio. Além da sensibilidade ao oxigênio, a presença de componentes altamente tóxicos trouxe limitações para a utilização dentro da clínica (Baldock, 2006).

Fong e colaboradores (2001) desenvolveram um dosímetro de gel polimérico, conhecido como MAGIC gel, que delimita o oxigênio atmosférico em um complexo metalorgânico, portanto removendo o problema da inibição pelo oxigênio e permitindo a produção de dosímetros de gel polimério em atmosfera 
comum. Este tipo de gel ficou conhecido como gel normóxico; por outro lado, as formulações anteriores de PAG ficaram conhecidas como géis hipóxicos. A formulação do MAGIC gel consiste de ácido metacrílico, ácido ascórbico, gelatina e cobre. O ácido ascórbico é o responsável pela 'captura' do oxigênio (envolvendo o oxigênio livre na matriz gelatinosa e aprisionando-o nos complexos metalorgânicos), cujo processo é iniciado pelo sulfato de cobre. Outros agentes antioxidantes também foram apresentados como possibilidade de uso na produção de géis normóxicos, como cloreto de tetrakis (hidroximethil) fosfônio (THPC) (De Deene et al, 2002; Bayreder et al, 2006).

A formulação do gel polimérico utilizada neste trabalho foi proposta por Berg (2009) e consiste em uma variação do MAGIC gel.

\subsubsection{Mecanismo Químico}

Normalmente os géis poliméricos são compostos por cerca de $90 \%$ de água. Em geral, os demais componentes não são afetados diretamente pela radiação, e sim indiretamente, por entidades produzidas a partir da água, pelo chamado processo de radiólise. Quando irradiadas, as moléculas de água são ionizadas em diversos radicais e íons altamente reativos.

$\mathrm{Na}$ irradiação com raios $X$, esses radicais e íons são produzidos em períodos da ordem de $10^{-15} \mathrm{~s}$. A partir do momento da produção, a probabilidade destas partículas reativas se encontrarem por movimento browniano e, então, reagirem umas com as outras aumenta com o tempo. $O$ equilíbrio térmico da recombinação das partículas reativas é alcançado após aproximadamente $10^{-11} \mathrm{~s}$. As partículas remanescentes difundem sofrendo um deslocamento aproximado de 0,28 nm, que corresponde a um décimo da distância intermolecular dos monômeros. Então os produtos da radiólise da água começam a reagir com os monômeros. Por exemplo, um elétron hidratado, $e_{a q}^{-}$, reage com um monômero formando um radical ânion que pode ser neutralizado posteriormente por um próton.

Resumidamente, a decomposição destes intermediários reativos $\left(R^{\circ}\right)$ pode ser escrita de modo simplificado:

$$
\mathrm{H}_{2} \mathrm{O} \stackrel{k_{D}}{\longrightarrow} 2 \mathrm{R}^{\circ}
$$

em que $\left(k_{D}\right)$ é proporcional à dose absorvida. 
Os radicais iniciam a polimerização reagindo com os monômeros. A iniciação pode ser escrita assim:

$$
R^{\circ}+M \stackrel{k_{l}}{\longrightarrow} M_{1}^{\circ}
$$

com a taxa de iniciação da reação, $k_{l}$, constante.

O crescimento do polímero continua por meio de reações de propagação da cadeia polimérica, em que os radicais poliméricos prosseguem reagindo e agregando monômeros. O caso geral apresentado a seguir descreve um radical polimérico com $n$ monômeros que reage com um monômero ou com uma cadeia inativa de polímeros contendo $m$ monômeros.

$$
M_{m}^{o}+M_{n} \stackrel{k_{T} c(n, m)}{\longrightarrow} M_{n+m}^{o}
$$

A terminação da reação de polimerização ocorre através da reação entre dois radicais, seja por combinação ou desproporcionamento:

$$
\begin{gathered}
M_{m}^{o}+M_{n}^{o} \stackrel{k_{T} c(n, m)}{\longrightarrow} M_{n+m} \\
M_{m}^{o}+M_{n}^{o} \stackrel{k_{T} d(n, m)}{\longrightarrow} M_{m}+M_{n}
\end{gathered}
$$

Os radicais primários, gerados pela radiólise da água, também podem reagir com uma cadeia polimérica crescente causando a terminação:

$$
R^{o}+M_{n}^{o} \stackrel{k_{T} c(o, m)}{\longrightarrow} M_{n}
$$

Os radicais primários também podem reiniciar o processo de polimerização de uma cadeia polimérica já inativa:

$$
R^{o}+M_{n} \stackrel{k_{l}(n)}{\longrightarrow} M_{n}^{o}
$$

Além da terminação, um radical polimérico crescente pode terminar transferindo o grupo radical a outras moléculas:

$$
M_{m}^{o}+M_{n} \stackrel{k_{\text {Trans }}}{\longrightarrow} M_{m}+M_{n}^{o}
$$

O sítio radicalar da cadeia polimérica em crescimento pode ser transferido para a cadeia do biopolímero da gelatina. Os radicais poliméricos de gelatina possuem uma propagação mais lenta, de modo que o aumento na concentração de gelatina resulta em uma redução na extensão da polimerização.

Os radicais peróxido são criados quando há oxigênio no gel:

$$
\begin{aligned}
& R^{\circ}+\mathrm{O}_{2} \stackrel{k_{01}}{\longrightarrow} \mathrm{ROO}^{\circ} \\
& \mathrm{M}_{n}^{\circ}+\mathrm{O}_{2} \stackrel{k_{02}}{\longrightarrow} \mathrm{M}_{n} \mathrm{OO}^{\circ}
\end{aligned}
$$


Estes radicais peróxido reagem rapidamente com outros radicais, levando-os à terminação.

$$
\begin{aligned}
& R O O^{\circ}+R^{\circ} \stackrel{k_{R 11}}{\longrightarrow} R O O R \\
& R O O^{\circ}+M_{n}^{\circ} \stackrel{k_{R 12}}{\longrightarrow} R^{\circ} O_{n} \\
& M_{n} O O^{\circ}+R^{\circ} \stackrel{k_{R 21}}{\longrightarrow} M_{n} O O R \\
& M_{n} O^{\circ}+M_{m}^{\circ} \stackrel{k_{R 22}}{\longrightarrow} M_{n} O O M_{m}
\end{aligned}
$$

A estrutura dos géis poliméricos antes da irradiação é basicamente baseada na gelificação da solução aquosa de gelatina, determinada pelo crescimento de uma rede tridimensional de cadeias de biopolímeros. As junções desta rede tridimensional resultam da renaturação do colágeno. O processo de gelificação ocorre muito rapidamente quando a temperatura da solução é menor que $35^{\circ} \mathrm{C}$ e progride muito lentamente nas horas seguintes, em um processo que leva mais de uma semana para se estabilizar.

Sob irradiação, diversas estruturas poliméricas são criadas no gel, modificando diversas características físico-químicas, como viscosidade, mobilidade molecular, opacidade, densidade eletrônica, propagação acústica, entre outras (Baldock et al, 2010). 


\subsection{Ressonância Magnética Nuclear}

A Ressonância Magnética Nuclear (NMR) é uma técnica que permite analisar a estrutura de diversas moléculas químicas. A determinação das propriedades da substância é dada pela correlação entre a energia absorvida e a frequência do sinal emitido, na região de radiofreqüência (RF) do espectro eletromagnético ( $\mathrm{RF}$, da ordem de $\mathrm{MHz}$ ). A técnica utiliza transições entre os níveis de energia rotacional do núcleo da substância contida na amostra. Esse efeito ocorre necessariamente sob a influência de um campo magnético $\left(\boldsymbol{B}_{\boldsymbol{0}}\right)$ e a concomitante irradiação com ondas pulsadas de radiofrequência (Figura 3.7). O sinal emitido fornece informações sobre como os átomos estão arranjados na molécula e depende principalmente do tipo de núcleo e da magnitude do campo magnético (B⿱一⿻上丨) $)$. (Bruker, 2003)

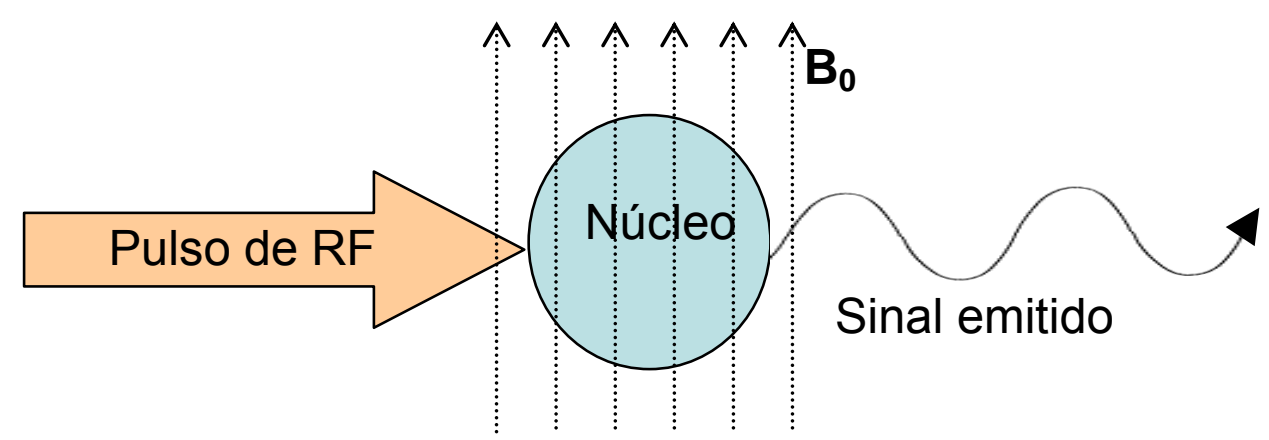

Figura 3.7 - Diagrama simplificado de representação da técnica de ressonância magnética nuclear.

\subsubsection{Princípios Básicos}

Todas as partículas, como elétrons, nêutrons e prótons, apresentam uma propriedade chamada spin. Embora esta seja uma propriedade quântica, o spin é frequentemente associado ao modelo clássico, no qual o spin é tratado como a rotação de uma partícula em torno do próprio eixo. O spin tem valores múltiplos de $1 / 2$ e pode ser positivo ou negativo. Um elétron, um próton ou um nêutron individual não pareado possui spin $1 / 2$. Como descrito anteriormente, por ser a partícula de interesse em dosimetria com gel polimérico, o próton (ou núcleo de hidrogênio) será enfatizado neste texto.

Em razão da dificuldade em descrever o processo de ressonância magnética em escala microscópica, é comum analisar o conjunto dos spins 
submetidos ao mesmo campo magnético. Portanto, o campo magnético produzido pelos spins de um mesmo conjunto é chamado de vetor de magnetização $(\boldsymbol{M})$.

Quando inseridos em um campo magnético $\left(\boldsymbol{B}_{0}\right)$, os spins dos prótons podem se dividir em dois grupos (Figura 3.8). O primeiro se alinha à direção a ao sentido do campo magnético $\left(N_{p a r}\right)$, enquanto o segundo se alinha à direção do campo magnético, porém em sentido oposto ( $\left.N_{\text {antipar }}\right)$.

Em campos magnéticos de pouca intensidade (como o campo terrestre), os spins se dividem quase igualmente entre os dois grupos, portanto o vetor de magnetização é quase nulo.

$$
N_{p a r} \cong N_{a n t i p a r}
$$

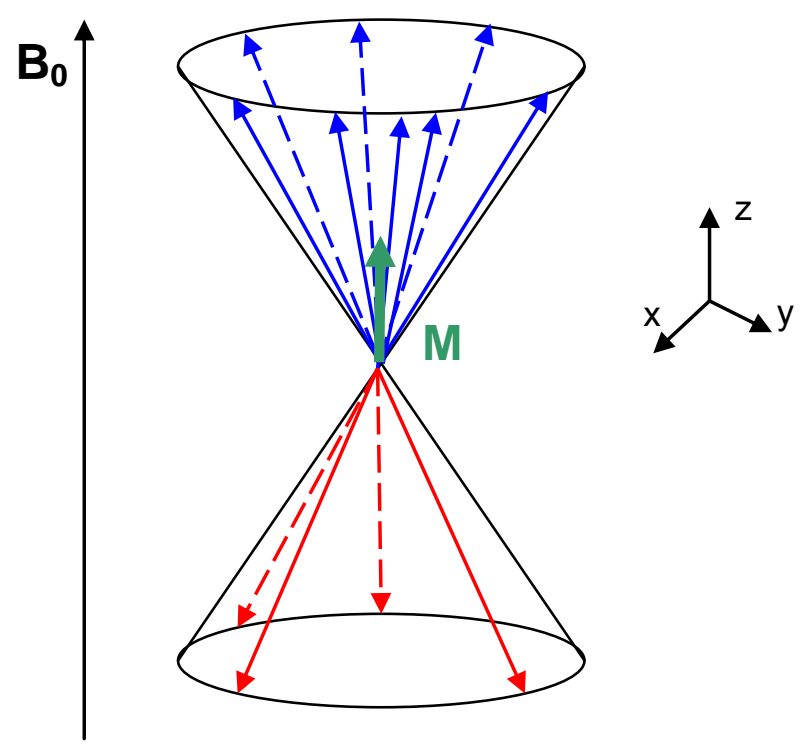

Figura 3.8 - Diagrama de representação da distribuição dos spins sob a influência de um campo magnético $\boldsymbol{B}_{\boldsymbol{0}}$, produzindo um vetor de magnetização $\boldsymbol{M}$.

No entanto, quando submetidos a campos magnéticos mais intensos, os prótons tendem a se alinhar preferencialmente ao sentido do campo magnético em movimento de precessão em torno do eixo $z$.

$$
N_{\text {par }}>>N_{\text {antipar }}
$$

A frequência de precessão é chamada frequência de Larmor $(v)$ e é característica de cada núcleo e depende da intensidade do campo magnético no qual a amostra está inserida. No caso dos núcleos de hidrogênio,

$$
v=42,58 \mathrm{MHz} / \text { Tesla. }
$$


Isso significa que os núcleos de hidrogênio submetidos a um campo magnético de 1 Tesla necessitam ser irradiados com ondas de radiofrequência com 42,58 MHz para serem excitados. Este processo se chama ressonância.

$\mathrm{Na}$ verdade, a exposição dos núcleos de hidrogênio aos pulsos de radiofrequência dá-se por intervalos curtos de tempo. Estes pulsos fazem com que o ângulo de precessão $\theta$ aumente (Figura 3.9). Quando os pulsos são interrompidos, os núcleos de hidrogênio emitem a energia da excitação na forma de fótons, à medida que o vetor de magnetização retorna ao estado inicial. Este retorno do vetor de magnetização ao estado inicial é chamado de relaxação longitudinal.

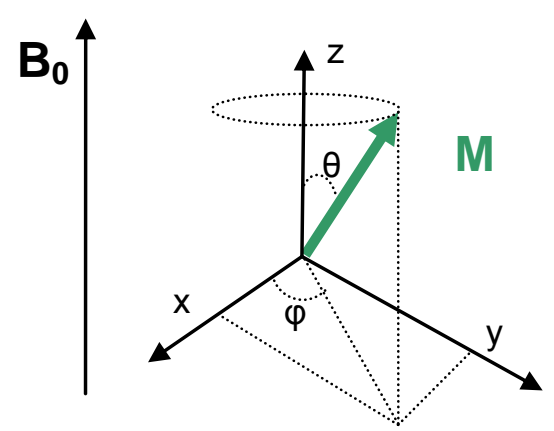

Figura 3.9 - Diagrama de representação do vetor de magnetização dos núcleos de hidrogênio após a irradiação com pulsos de RF.

\subsubsection{Relaxação Longitudinal}

Em equilíbrio, o vetor de magnetização tem a mesma direção e sentido do campo magnético $\boldsymbol{B}_{\boldsymbol{0}}$ e é chamado de magnetização de equilíbrio $\left(\boldsymbol{M}_{\boldsymbol{0}}\right)$. Nesta configuração de equilíbrio, o vetor de magnetização possui componente apenas no eixo $\boldsymbol{z}, \boldsymbol{M}_{\boldsymbol{z}}$. Não há magnetização transversa, e $\boldsymbol{M}_{\boldsymbol{x}}$ ou $\boldsymbol{M}_{\boldsymbol{y}}$.

Quando um pulso de radiofrequência com a frequência de Larmor do núcleo em questão é aplicado, a magnetização é modificada. Com energia suficiente, o pulso (chamado de $90^{\circ}$ ) é capaz de zerar $\boldsymbol{M}_{\boldsymbol{z}}$, transferindo toda a magnetização ao plano xy (Figura 3.10).

Após a irradiação com pulsos de radiofrequência, a componente $\boldsymbol{M}_{\boldsymbol{z}}$ começa a se recuperar, até alcançar novamente a magnetização de equilíbrio $\left(\boldsymbol{M}_{\boldsymbol{0}}\right)$. Esta recuperação é governada por: 


$$
M_{z}=M_{0}\left(1-e^{\frac{-t}{T_{1}}}\right)
$$

em que $T_{1}$ é o chamado tempo de relaxação longitudinal, ou relaxação spin-rede, e corresponde ao tempo necessário para o vetor de magnetização recuperar $(1-1 / e) \cdot M_{0} \approx 63 \%$ da magnetização de equilíbrio. $O$ comportamento da recuperação da componente $z$ do vetor de magnetização está representado na Figura 3.11.

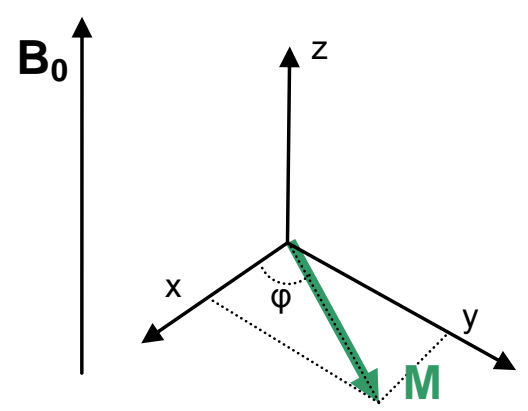

Figura 3.10 - Diagrama de representação do vetor de magnetização dos núcleos de hidrogênio após a irradiação com pulsos de RF de $90^{\circ}$.

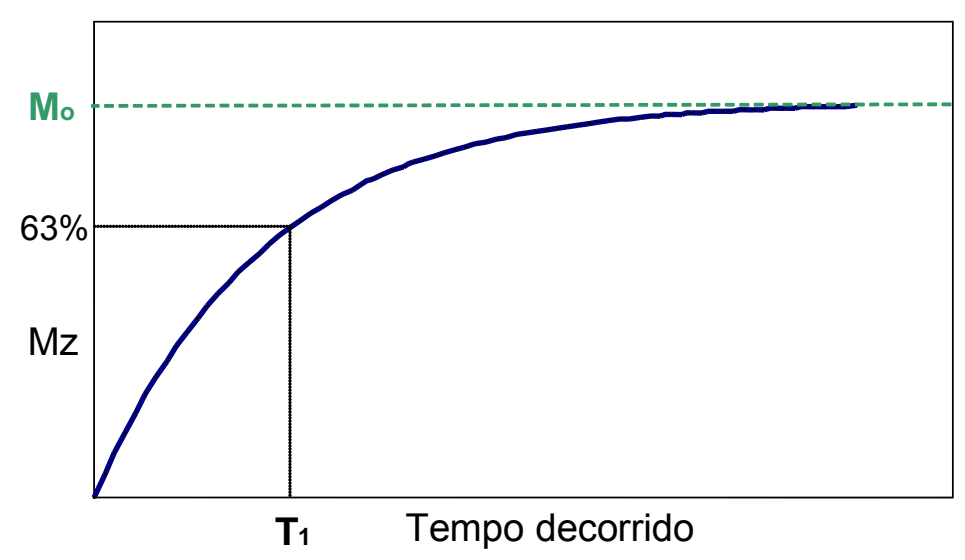

Figura 3.11 - Comportamento da componente $z$ do vetor de magnetização $\left(\mathrm{M}_{\mathrm{z}}\right)$ em relação ao tempo decorrido após a irradiação com RF. $M_{\circ}$ é a magnetização de equilíbrio e $T_{1}$ é o tempo de relaxação longitudinal.

\subsubsection{Relaxação Transversal}

Imediatamente após ser defletido ao plano xy pelo pulso de radiofrequência, o vetor de magnetização em xy $\left(\boldsymbol{M}_{x y}\right)$ possui a mesma magnitude que $\boldsymbol{M}_{\boldsymbol{0}}$. Em seguida, os momentos magnéticos dos núcleos de hidrogênio começam a se defasar. Isto ocorre porque cada spin está submetido a um campo 
magnético ligeiramente diferente do outro por causa da interação entre os spins da vizinhança.

A perda de coerência de fase no plano xy é chamada de relaxação transversal, ou relaxação spin-spin. Conforme o tempo passa, maior é a diferença de fase, como descrito por:

$$
M_{x y}=M_{0} \cdot e^{\frac{-t}{T_{2}}}
$$

em que $\mathrm{T}_{2}$ é o tempo que o vetor de magnetização transversal leva para decair a $\sim 37 \%$ do valor inicial, $M_{x y}=M_{0} /$ e. O comportamento de $\mathrm{T}_{2}$ está representado na Figura 3.12.

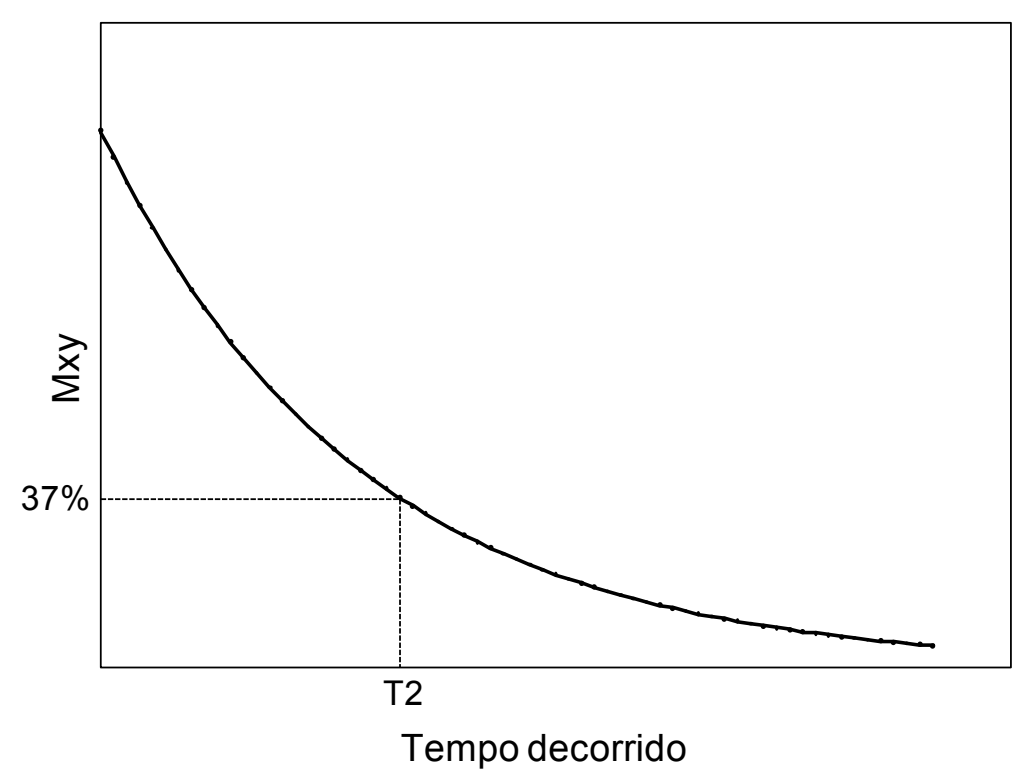

Figura 3.12 - Comportamento da componente transversal (plano xy) do vetor de magnetização $\left(\mathrm{M}_{\mathrm{xy}}\right)$ em relação ao tempo decorrido após a irradiação com RF. $M_{0}$ é a magnetização de equilíbrio e $T_{2}$ é o tempo de relaxação transversal.

Ambos processos, relaxação transversal e relaxação longitudinal, ocorrem simultaneamente, portanto o valor de $\mathrm{T}_{2}$ é sempre menor ou igual ao valor de $\mathrm{T}_{1}$ pois a magnetização transversal decresce até ser nulo, enquanto a magnetização longitudinal aumenta até atingir $M_{0}$. (Hornak, 2011) 


\subsubsection{Avaliação dos Dosímetros de Gel Polimérico utilizando Ressonância Magnética Nuclear (NMR)}

A dose de irradiação recebida pelo dosímetro de gel polimérico determina a extensão da reação de polimerização e, consequentemente, o efeito causado nas taxas de relaxação de ressonância magnética. A compreensão deste efeito depende de algumas considerações.

Considerando diferentes grupos de prótons (núcleos de hidrogênio) de acordo com o ambiente químico a que eles pertencem, é possível separar os prótons do gel polimérico em três grupos. O primeiro grupo consiste de prótons livres ou quasi-livres, mob, pertencentes às moléculas de água livres e monômeros não iniciados. O segundo grupo consiste de prótons de moléculas de água ligadas às macromoléculas (polímeros), poly. $\mathrm{O}$ terceiro grupo consiste de prótons pertencentes às moléculas da matriz gelatinosa e às moléculas associadas à gelatina, gela.

A relaxação spin-spin $\left(R_{2}\right)$ dos diferentes grupos é determinada pela taxa de agitação molecular e pelo movimento browniano das moléculas que contêm estes prótons. Estes fatores resultam em uma mudança da eficiência do acoplamento bipolar entre prótons vizinhos e leva a uma mudança na taxa de defasagem do momento de dipolo spin-magnético. Como este fator está diretamente relacionado com a relaxação spin-spin, espera-se que a taxa de relaxação dos grupos de prótons seja relacionada inversamente com a mobilidade dos prótons presentes nestes grupos, caracterizando, então, cada grupo por diferentes taxas de relaxação. Cada ambiente tem uma taxa de relaxação intrínseca $R_{2, \text { mob }}, R_{2, \text { poly }}$ e $R_{2, \text { gela. }}$.

O intervalo em que os prótons levam para trocar de grupo é curto em comparação a esses tempos de relaxação, levando a curva de relaxação a um comportamento monoexponencial com uma taxa de relaxação dada pela média ponderada das taxas de relaxação dos diferentes grupos de prótons da amostra:

$$
R_{2}=f_{\text {mob }} \cdot R_{2, \text { mob }}+f_{\text {poly }} \cdot R_{2, \text { poly }}+f_{\text {gela }} \cdot R_{2, \text { gela }}
$$

em que $f_{\text {mob}}, f_{\text {poly }}$ e $f_{\text {gela }}$ são as frações relativas de prótons nos grupos livre, polímero e gelatina, respectivamente. 
Antes da irradiação o segundo grupo de prótons está vazio, enquanto o primeiro está cheio. Sob irradiação, o segundo grupo começa a crescer às custas do primeiro grupo.

A mobilidade dos monômeros é relativamente alta e, portanto, a mobilidade de moléculas de água ligadas a monômeros por pontes de hidrogênio também é alta. No entanto, sob irradiação dos dosímetros de gel polimérico, a mobilidade molecular é notavelmente reduzida. Como a mobilidade das moléculas de água ligadas também é reduzida, a relaxação spin-spin é mais eficaz, o que pode ser observado pelo aumento em $R_{2}$. Sob um outro ponto de vista, a troca de prótons da água com prótons de polímeros de rápida relaxação aumenta $R_{2}$ (Baldock et al, 2010). 


\subsection{Método de Monte Carlo}

O método de Monte Carlo é uma técnica de análise numérica que calcula probabilidades e a relação entre grandezas por meio do uso de sequências de números aleatórios. No caso de uma única variável aleatória, o procedimento pode ser dividido entre dois estágios.

Primeiramente uma série de valores aleatórios $r_{1}, r_{2}, r_{3}, \ldots$ é gerada de acordo com uma distribuição uniforme dentro do intervalo $0<r<1$, sendo a função densidade de probabilidade (fdp) dada por:

$$
\begin{aligned}
& g(r)=1, \text { se } 0<r<1 \text { ou } \\
& g(r)=0 \text { para todos os outros casos. }
\end{aligned}
$$

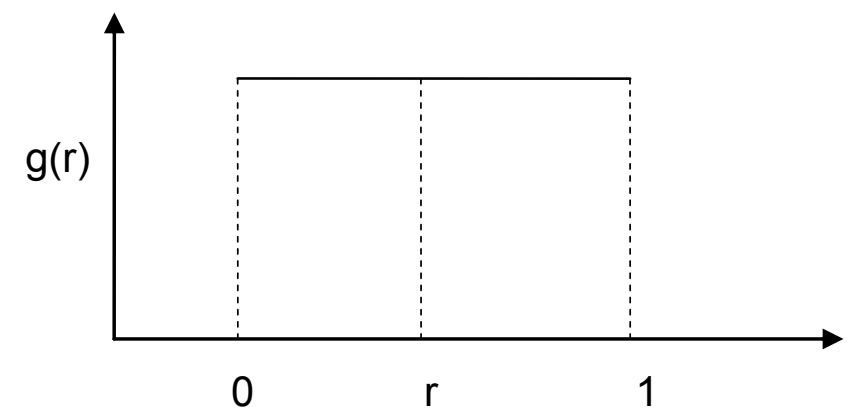

Figura 3.13 - Função densidade de probabilidade $g(r)$.

O segundo estágio consiste em utilizar a sequência $r_{1}, r_{2}, r_{3}, \ldots$ para determinar uma outra sequência $x_{1}, x_{2}, x_{3}, \ldots$ de modo que os valores de $x$ sejam distribuídos de acordo com a fdp $f(x)$ de interesse. Os valores de x podem ser tratados como medições simuladas e, a partir destes valores, é possível estimar a probabilidade de $x$ adotar valores em uma certa região. Desta maneira é possível calcular uma integral de $f(x)$.

Este exemplo monodimensional é simples e poderia ser realizado por outros métodos, porém, tomando problemas multidimensionais, a utilidade desta técnica se torna mais óbvia.

\subsubsection{Números Aleatórios Uniformemente Distribuídos}

Em princípio, uma sequência de números aleatórios uniformemente distribuídos poderia ser gerada por meio do uso de um processo físico aleatório, como jogar uma moeda repetidamente. Na prática, entretanto, esta tarefa é quase 
sempre executada por um algoritmo computacional chamado gerador de números aleatórios.

Um tipo de gerador de números aleatórios geralmente utilizado é baseado no algoritmo multiplicativo linear congruente. Começando em um valor inteiro inicial chamado semente, $\mathrm{n}_{0}$, uma sequência de números inteiros $n_{1}, n_{2}, n_{3}$, ... é gerada de acordo com a regra:

$$
n_{i+1}=\left(a n_{i}\right) \bmod m
$$

em que o multiplicador a e o módulo $m$ são inteiros constantes e o operador mod é o resto da divisão de $a n_{i}$ por $m$. Os valores $n_{i}$ seguem uma sequência periódica no intervalo [1, m-1]. Para obter valores uniformemente distribuídos em $(0,1)$, é necessário utilizar a transformação:

$$
r_{i}=n_{i} / m
$$

O valor inicial $n_{0}$ e as duas constantes a e $m$ determinam a sequência toda, que, obviamente, não é verdadeiramente aleatória, mas sim estritamente determinada. Portanto, os valores resultantes são chamados pseudo-aleatórios.

Estes valores podem ser tratados como sendo verdadeiros números aleatórios em praticamente todas aplicações, com exceção do fato destes valores serem reprodutíveis caso a mesma semente seja utilizada.

Os valores de $m$ e a são escolhidos de modo que os números gerados tenham um desempenho satisfatório sob diversos testes de aleatoriedade. O mais importante é que haja um longo período sem que a sequência comece a se repetir. Além disso, é necessário que os pares de números gerados tenham a menor correlação possível entre si.

\subsubsection{O Método de Transformação}

Dada uma sequência de números aleatórios $r_{1}, r_{2}, \ldots$ uniformemente distribuídos em $[0,1]$, o próximo passo é determinar a sequência $x_{1}, x_{2}, \ldots$ distribuída de acordo com a fdp $f(x)$ de interesse. No método de transformação, esta tarefa é realizada encontrando uma função $x(r)$ que forneça diretamente a sequência desejada quando testada com os valores de $r$ uniformemente gerados.

A tarefa é encontrar uma função $x(r)$ que seja distribuída de acordo com

uma $f(x)$ específica, dado que $r$ segue uma distribuição uniforme entre 0 e 1 (Figura 3.13). 
A probabilidade de obter um valor de $r$ no intervalo $[r, r+d r]$ é $g(r) d r$, e esta probabilidade deveria ser igual à probabilidade de obter um valor de $x$ no intervalo correspondente $[x(r), x(r)+d x(r)]$, que é $f(x) d x$. Para determinar $x(r)$ que faça esta correspondência ser verdadeira é necessário que a probabilidade de $r$ ser menor que qualquer valor $r$ ' seja igual à probabilidade de $x$ ser menor que $x\left(r^{\prime}\right)$. É necessário encontrar uma função $x(r)$ em que $F(x(r))=G(r)$, sendo $F$ e $G$ as distribuições cumulativas correspondentes às fdps $f$ e $g$. Como as distribuições cumulativas para a fdp uniforme é $G(r)=r \operatorname{com} 0 \leq r \leq 1$, resulta que

$$
F(x(r))=\int_{-\infty}^{x(r)} f\left(x^{\prime}\right) d x^{\prime}=\int_{-\infty}^{r} g\left(r^{\prime}\right) d r^{\prime}=r
$$

Dependendo da $f(x)$ em questão, pode ser que não seja possível encontrar uma solução para $x(r)$ utilizando a equação 3.50. Então, no caso de uma distribuição exponencial, a função ficaria:

$$
\int_{0}^{x(r)} \frac{1}{\xi} e^{-x^{\prime} / \xi} d x^{\prime}=r
$$

que integrada sobre $x$ fica:

$$
x(r)=-\xi \log (1-r)
$$

Como $r$ é uniformemente distribuída entre 0 e 1 , então $r^{\prime}=1-r$, o que resulta em:

$$
x(r)=-\xi \log (r)
$$

com a propriedade desejada. Se $r$ segue uma distribuição uniforme entre 0 e 1, então $x(r)=-\xi \log (r)$ seguirá uma distribuição exponencial com média $\xi$.

\subsubsection{O Método de Aceitação-Rejeição}

Resolver analiticamente a equação 3.50 em $x(r)$ para aplicações práticas é extremamente difícil. Uma alternativa útil é a técnica de aceitaçãorejeição de Neumann. Considerando uma fdp $f(x)$ que possa ser completamente confinada por uma caixa entre $x_{\min }$ e $x_{\max }$ de altura $f_{\max }$, como demonstrado na Figura 3.14, é possível gerar uma série de números distribuídos de acordo com $f(x)$ seguindo o seguinte algoritmo: 
1- Gerar um número aleatório $x$ uniformemente distribuído entre $x_{\min } \mathrm{e}$ $x_{\max }$, ou seja, $x=x_{\min }+r 1\left(x_{\max }-x_{\min }\right)$, em que $r_{1}$ é uniformemente distribuído entre 0 e 1 ;

2- Gerar um segundo número aleatório (independente do primeiro) $u$ uniformemente distribuído entre 0 e $f_{\max }$, ou seja, $u=r 2 . f_{\max }$;

3- Se $u<f(x)$, $x$ é aceito. Se não, $x$ é rejeitado e o método é repetido.

Os valores de $x$ aceitos serão distribuídos de acordo com $f(x)$, uma vez que, para cada valor de $x$ obtido no primeiro passo, a probabilidade de aceitação é proporcional a $f(x)$.

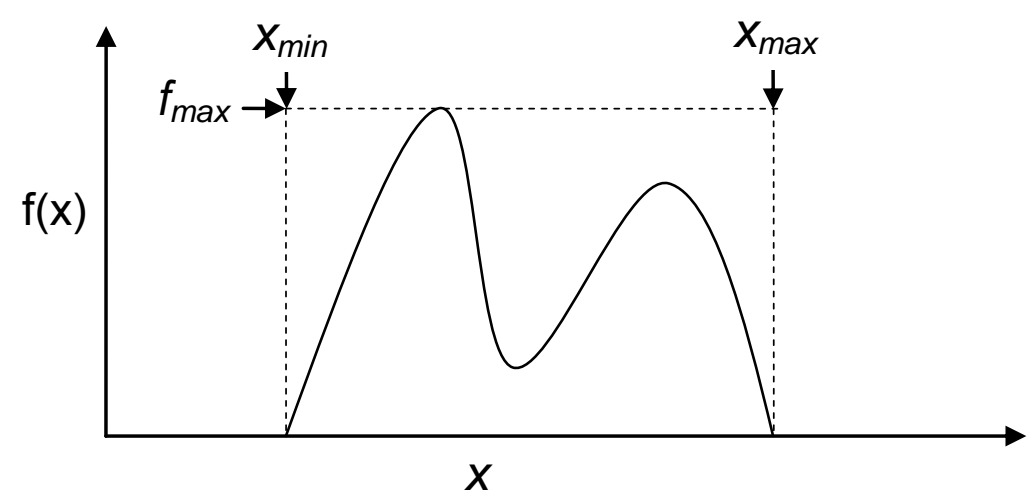

Figura 3.14 - Função densidade de probabilidade $f(x)$ confinada por uma caixa de dimensões entre $x_{\min }$ e $x_{\max }$, com altura $f_{\max }$.

\subsubsection{Aplicações do Método de Monte Carlo}

O método de Monte Carlo pode ser aplicado em qualquer problema cuja solução seja relacionada a um parâmetro de distribuição de probabilidade. O parâmetro pode ser explicitamente regido por uma fdp ou pela integral da distribuição sobre alguma região. Uma sequência de valores gerados por Monte Carlo é utilizada para avaliar um estimador do parâmetro (ou da integral), como seria realizado com dados reais. Uma característica importante do estimador é a propriedade da exatidão estatística aumentar conforme o número de valores $n$ da amostra de dados aumenta. Em geral, o desvio-padrão de um estimador é inversamente proporcional a $\sqrt{n}$. Portanto o método de Monte Carlo representa uma técnica de integração cuja exatidão aumenta com $1 / \sqrt{n}$.

No caso de integrais monodimensionais, outros métodos de integração apresentam melhor exatidão em relação ao número de dados na amostra que o 
método de Monte Carlo. Porém, para dimenões acima de 4, a dependência da exatidão em relação a $n$ é sempre superior com o método de Monte Carlo.

O método de Monte Carlo geralmente é utlizado para simular dados experimentais. Em física de partículas, por exemplo, este processo é realizado em dois passos: geração de eventos e simulação do detector.

Tomando o exemplo de um experimento consistindo de um fóton de radiação $X$ incidindo sobre um alvo, sendo espalhado por este e, então detetado; a probabilidade de um determinado evento ocorrer em função do ângulo de espalhamento é prevista por uma teoria complexa (como a seção de choque diferencial). Inicialmente é necessário um programa de Monte Carlo (chamado gerador de eventos) que gere valores para os ângulos de espalhamento dos fótons/partículas finais e, consequentemente, seus vetores de momento. Depois, os dados de saída do gerador de eventos (vetores de momento) são utilizados como dados de entrada do programa de simulação do detector. Uma vez que a resposta do detector à passagem da radiação espalhada envolve processos aleatórios, como produção de ionização e espalhamento Coulomb, o programa de simulação do detector também é implementado utilizando o método de Monte Carlo.

A maneira mais simples de compreender o método de Monte Carlo para a simulação de dados experimentais é pensando no método como uma implementação computacional de um processo intrinsicamente aleatório. As probabilidades podem ser naturalmente interpretadas como frequências relativas da saída de um experimento repetido diversas vezes pelo computador (Cowan, 1998). 


\section{MATERIAIS}

Este trabalho foi desenvolvido no Helmholtz Zentrum München Deutsches Forschungszentrum für Gesundheit und Umwelt (em tradução livre, Centro Helmholtz de Munique - Centro Alemão de Pesquisa em Saúde e Meio Ambiente) e a infraestrutura utilizada consistiu de dois equipamentos de radiação $X$, dois irradiadores gama, uma câmara de ionização padrão secundário acoplada a um eletrômetro, um equipamento de ressonância magnética nuclear. Estes equipamentos estão listados a seguir:

- Sistema de raios X Philips Industrial (atualmente Yxlon International) com um tubo MCN 323 (Sistema A) com janela de $4 \mathrm{~mm}$ de Berílio, que opera até 320 kV (Figura 4.1).

- Sistema de raios X Philips Industrial (atualmente Yxlon International) com um tubo MCN 165 (Sistema B) com janela de 0,8 mm de Berílio, que opera até $160 \mathrm{kV}$.

As especificações dos feixes de raios $X$ utilizados estão apresentados na Tabela 4.1.

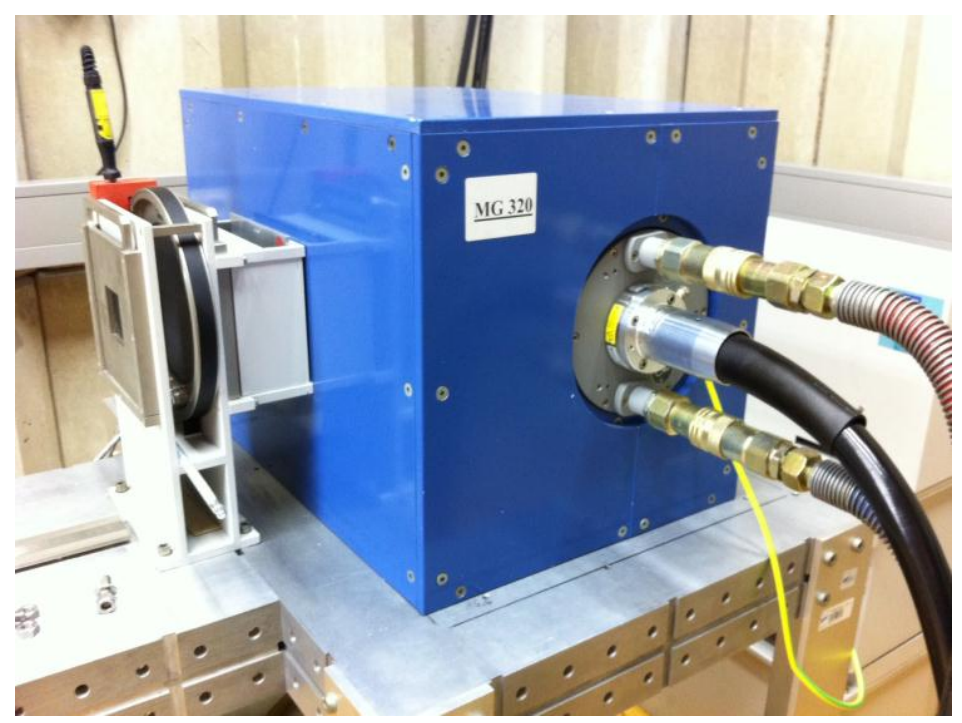

Figura 4.1 - Sistema de raios X Philips Industrial MCN 323. 
Tabela 4.1 - Especificações dos feixes de raios $X$ utilizados neste trabalho produzidos pelos sistemas $\mathrm{A}$ e $\mathrm{B}$. A Tabela apresenta feixes da série $\mathrm{N}$ (Narrow) sugeridos pela norma ISO 4037 (1994) e feixes modifcados $\left({ }^{*}\right)$.

\begin{tabular}{|c|c|c|c|}
\hline Feixe & $\begin{array}{c}\text { Tensão } \\
(\mathrm{kV})\end{array}$ & $\begin{array}{c}\text { Filtração adicional } \\
(\mathrm{mm})\end{array}$ & $\begin{array}{c}\text { Energia } \\
\text { média } \\
(\mathrm{keV})\end{array}$ \\
\hline $\mathrm{N}-40$ & $40(\mathrm{~B})$ & $4 \mathrm{Al}+0,21 \mathrm{Cu}$ & 33 \\
\hline $\mathrm{N}-60$ & $60(\mathrm{~B})$ & $4 \mathrm{Al}+0,6 \mathrm{Cu}$ & 48 \\
\hline $\mathrm{N}-80$ & $80(\mathrm{~B})$ & $4 \mathrm{Al}+2 \mathrm{Cu}$ & 65 \\
\hline $\mathrm{N}-100$ & $100(\mathrm{~B})$ & $4 \mathrm{Al}+5 \mathrm{Cu}$ & 83 \\
\hline $\mathrm{N}-120$ & $120(\mathrm{~B})$ & $4 \mathrm{Al}+5 \mathrm{Cu}+1 \mathrm{Sn}$ & 100 \\
\hline $\mathrm{N}-150$ & $150(\mathrm{~B})$ & $4 \mathrm{Al}+2,5 \mathrm{Sn}$ & 118 \\
\hline $\mathrm{N}-200$ & $200(\mathrm{~A})$ & $4 \mathrm{Al}+2 \mathrm{Cu}+3 \mathrm{Sn}$ & 164 \\
\hline $\mathrm{N}-250$ & $250(\mathrm{~A})$ & $4 \mathrm{Al}+2 \mathrm{Sn}+3 \mathrm{~Pb}$ & 208 \\
\hline $50^{*}$ & $50(\mathrm{~B})$ & $4 \mathrm{Al}$ & - \\
\hline $150^{*}$ & $150(\mathrm{~B})$ & $4 \mathrm{Al}+5 \mathrm{Cu}$ & - \\
\hline $200^{*}$ & $200(\mathrm{~A})$ & $4,05 \mathrm{Al}+0,96 \mathrm{Cu}$ & - \\
\hline $320^{*}$ & $320(\mathrm{~A})$ & $4,05 \mathrm{Al}+0,21 \mathrm{Cu}$ & - \\
\hline
\end{tabular}

- Software SpekCalc (Poludniowski et al, 2009), que permite simular espectros de raios $X$, inserindo as especificações técnicas dos sistemas de irradiação, potencial aplicado ao tubo de raios $X$ e filtração adicional.

- Dois sistemas de irradiação tipo Gamma Cell, modelo 220 (Figura 4.2), com fontes de Cobalto-60. Os irradiadores possuem um volume de irradiação cilíndrico com 20,6 cm de altura e 15,2 cm de diâmetro. Cada irradiador possui fontes puntiformes distribuídas em um anel e um filtro de chumbo que reduz a taxa de dose a $56 \%$ da taxa de dose sem filtro. As especificações dos irradiadores estão apresentadas na Tabela 4.2. 


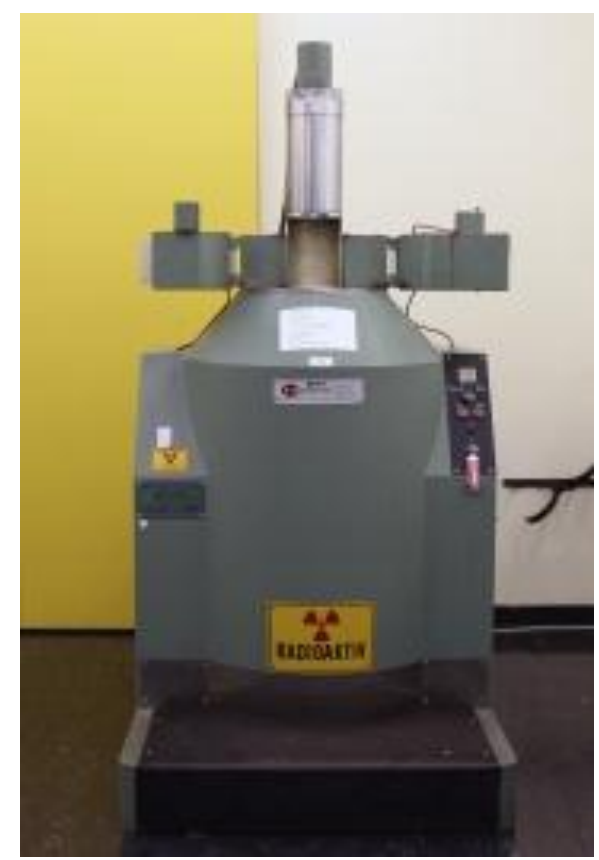

Figura 4.2 - Irradiador de Cobalto-60, Gamma Cell 220 I.

Tabela 4.2 - Especificações dos irradiadores utilizados neste trabalho, fornecidas pelo Laboratório Padrão Secundário de Dosimetria do Centro Helmholtz de Munique.

\begin{tabular}{|c|c|c|c|}
\hline Irradiador & $\begin{array}{c}\text { Atividade } \\
\text { em } \\
\text { maio/2010 } \\
\text { (TBq) }\end{array}$ & $\begin{array}{c}\text { Taxa de dose } \\
\text { absorvida na } \\
\text { água } \\
\text { sem filtro } \\
\text { (Gy/min) }\end{array}$ & $\begin{array}{c}\text { Taxa de dose } \\
\text { absorvida na } \\
\text { água } \\
\text { com filtro } \\
\text { (Gy/min) }\end{array}$ \\
\hline $\begin{array}{c}\text { Gamma Cell } \\
220 \text { I }\end{array}$ & 7,3 & 2,65 & 1,484 \\
\hline $\begin{array}{c}\text { Gamma Cell } \\
220 \text { II }\end{array}$ & 31,6 & 17,94 & 10,05 \\
\hline
\end{tabular}

- Dosímetro padrão secundário (rastreado ao laboratório padrão primário Physikalisch-Technische Bundesanstalt) composto por uma câmara de ionização PTW (modelo 23361, com volume sensível de $30 \mathrm{~cm}^{3}$ ) acoplada a um eletrômetro PTW Unidos. 
- Sistema de Ressonância Magnética Nuclear, marca Bruker-Biospin, modelo BioSpec 94/20 USR, com campo magnético estático de 9,4T, equipado com diversas bobinas de radiofrequência (Figura 4.3).

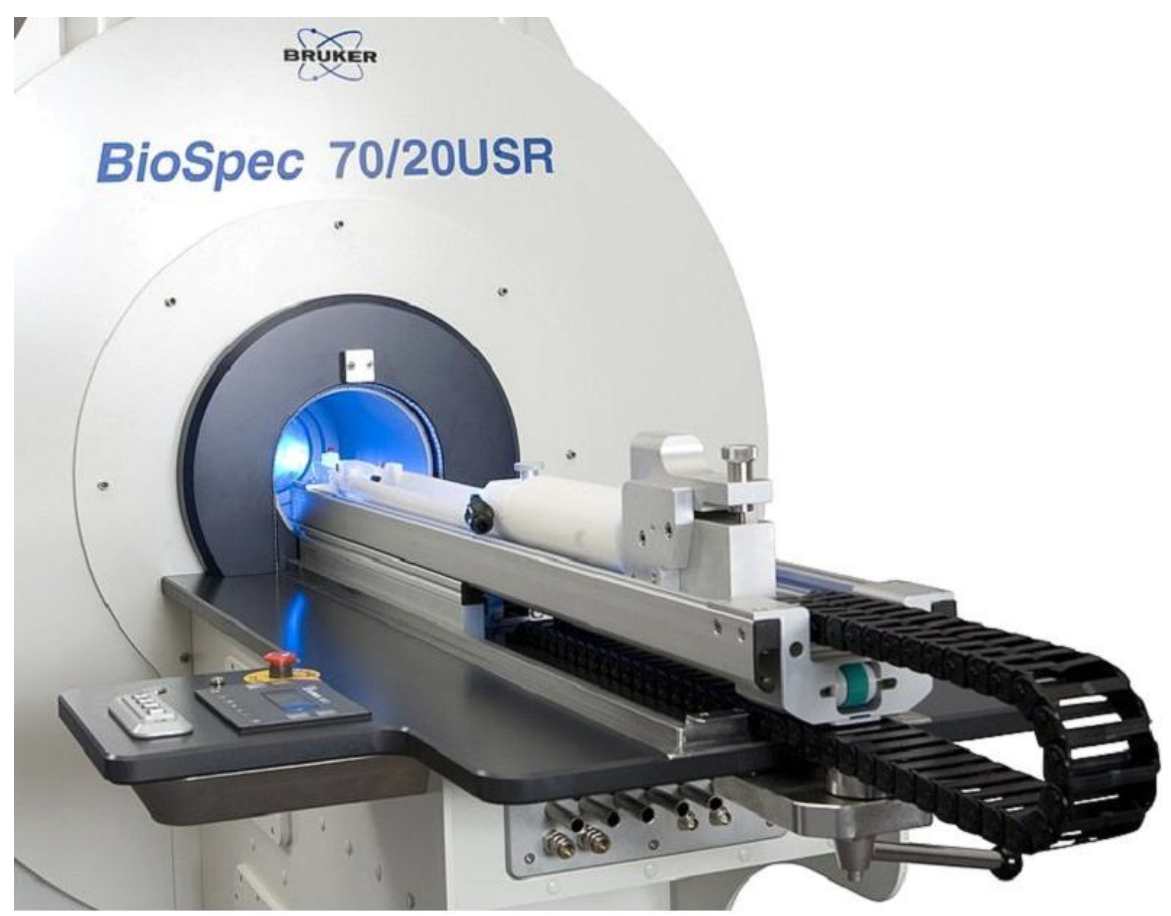

Figura 4.3 - Sistema de Ressonância Magnética Nuclear marca BrukerBiospin, modelo BioSpec 70/20 USR, semelhante ao sistema utilizado neste trabalho.

- Geant 3.21, software desenvolvido pelo CERN (Organização Europeia para Pesquisa Nuclear, Brun et al, 1987) que simula a passagem de partículas elementares pela matéria.

- Folhas de ouro com $100 \mathrm{~nm}$ de espessura, com 99,9\% de pureza, marca Dukat.

- Folha de ouro com 0,1 mm de espessura, com 99,99\% de pureza, marca Good Fellow.

- Microesferas de ouro com diâmetro de $(1,0 \pm 0,2) \mu \mathrm{m}$, com 99,99\% de pureza, marca Alfa Aesar.

Além destes equipamentos e softwares, foi utilizado um laboratório químico equipado com misturadores elétricos, equipamento de banho-maria, reagentes químicos para a produção do gel polimérico e frascos porta-amostras (Figura 4.4). 


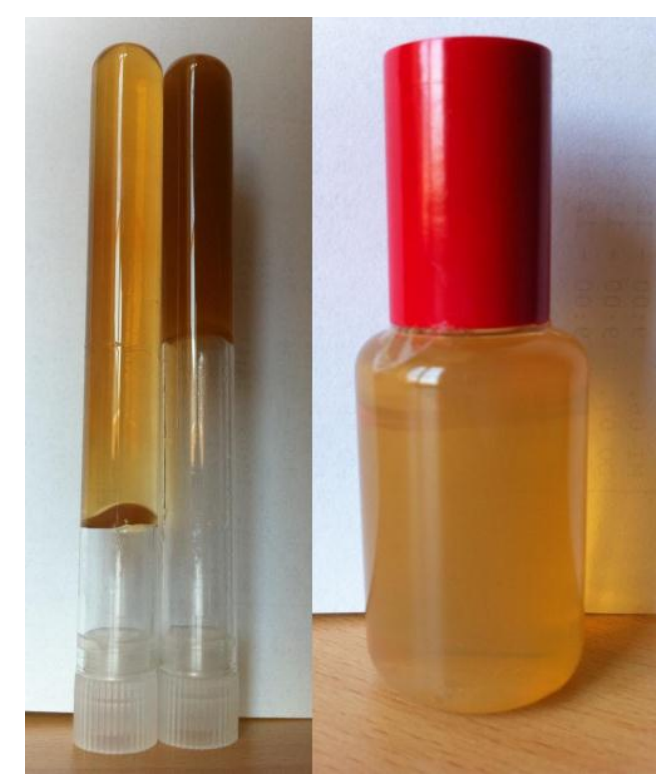

Figura 4.4 - Exemplos de porta-amostras utilizados neste trabalho. À esquerda: tubos de ensaio de vidro (com $10 \mathrm{~cm}$ de comprimento e 1,2 cm de diâmetro interno) e à direita: frasco de plástico Barex ${ }^{\circledR}(\operatorname{com~} 6 \mathrm{~cm}$ de comprimento e com $3 \mathrm{~cm}$ de diâmetro). 


\section{METODOLOGIA E RESULTADOS}

Neste capítulo serão apresentados os procedimentos realizados seguidos dos respectivos resultados.

\subsection{Caracterização do Dosímetro de Gel Polimérico}

\subsubsection{Produção do Dosímetro de Gel Polimérico}

O dosímetro de gel polimérico produzido neste trabalho é composto pelos reagentes químicos apresentados na Tabela 4.2, corforme proposto por Berg (2009).

Tabela 4.2: Composição do gel polimérico produzido para a realização deste trabalho.

\begin{tabular}{|c|c|}
\hline Componente & Massa (\%) \\
\hline Água destilada & 79,97 \\
\hline $\begin{array}{c}\text { (300 belatina } \\
\text { bloom, pele suína, }\end{array}$ & 13,99 \\
\hline $\begin{array}{c}\text { Ácido metacrílico 99\% } \\
\text { (Sigma-Aldrich) }\end{array}$ & 5,99 \\
\hline $\begin{array}{c}\text { Ácido ascórbico } \\
\text { (Merck) }\end{array}$ & 0,035 \\
\hline $\begin{array}{c}\text { Sulfato de Cobre } \\
\text { Pentaidratado (Merck) }\end{array}$ & 0,0025 \\
\hline
\end{tabular}

Inicialmente a gelatina e a água destilada são adicionadas em um béquer e são misturadas até que a gelatina absorva toda a água. Em seguida a mistura é colocada em banho-maria para derreter, com temperatura ajustada para $55^{\circ} \mathrm{C}$. Quando a solução se liquefaz, ainda em banho-maria, o ácido ascórbico e o 
sulfato de cobre são adicionados e dissolvidos com o auxílio de um misturador elétrico. Por último, o ácido metacrílico é misturado à solução. A solução é deixada em banho-maria até clarear e diminuir a espuma que se forma na superfície. Depois a solução é despejada nos frascos a serem utilizados no experimento. Os frascos devem ser cobertos com um filme de PVC e/ou com uma tampa apropriada para impedir a contaminação com oxigênio atmosférico. As amostras são deixadas para esfriarem e gelificarem em temperatura ambiente.

As amostras são irradiadas 24 horas depois da preparação. Após a irradiação, as amostras são levadas ao Laboratório de Ressonância Magnética Nuclear com 24 horas de antecedência à avaliação, para que as amostras entrem em equilíbrio térmico com o ambiente. Estes intervalos de tempo foram determinados em vista dos resultados dos testes de dependência dosimétrica em relação ao intervalo entre a produção e a irradiação e em relação ao intervalo entre a irradiação e a avaliação por ressonância magnética nuclear.

Todos os frascos utilizados como porta-amostra do gel polimérico foram imersos por cerca de 24 horas em uma solução "capturadora de oxigênio", composta por água destilada, ácido ascórbico e sulfato de cobre, para eliminar as moléculas de oxigênio aderidas às paredes dos frascos.

\subsubsection{Avaliação do Gel Polimérico com Ressonância Magnética Nuclear}

Neste trabalho, a avaliação das amostras de gel polimérico com a técnica de ressonância magnética nuclear foi realizada utilizando uma sequência Multi-Slice Multi-Echo (MSME, Multi-fatia multi-eco, em tradução livre). A sequência MSME produz imagens do sinal emitido durante a desexcitação da amostra (cujo comportamento foi apresentado na Figura 3.12, seção 3.4.3). Os sinais obtidos são ajustados a uma função monoexponencial, do qual o tempo de relaxamento transversal (T2) é obtido de acordo com:

$$
S=a+c \cdot e^{(-t / T 2)}
$$

em que $S$ é o sinal obtido no tempo t. Os parâmetros a e c estão relacionados ao campo magnético estático e aos pulsos de excitação aplicados às amostras.

Os valores de taxa de relaxamento $\left(R_{2}=1 / T_{2}\right)$ são, então, relacionados com a dose de radiação aplicada a cada amostra. 
Os parâmetros TE (tempo de eco, intervalo entre as aquisições dos sinais de desexcitação) e TR (tempo de repetição, intervalo entre as excitações da amostra) são de extrema importância para a análise adequada dos dosímetros de gel polimérico, pois determinam a qualidade do sinal (S) gerado pela desexcitação da amostra (ruído, incerteza na obtenção de $T_{2}$ ) e, consequentemente, o valor de $\mathrm{R}_{2}$. Estes parâmetros dependem fortemente do campo magnético estático (no caso, 9,4 T), do tipo de amostra (massa, densidade de prótons, susceptibilidade magnética, etc.), e do tipo de informação que se deseja extrair da amostra (T1, T2, transferência de magnetização).

Neste experimento, para desenvolver uma metodologia de avaliação das amostras com a técnica de ressonância magnética nuclear, uma amostra de gel polimérico foi utilizada.

Os parâmetros TE e TR foram variados com o objetivo de melhorar o sinal obtido para não comprometer a análise do desempenho dosimétrico dos dosímetros, causado pela propagação das incertezas sistemáticas. O campo de visão (Field of View, FOV) sempre foi mantido grande o suficiente para incluir a amostra inteira na imagem e a espessura das fatias foi mantida em $1 \mathrm{~mm}$, com resolução de $(100 \mu \mathrm{m})^{3}$.

Os parâmetros TE e TR foram variados conforme apresentado na Tabela 5.1.

Tabela 5.1 - Variação dos parâmetros da sequência MSME.

\begin{tabular}{|c|c|c|c|}
\hline Número de ecos & TE $(\mathrm{ms})$ & TR $(\mathrm{ms})$ & Resultado \\
\hline 8 & $40,80, \ldots, 320$ & 2000 & Figura 5.1 \\
\hline 32 & $30,60, \ldots, 960$ & 5000 & Figura 5.2 \\
\hline 16 & $30,60, \ldots, 480$ & 2500 & Figura 5.3 \\
\hline 16 & $20,40, \ldots, 320$ & 2500 & Figura 5.4 \\
\hline
\end{tabular}




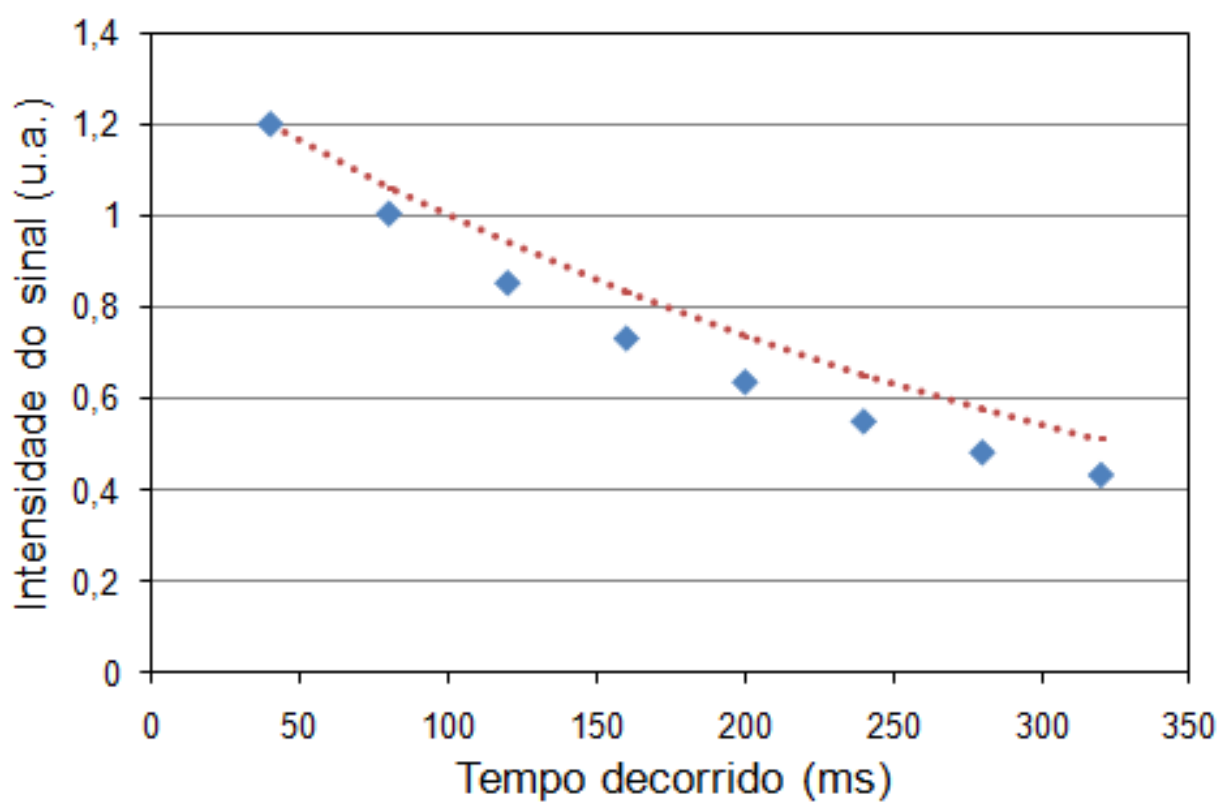

Figura 5.1 - Ajuste monoexponencial dos sinais da sequência MSME com 8 ecos, TE $=40 \mathrm{~ms}$ e TR=2000 ms. Os pontos azuis representam os sinais experimentais e a linha tracejada vermelha representa o ajuste monoexponencial.

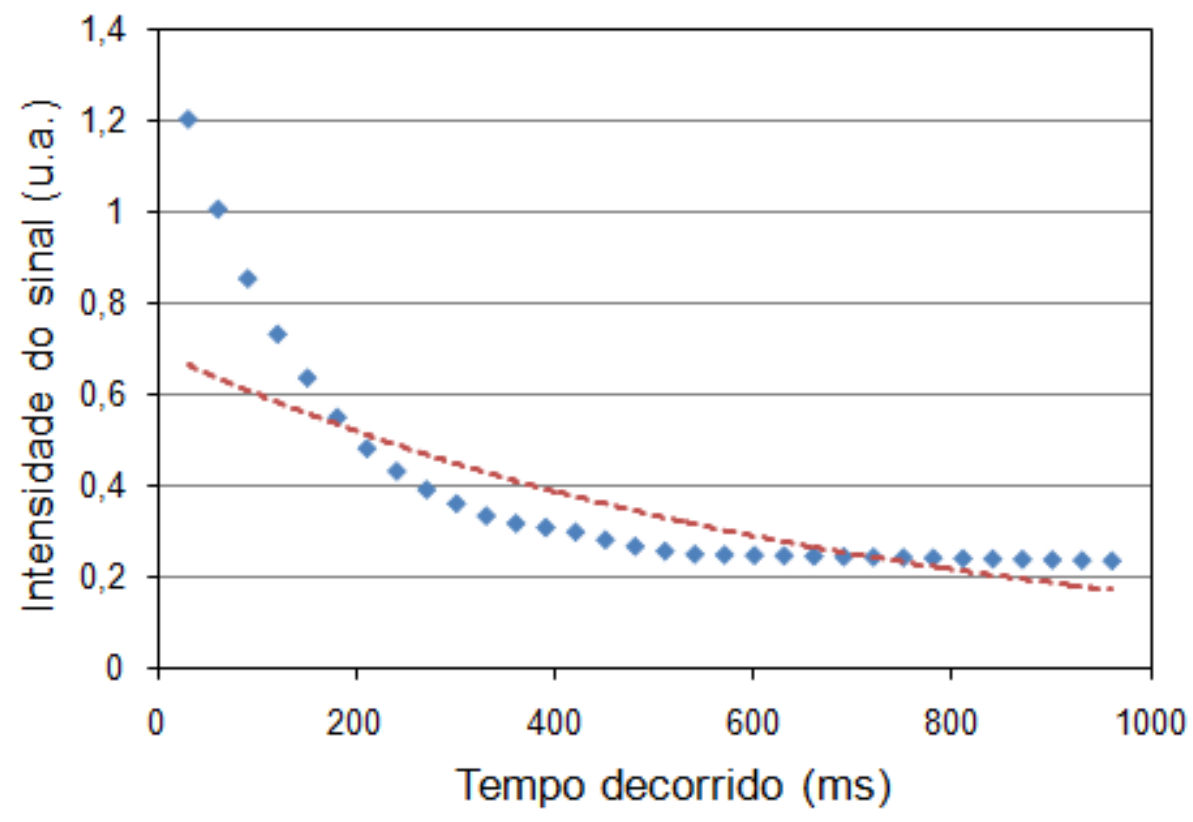

Figura 5.2 - Ajuste monoexponencial dos sinais da sequência MSME com 16 ecos, TE= $30 \mathrm{~ms}$ e TR= $5000 \mathrm{~ms}$. Os pontos azuis representam os sinais experimentais e a linha tracejada vermelha representa o ajuste monoexponencial. 


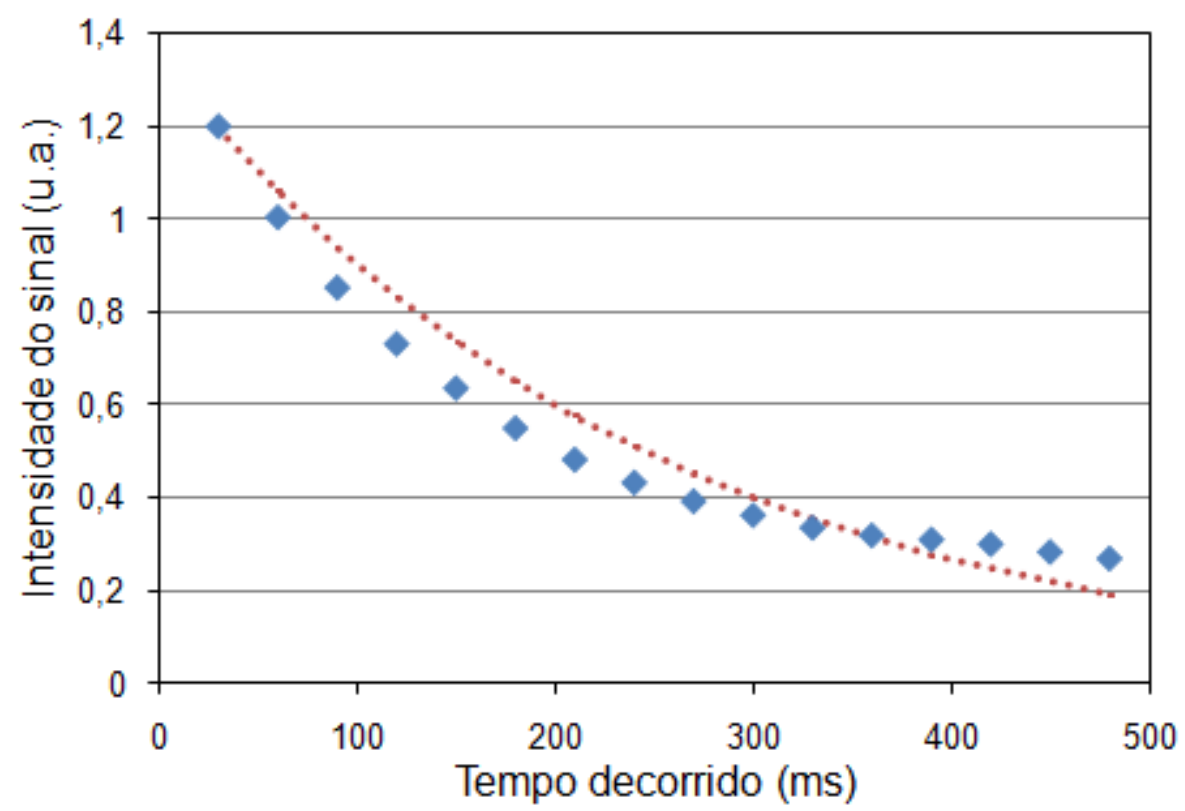

Figura 5.3 - Ajuste monoexponencial dos sinais da sequência MSME com 32 ecos, TE= $30 \mathrm{~ms}$ e TR= $2500 \mathrm{~ms}$. Os pontos azuis representam os sinais experimentais e a linha tracejada vermelha representa o ajuste monoexponencial.

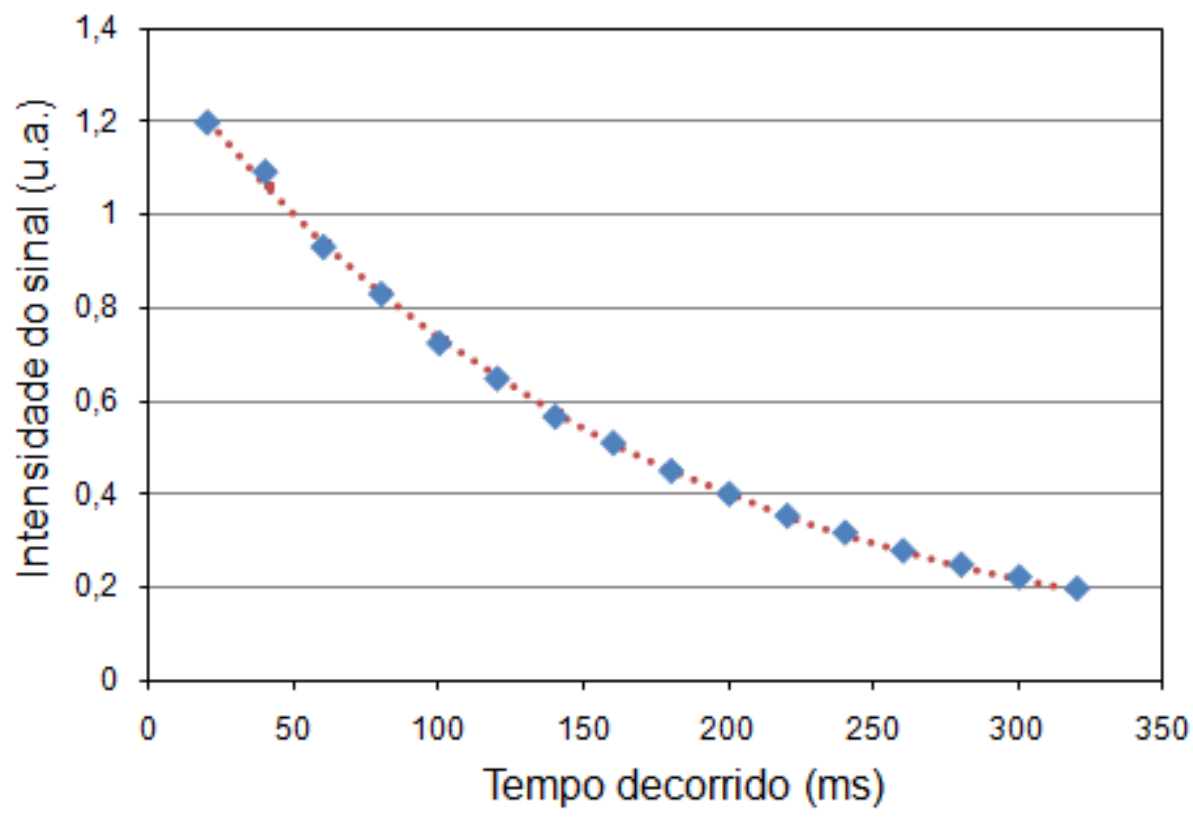

Figura 5.4 - Ajuste monoexponencial dos sinais da sequência MSME com 16 ecos, TE= $20 \mathrm{~ms}$ e TR= $2500 \mathrm{~ms}$. Os pontos azuis representam os sinais experimentais e a linha tracejada vermelha representa o ajuste monoexponencial. 
Os resultados mostram que os parâmetros mais adequados para a avaliação das amostras utilizando a sequência Multi-Slice Multi-Echo são: 16 ecos, com tempo de eco de 20, 40, .., 320 ms e tempo de repetição de 2500 ms, pois os sinais medidos possuem o comportamento monoexponencial descrito pela teoria de relaxação transversal (item 3.4.3).

\subsubsection{Dependência do Dosímetro em Relação aos Intervalos Produção-}

\section{Irradiação e Irradiação-Avaliação}

Como discutido anteriormente, o processo de gelificação do gel polimérico (ou de qualquer gel à base de colágeno) leva semanas para se estabilizar, podendo causar uma variação no comportamento químico se irradiado e/ou avaliado em diferentes momentos deste processo. Em vista disto, esse experimento teve como objetivo analisar a dependência do gel polimérico em relação à variação dos intervalos entre a produção e a irradiação e entre a irradiação e a avaliação com a técnica de ressonância magnética nuclear, designados aqui por intervalo $\mathrm{PI}$ e intervalo IA, respectivamente.

Para a realização deste experimento, um lote de 76 amostras foi produzido, das quais 4 amostras foram utilizadas como controle (zero). As demais amostras (72) foram divididas entre três grupos de intervalos entre a produção e a irradiação: 1, 2 e 3 dias, $\mathrm{PI}=1, \mathrm{PI}=2$ e $\mathrm{PI}=3$, respectivamente. Cada grupo, consistindo de 24 amostras, foi irradiado com o espectro padrão N-250 de raios $\mathrm{X}$ sugerido pela ISO 4037 (1994), produzido pelo sistema Philips MCN 323, com as seguintes doses absorvidas em grays: 1, 2, 4, 6, 8, 10. A taxa de dose absorvida foi obtida no ponto de referência $(70 \mathrm{~cm})$ utilizando 0 dosímetro padrão secundário descrito anteriormente e corresponde a 7,37.10-2 $\mathrm{mGy} / \mathrm{s}( \pm 1,5 \%$ de incerteza combinada, incluindo posicionamento, fator de calibração, estabilidade instrumental e correções para a densidade do ar). $\mathrm{O}$ arranjo de irradiação das amostras está representado na Figura 5.5. 


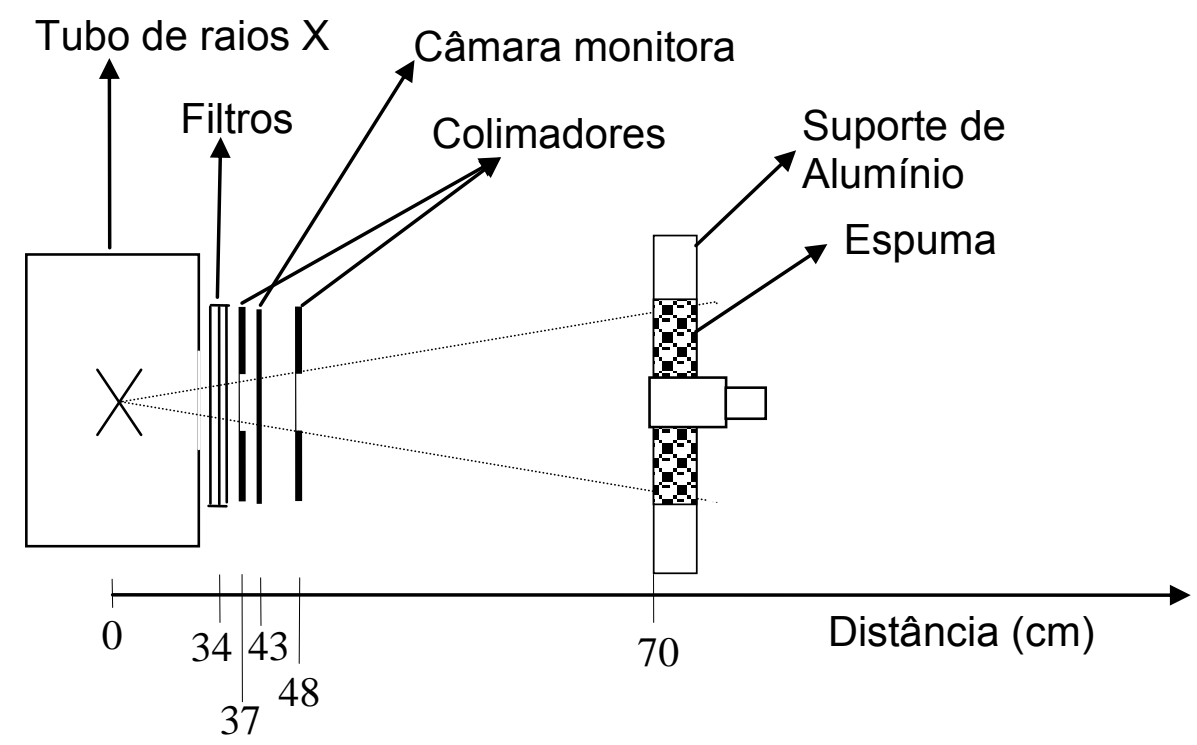

Figura 5.5 - Arranjo de irradiação com o sistema de raios $X$ (fora de escala).

Cada grupo PI foi avaliado utilizando a técnica de ressonância magnética nuclear, variando o tempo decorrido após a irradiação (IA) em dias. O grupo de controle também foi avaliado utilizando a técnica de ressonância magnética nuclear todos os dias de avaliação dos grupos. Em cada avaliação $T_{2}$ foi medido para obtenção de $R_{2}$, que, por sua vez, foi relacionada com a dose absorvida aplicada a cada amostra (tomando sempre o valor médio de $R_{2}$ por dose). A média dos valores de $R_{2}$ do grupo de controle $\left(R_{2}(0)\right)$ foram subtraídos dos valores de $\mathrm{R}_{2}$ obtidos pelas amostras. Esta diferença foi relacionada à dose absorvida aplicada às amostras, obtendo-se, então, curvas de "dose absorvida" versus " $R_{2}-R_{2}(0)$ ".

O grupo $\mathrm{PI}=1$ foi avaliado 1, 2, 3, 6 e 7 dias após a irradiação (IA = 1,2,3,6,7). O grupo $\mathrm{PI}=2$ foi avaliado $1,2,5$ e 6 dias após a irradiação ( $\mathrm{I} A=$ 1,2,5,6). $\mathrm{O}$ grupo $\mathrm{PI}=3$ foi avaliado 1,4 e 5 dias após a irradiação $(\mathrm{IA}=1,4,5)$.

As curvas de "dose absorvida" versus " $R_{2}-R_{2}(0)$ " obtidas para os diversos valores de intervalos entre irradiação e avaliação (IA) foram comparadas entre si, dentro do grupo $\mathrm{PI}=1$. $\mathrm{O}$ mesmo foi realizado com $\mathrm{PI}=2$ e $\mathrm{PI}=3$.

$O$ resultado do grupo $P I=1$ dia, com $I A=1,2,3,6$ e 7 dias está representado na Figura 5.6. $\mathrm{O}$ resultado do grupo $\mathrm{PI}=2$ dias, com $\mathrm{IA}=1,2,5$ e 6 dias está representado na Figura 5.7. $\mathrm{O}$ resultado do grupo $\mathrm{PI}=3$ dias, com $\mathrm{IA}=$ 
1, 4 e 5 dias está representado na Figura 5.8. Os ajustes lineares de cada caso também estão representados.

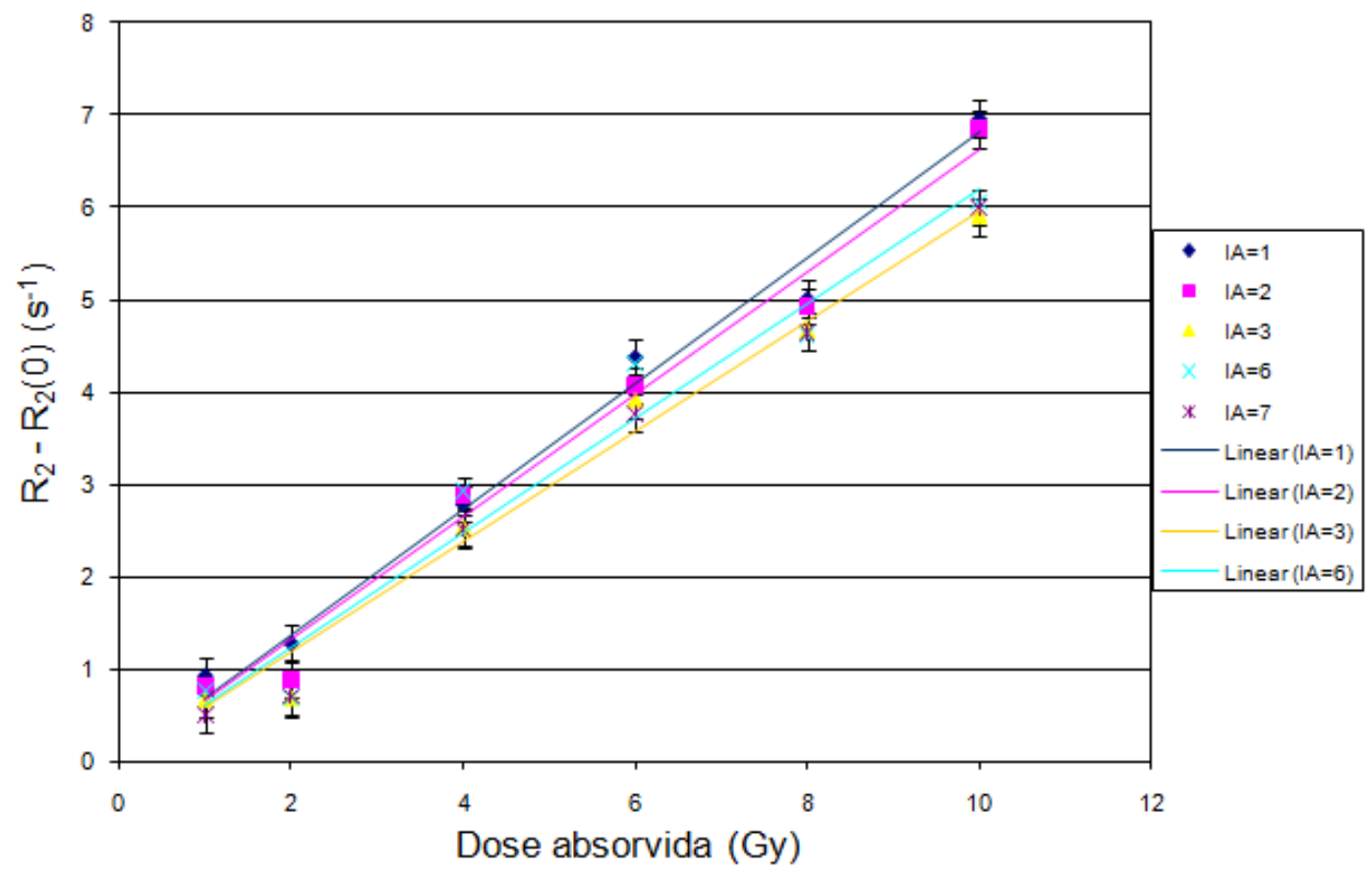

Figura $5.6-\mathrm{PI}=1$ dia, relação entre a dose absorvida e $R_{2}-R_{2}(0)$ para $\mathrm{IA}=1,2,3,6$ e 7 dias.

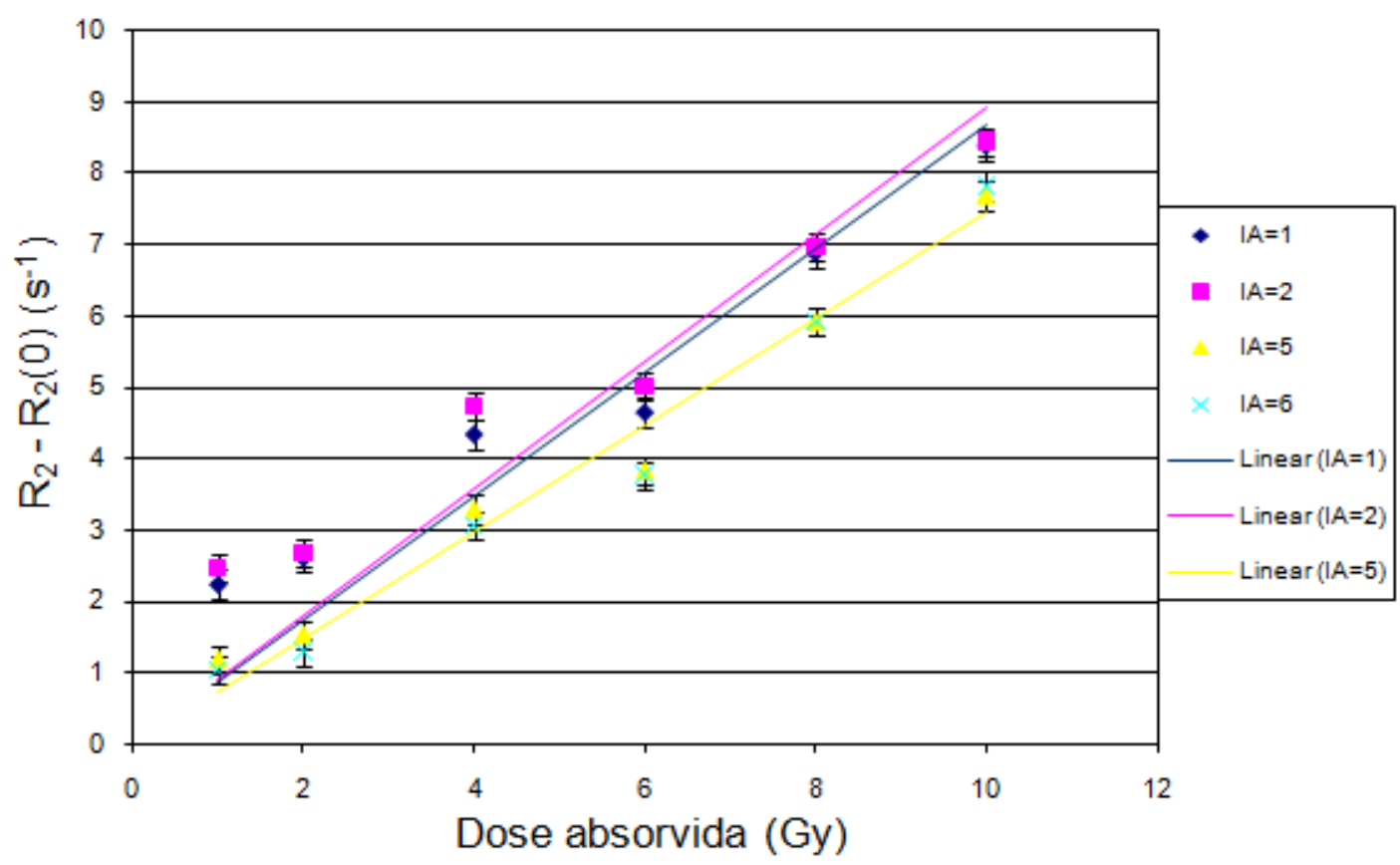

Figura 5.7 - $\mathrm{PI}=2$ dias, relação entre a dose absorvida e $\mathrm{R}_{2}-\mathrm{R}_{2}(0)$ para $\mathrm{IA}=1,2,5$ e 6 dias. 


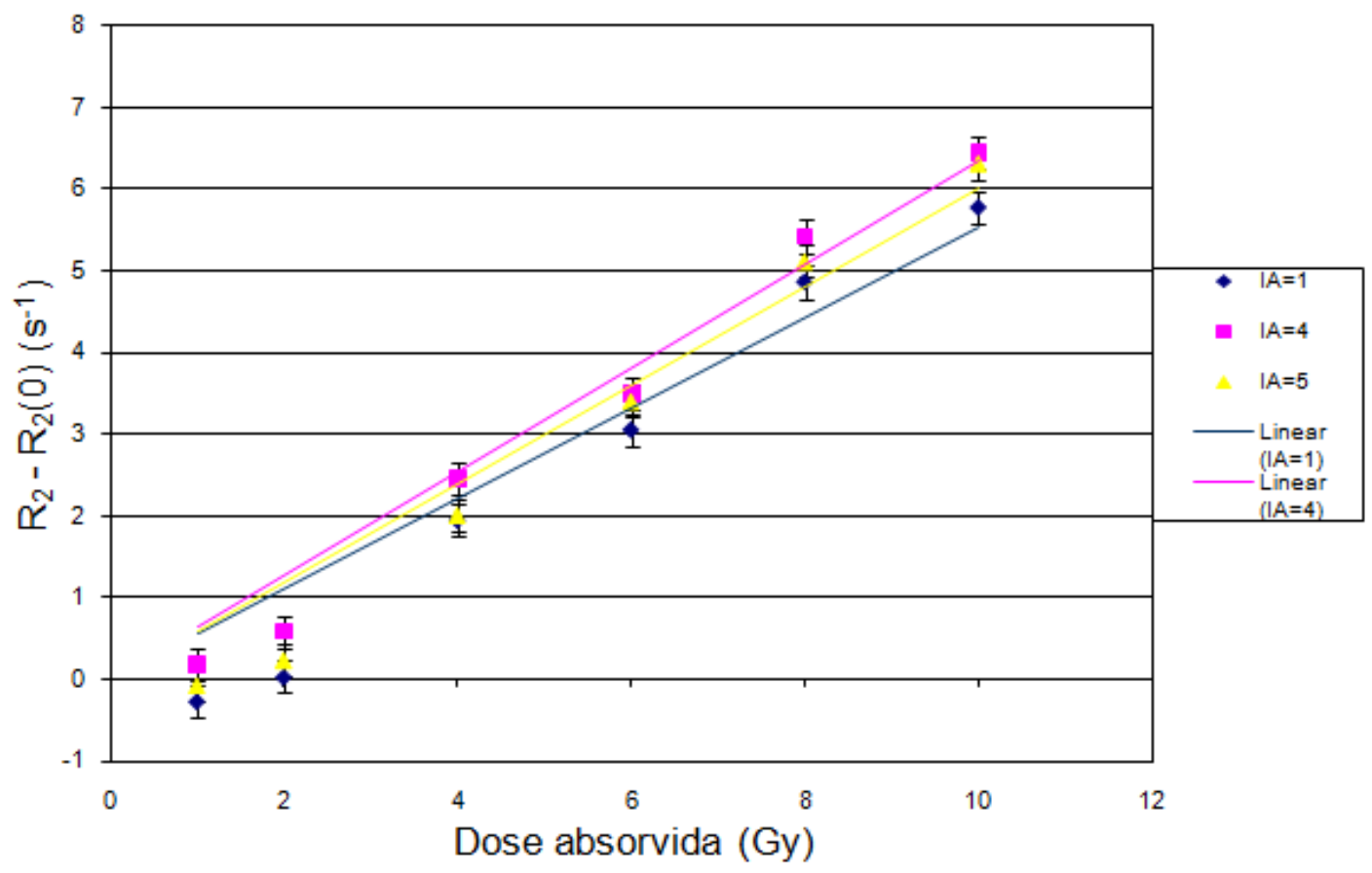

Figura 5.8 - PI = 3 dias, relação entre a dose absorvida e $R_{2}-R_{2}(0)$ para $\mathrm{IA}=1,4$ e 5 dias.

A Figura 5.6 mostra que as amostras irradiadas um dia após a produção $(\mathrm{PI}=1)$ não apresentam variação considerável de resposta nos primeiros dois dias ( $I A=1$ e 2$)$. Esta pequena variação entre os dados de $I A=1$ e os dados de $\mathrm{IA}=2$ pode ser inserida na incerteza, equivalente a $10 \%$. A partir do terceiro dia após a irradiação, no entanto, a resposta varia mais que a faixa de incerteza dos dados do primeiro dia, alterando a inclinação da reta ajustada, ou seja, alterando também a relação dose-resposta do dosímetro.

A Figura 5.7 mostra que as amostras irradiadas dois dias após a produção $(\mathrm{PI}=2)$ apresentam oscilações na resposta em relação à dose até mesmo no primeiro dia de avaliação $(I A=1)$. As respostas dos dias seguintes também oscilam.

A Figura 5.8 mostra que as amostras irradiadas 3 dias após a produção $(P I=3)$ apresentam grandes variações na resposta em relação à dose para os três casos testados: $\mid A=1,4$ e 5 dias.

Estes resultados indicam que os valores de $R_{2}$ decrescem com 0 aumento dos intervalos entre a produção e a irradiação $(\mathrm{PI})$ e entre a irradiação e a avaliação (IA) com a técnica de ressonância magnética nuclear. Apenas o 
intervalo entre produção e irradiação de um dia apresentou resultados satisfatórios, ainda assim limitados ao intervalo entre irradiação e avaliação com a técnica de ressonância magnética nuclear de até 2 dias.

Baseando-se nesses resultados, um procedimento padrão foi estabelecido para ser utilizado neste trabalho. Os intervalos estabelecidos foram de um dia entre a produção e a irradiação do gel polimérico e um dia entre a irradiação e a avaliação com a técnica de ressonância magnética nuclear. Alguns poucos experimentos fogem deste procedimento padrão por terem sido realizados antes deste estudo.

\subsubsection{Comportamento Dosimétrico para Fótons}

Os dosímetros de gel polimérico foram avaliados em relação à resposta quando irradiados com diferentes doses e energias de fótons de raios $X$ e raios gama, assim como em relação ao comportamento dosimétrico sob diferentes taxas de dose.

\section{Primeiro Experimento - Dose x $\mathbf{R}_{\mathbf{2}}$ : feixe $\mathbf{N}-250$}

O primeiro experimento consistiu na avaliação do comportamento dosimétrico do gel polimérico sob irradiação com raios $X$ produzidos pelo sistema Philips MCN 323, com $250 \mathrm{kV}, 15 \mathrm{~mA}$, filtrado com $4 \mathrm{mmAl}, 2 \mathrm{mmSn}$ e $3 \mathrm{mmPb}$, qualidade N-250 da norma ISO 4037 (1994). Foram produzidas 10 amostras ( $40 \mathrm{ml}$ por amostra) de gel polimérico. As amostras foram irradiadas 2 dias após a produção com doses absorvidas no ar de 1, 2, 3 e $4 \mathrm{~Gy}$, com taxa de dose absorvida constante de 7,3.10-2 $\mathrm{mGy} / \mathrm{s}( \pm 1,5 \%)$. Duas amostras por dose foram irradiadas e duas amostras foram tomadas como controle (não irradiadas).

As amostras foram avaliadas 1 dia após a irradiação utilizando a técnica de ressonância magnética nuclear. A média dos valores de $R_{2}$ do grupo de controle $\left(R_{2}(0)\right)$ foi subtraída dos valores médios de $R_{2}$ obtidos pelas amostras. Esta diferença foi relacionada à dose absorvida aplicada às amostras, obtendose, então, uma curva de " $R_{2}-R_{2}(0)$ " versus dose absorvida. Esta curva está representada na Figura 5.9. 


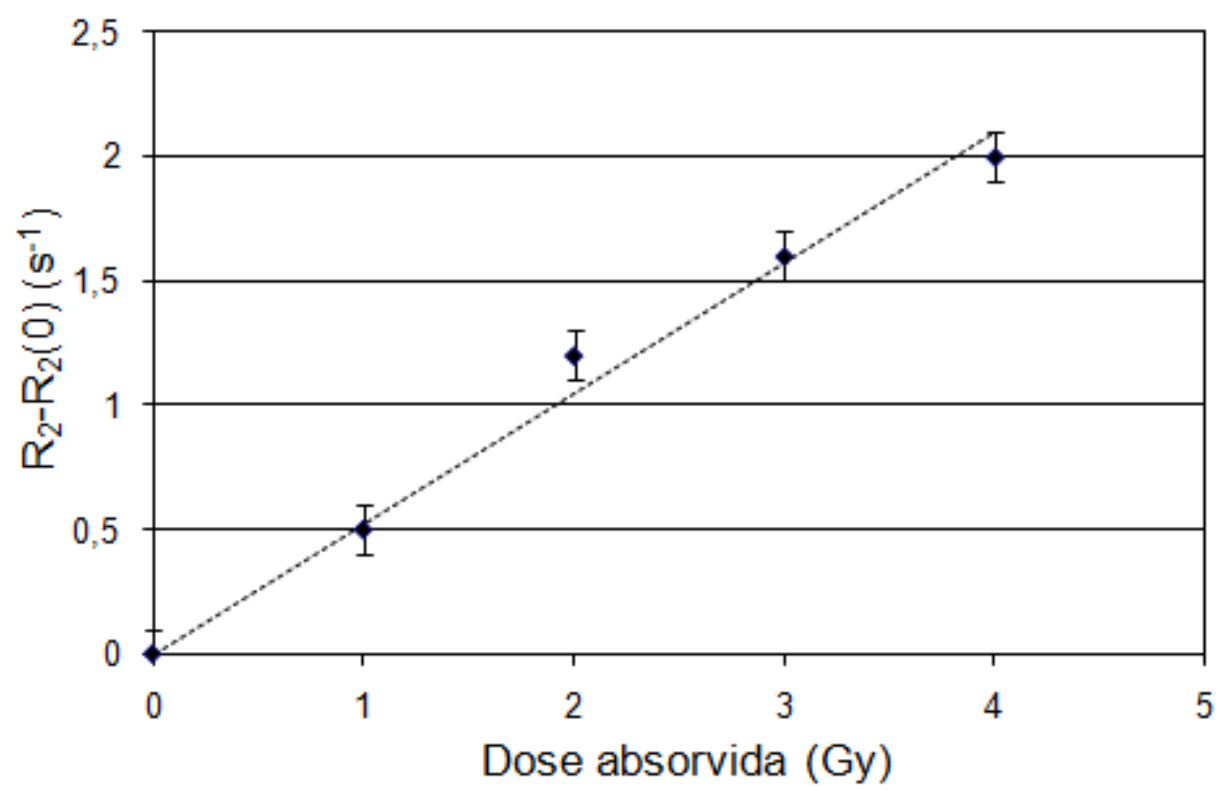

Figura 5.9 - Relação entre $R_{2}-R_{2}(0)$ e a dose absorvida para o feixe de raios $X \mathrm{~N}-250$. Cada ponto representa duas amostras. As incertezas representadas no gráfico são provenientes da propagação das incertezas do ajuste monoexponencial de $\mathrm{T}_{2}$. $\mathrm{O}$ coeficiente de correlação do ajuste linear é $R^{2}=0,98$.

Os resultados mostram um comportamento linear do dosímetro para o feixe N-250.

\section{Segundo Experimento - Dose x $\mathbf{R}_{2}$ : feixe $320^{*}$}

O segundo experimento foi realizado de maneira similar ao primeiro, sob irradiação com raios $X$ produzidos pelo sistema Philips MCN 323, porém o feixe utilizado foi gerado por um potencial de $320 \mathrm{kV}, 13,1 \mathrm{~mA}$, filtrado com $4,05 \mathrm{mmAl}$ e $0,21 \mathrm{mmCu}$ (feixe $320^{*}$ ). Neste caso foi utilizada pouca filtração para evitar o caso de baixa taxa de dose, que demandaria longos períodos de irradiação e ocorreria defasagem de comportamento químico entre as amostras, de modo que a resposta entre as primeiras amostras e as últimas amostras irradiadas não poderiam ser comparadas.

Foram produzidas 18 amostras ( $40 \mathrm{ml}$ por amostra) de gel polimérico. As amostras foram irradiadas 1 dia após a produção com doses absorvidas no ar de 1, 2, 3, 5, 6, 8, 9 e $10 \mathrm{~Gy}$, com taxa de dose absorvida constante de 20,3.10-2 $\mathrm{mGy} / \mathrm{s}( \pm 1,5 \%)$. Duas amostras por dose foram irradiadas e duas amostras foram tomadas como controle (não irradiadas). 
As amostras foram avaliadas 1 dia após a irradiação utilizando a técnica de ressonância magnética nuclear. A média dos valores de $R_{2}$ do grupo de controle $\left(R_{2}(0)\right)$ foi subtraída dos valores médios de $R_{2}$ obtidos pelas amostras. Esta diferença foi relacionada à dose absorvida aplicada às amostras, obtendose, então, uma curva de " $R_{2}-R_{2}(0)$ " versus dose absorvida. Esta curva está representada na Figura 5.10.

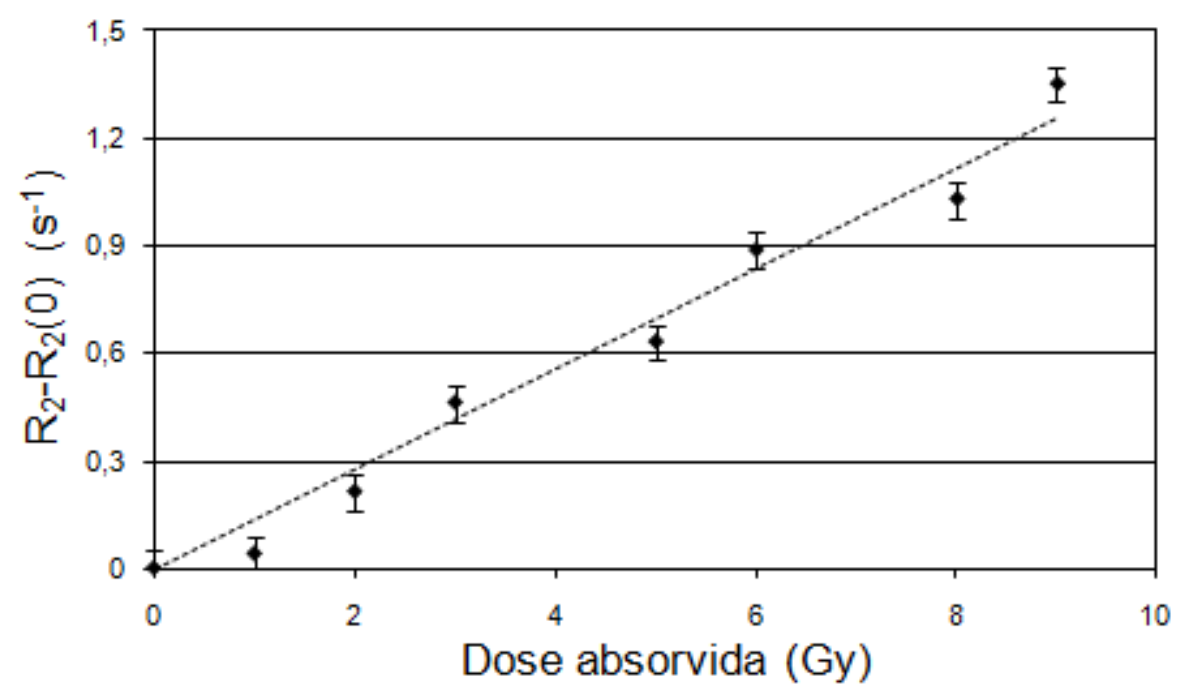

Figura 5.10 - Relação entre $R_{2}-R_{2}(0)$ e a dose absorvida para o feixe 320*. Cada ponto representa duas amostras. As incertezas representadas no gráfico são provenientes da propagação das incertezas do ajuste monoexponencial de $T_{2}$. O coeficiente de correlação do ajuste linear é $R^{2}=0,97$.

Estes resultados mostram um comportamento linear do dosímetro para o feixe utilizado.

\section{Terceiro Experimento - Dose x $\mathbf{R}_{2}$ : feixe 150 *}

O terceiro experimento foi realizado sob irradiação com raios $X$ produzidos pelo sistema Philips MCN 165. O feixe utilizado foi gerado por um potencial de $150 \mathrm{kV}, 20 \mathrm{~mA}$, filtrado com $4 \mathrm{mmAl}$ e $5 \mathrm{mmCu}$ (feixe 150*).

Foram produzidas 24 amostras de gel polimérico. As amostras foram irradiadas 1 dia após a produção com doses absorvidas no ar de 1, 2, 3, 5 e 6 Gy, com taxa de dose absorvida constante de 5,6.10-1 $\mathrm{mGy} / \mathrm{s}( \pm 1,5 \%)$. Quatro amostras por dose foram irradiadas e quatro amostras foram tomadas como controle (não irradiadas). 
As amostras foram avaliadas 1 dia após a irradiação utilizando a técnica de ressonância magnética nuclear. A média dos valores de $R_{2}$ do grupo de controle $\left(R_{2}(0)\right)$ foi subtraída dos valores médios de $R_{2}$ obtidos pelas amostras. Esta diferença foi relacionada à dose absorvida aplicada às amostras, obtendose, então, uma curva de " $R_{2}-R_{2}(0)$ " versus dose absorvida. Esta curva está representada na Figura 5.11.

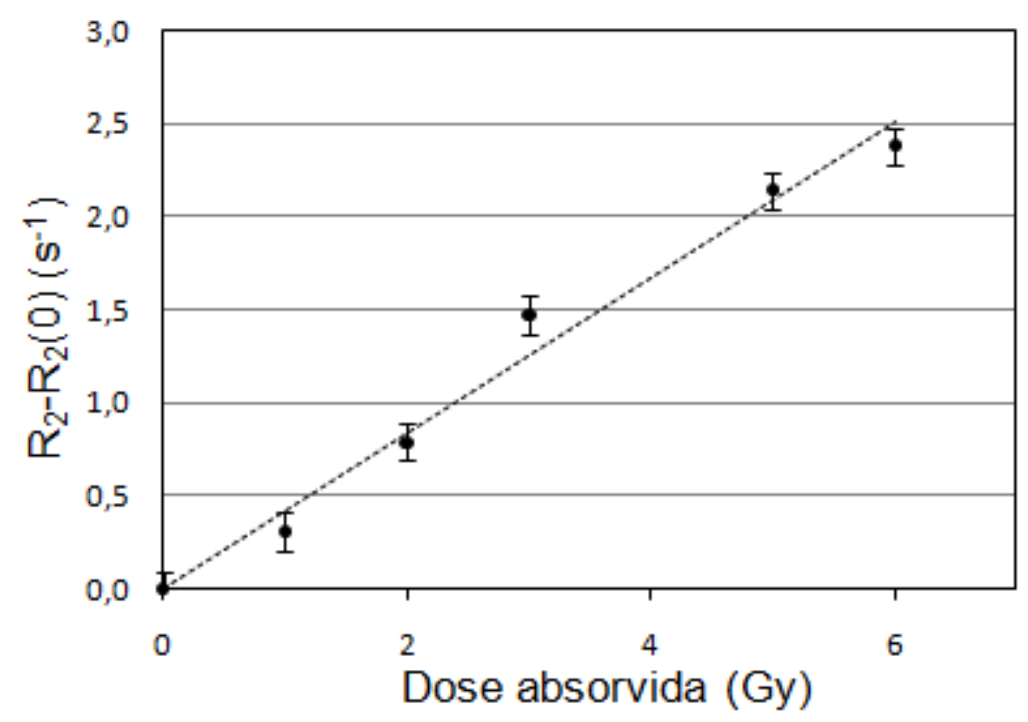

Figura 5.11 - Relação entre $R_{2}-R_{2}(0)$ e a dose absorvida para o feixe 150*. Cada ponto representa quatro amostras. As incertezas representadas no gráfico são provenientes da propagação das incertezas do ajuste monoexponencial de $T_{2}$. O coeficiente de correlação do ajuste linear é $R^{2}=0,97$.

Estes resultados mostram um comportamento linear do dosímetro para o feixe utilizado.

\section{Quarto Experimento - Dose x $\mathbf{R}_{2}$ : feixe 50*}

O quarto experimento foi realizado sob irradiação com raios $X$ produzidos pelo sistema Philips MCN 165. O feixe utilizado foi gerado por um potencial de $50 \mathrm{kV}, 20 \mathrm{~mA}$, filtrado com $4 \mathrm{mmAl}$ (feixe 50*).

Foram produzidas 20 amostras de gel polimérico. As amostras foram irradiadas 1 dia após a produção com doses absorvidas no ar de 0,5; 1; 2 e 3 Gy, com taxa de dose absorvida constante de 2,0 mGy/s ( $\pm 1,5 \%)$. Quatro amostras por dose foram irradiadas e quatro amostras foram tomadas como controle (não irradiadas). 
As amostras foram avaliadas 1 dia após a irradiação utilizando a técnica de ressonância magnética nuclear. A média dos valores de $R_{2}$ do grupo de controle $\left(R_{2}(0)\right)$ foi subtraída dos valores médios de $R_{2}$ obtidos pelas amostras. Esta diferença foi relacionada à dose absorvida aplicada às amostras, obtendose, então, uma curva de " $R_{2}-R_{2}(0)$ " versus dose absorvida. Esta curva está representada na Figura 5.12.

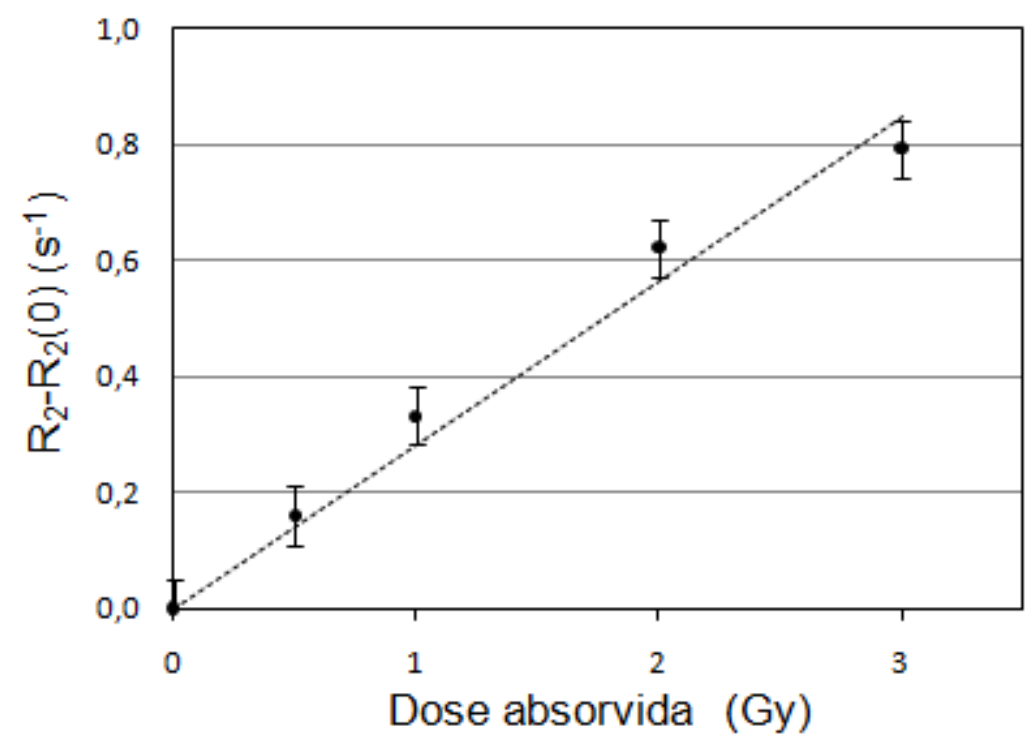

Figura 5.12 - Relação entre $R_{2}-R_{2}(0)$ e a dose absorvida para o feixe 50*. Cada ponto representa quatro amostras. As incertezas representadas no gráfico são provenientes da propagação das incertezas do ajuste monoexponencial de $T_{2}$. O coeficiente de correlação do ajuste linear é $R^{2}=0,98$.

Estes resultados mostram um comportamento linear do dosímetro para o feixe utilizado.

\section{Quinto Experimento - Dose x $\mathbf{R}_{2}$ : feixe $200^{*}$}

$O$ quinto experimento foi realizado sob irradiação com raios $X$ produzidos pelo sistema Philips MCN 323. O feixe utilizado foi gerado por um potencial de $200 \mathrm{kV}, 15 \mathrm{~mA}$, filtrado com 4,05 mmAl e 0,96 mmCu (feixe 200*).

Foram produzidas 24 amostras de gel polimérico. As amostras foram irradiadas 1 dia após a produção com doses absorvidas no ar de 1, 2, 3, 4 e 5 Gy, com taxa de dose absorvida constante de 6,3 mGy/s ( $\pm 1,5 \%)$. Quatro amostras por dose foram irradiadas e quatro amostras foram tomadas como controle (não irradiadas). 
As amostras foram avaliadas 1 dia após a irradiação utilizando a técnica de ressonância magnética nuclear. A média dos valores de $R_{2}$ do grupo de controle $\left(R_{2}(0)\right)$ foi subtraída dos valores médios de $R_{2}$ obtidos pelas amostras. Esta diferença foi relacionada à dose absorvida aplicada às amostras, obtendose, então, uma curva de " $R_{2}-R_{2}(0)$ " versus dose absorvida. Esta curva está representada na Figura 5.13.

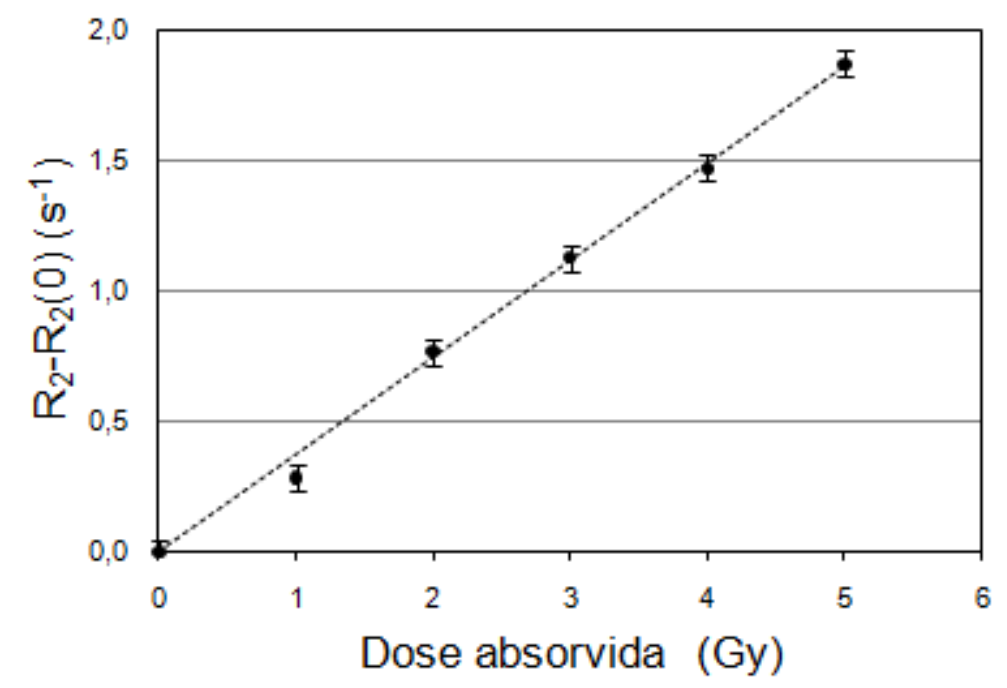

Figura 5.13 - Relação entre $R_{2}-R_{2}(0)$ e a dose absorvida para o feixe 200*. Cada ponto representa quatro amostras. As barras de erro representadas no gráfico são provenientes da propagação das incertezas do ajuste monoexponencial de $T_{2}$. O coeficiente de correlação do ajuste linear é $R^{2}=0,99$.

Estes resultados mostram um comportamento linear do dosímetro para o feixe utilizado.

Os resultados dos experimentos apresentados até aqui mostraram que o gel polimérico utilizado neste trabalho possui uma resposta linear para os diversos feixes de raios $X$ testados, no intervalo de doses considerado.

\section{Sexto Experimento - Taxa de Dose $x \mathbf{R}_{2}$ : feixe $320^{*}$}

O sexto experimento foi realizado sob irradiação com raios $X$ produzidos pelo sistema Philips MCN 323, com $320 \mathrm{kV}$, filtrado com 4,05 mmAl e $0,21 \mathrm{mmCu}$ (feixe $320^{*}$ ). Foram preparadas 12 amostras de gel polimérico. As amostras foram irradiadas 1 dia após a produção. A corrente aplicada ao tudo de raios $\mathrm{X}$ foi variada, permitindo, então, a variação da taxa de dose absorvida. 
Todas as amostras foram irradiadas com 2,0 Gy $( \pm 6 \%)$ e os valores de corrente utilizados foram 2, 4, 6, 8, 10 e 13,1 mA, correspondendo a 3,1; 6,2; 9,3; 12,$4 ; 15,5 ; 20,3 \mathrm{mGy} / \mathrm{s}( \pm 1.5 \%$ ). Duas amostras por taxa de dose absorvida foram utilizadas.

As amostras foram avaliadas 1 dia após a irradiação utilizando a técnica de ressonância magnética nuclear. Os valores médios de $\mathrm{R}_{2}$ obtidos pelas amostras foram relacionados à taxa de dose absorvida aplicada às amostras, obtendo-se, então, uma curva de " $\mathrm{R}_{2}$ " versus taxa de dose absorvida. Esta curva está representada na Figura 5.14.

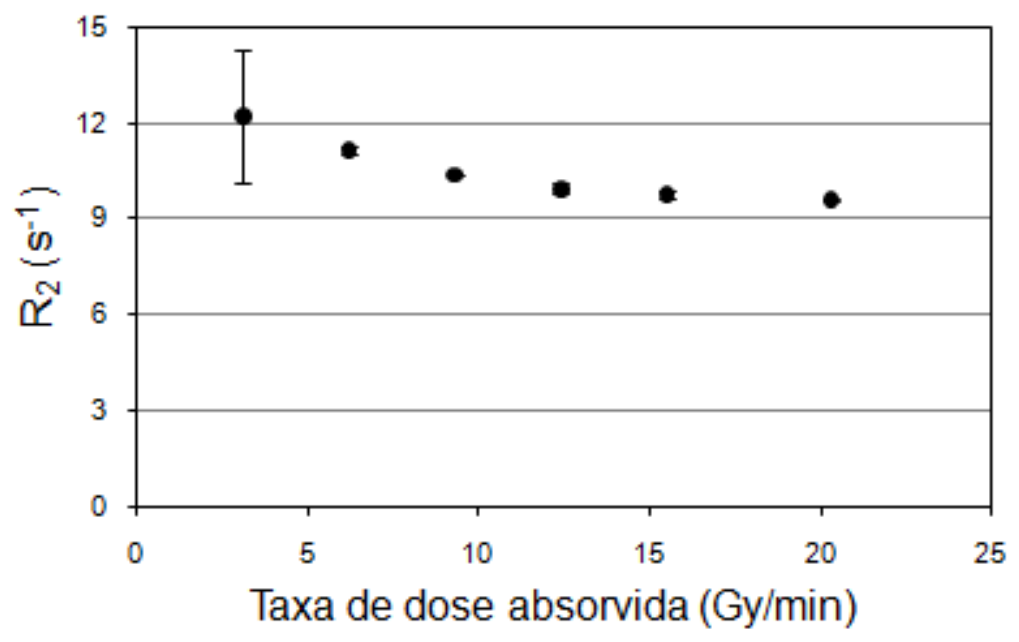

Figura 5.14 - Relação entre $R_{2}$ e a taxa de dose absorvida. Cada ponto representa duas amostras. As barras de erro representadas no gráfico são provenientes da propagação das incertezas do ajuste monoexponencial de $\mathrm{T}_{2}$.

Os resultados apresentados na Figura 5.14 indicam que o dosímetro de gel polimérico utilizado apresenta uma resposta quase independente da taxa de dose para feixes de raios $X$. No entanto, a discrepância do valor absoluto e da incerteza do primeiro ponto (representando a taxa de dose absorvida de 3,1 $\mathrm{mGy} / \mathrm{s}$ ) sugere uma análise mais apurada destes dados. Portanto, foi feita uma análise estatística tomando cada amostra de gel polimérico como um elemento da população estudada, contrariamente dos pontos apresentados na Figura 5.14, em que cada ponto representa uma média entre as duas amostras de gel polimérico para taxa de dose absorvida correspondente. Como o comportamento esperado do gel polimérico é que a resposta não varie com a variação da taxa de dose, supostamente os valores de $\mathrm{R}_{2}$ obtidos para esta população de amostras de gel 
polimérico deveriam seguir uma distribuição normal, e portanto um histograma foi construído (Figura 5.15).

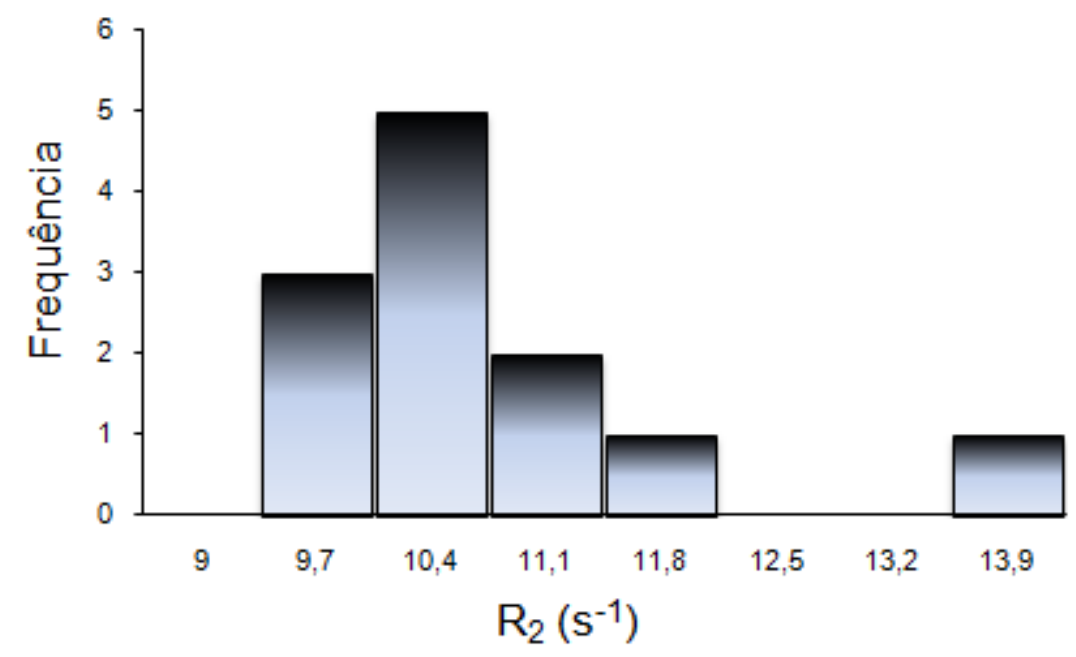

Figura 5.15 - Histograma de distribuição dos valores de $\mathrm{R}_{2}$ obtidos de cada amostra individual de gel polimético, totalizando 12 elementos na população.

Analisando a Figura 5.15, é possível concluir que há apenas uma amostra de gel polimérico claramente discrepante. Isso pode ser uma consequência de uma possível contaminação da amostra de gel polimérico com oxigênio atmosférico, devido a uma provável falha no fechamento da tampa desta amostra.

A média aritmética dos valores de $R_{2}$ desta população formada por 12 amostras de gel polimérico é $(10,51 \pm 1,15) \mathrm{s}^{-1}$. Excluindo o ponto discrepante, esta média fica $(10,21 \pm 0,58) \mathrm{s}^{-1}$, resultando em uma diminuição de $50 \%$ no desvio padrão da média.

\section{Sétimo Experimento - Dose $x \mathbf{R}_{2}$ e Taxa de dose $x \mathbf{R}_{2}$ : raios gama}

O sétimo experimento consistiu na avaliação do comportamento dosimétrico do gel polimérico sob irradiação com raios gama utilizando os irradiadores Gamma Cell 220 I e II. Foram preparadas 24 amostras de gel polimérico. Quatro amostras de gel polimérico foram tomadas como controle (não irradiadas). As amostras restantes foram divididas em quatro grupos, correspondentes às diferentes taxas de dose apresentadas na Tabela 4.1. Os grupos foram designados por I, If, II e Ilf, correspondendo à irradiação com: 
Gamma Cell I, Gamma Cell I com filtro, Gamma Cell II e Gamma Cell II com filtro, respectivamente.

As amostras foram irradiadas 2 dias após a produção, sob condições de equilíbrio eletrônico. As doses absorvidas utilizadas foram 8, 16, 24, 32 e 40 Gy para as amostras I, II e IIf. Apenas as amostras If foram irradiadas com 8,9; 17; 26,7; 35,7 e 44,7 Gy, devido a um erro inicial de cálculo. Uma amostra por dose foi utilizada.

As amostras foram avaliadas 1 dia após a irradiação utilizando a técnica de ressonância magnética nuclear. A média dos valores de $R_{2}$ do grupo de controle $\left(R_{2}(0)\right)$ foi subtraída dos valores de $R_{2}$ obtidos pelas amostras. Esta diferença foi relacionada à dose absorvida aplicada às amostras, obtendo-se, então, uma curva de " $R_{2}-R_{2}(0)$ " versus dose absorvida para cada grupo (I, If, II e IIf).

Os dados de cada grupo foram ajustados a uma função linear e os coeficientes lineares dos grupos foram analisados em um gráfico que os relaciona com a taxa de dose.

As curvas de "R $R_{2}-R_{2}(0)$ " versus dose absorvida para os grupos I, If, II e IIf estão representadas na Figura 5.16. 


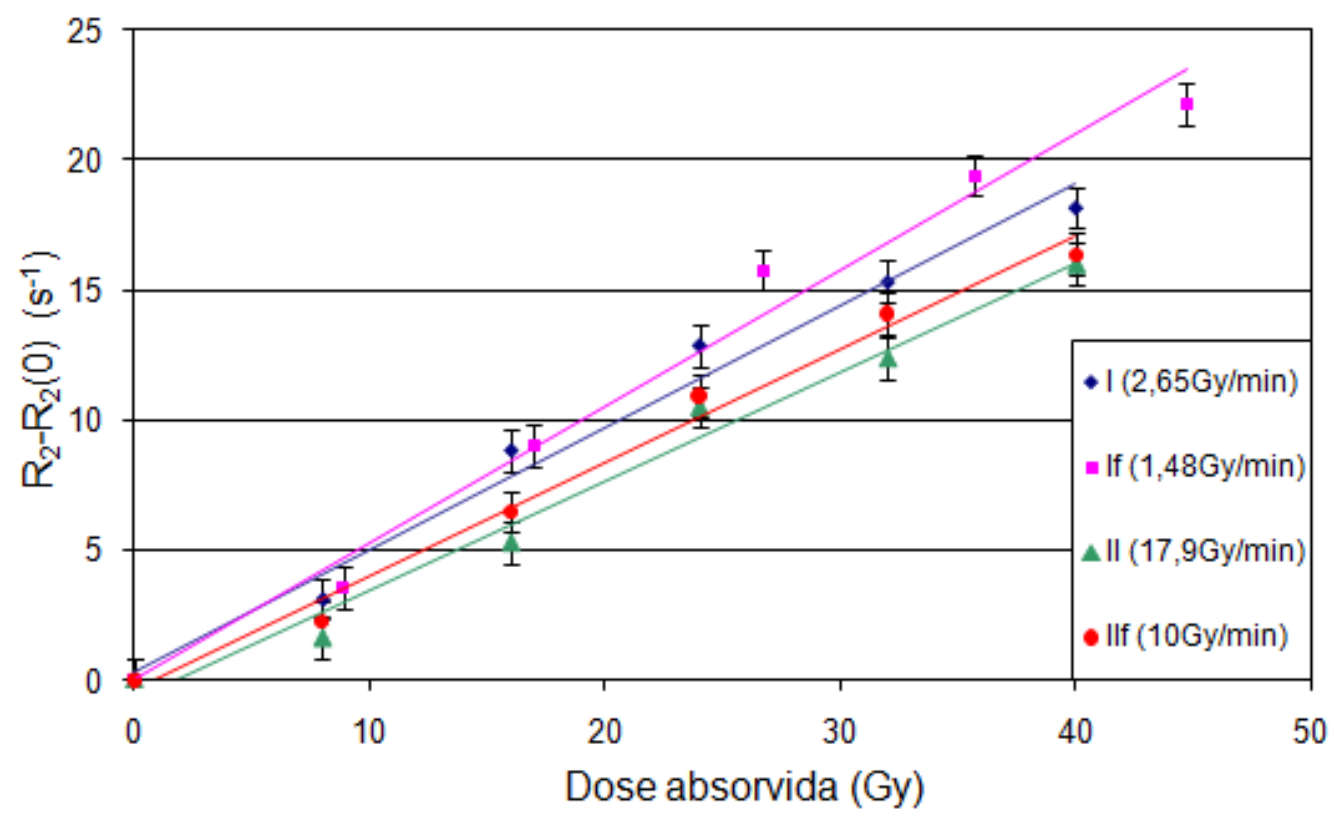

Figura 5.16 - Relações entre $R_{2}-R_{2}(0)$ e a dose absorvida para as diversas taxas de dose e os respectivos ajustes lineares. Cada ponto representa uma amostra.

Os coeficientes angulares obtidos dos ajustes lineares foram relacionados com as taxas de dose e estão apresentados na Figura 5.17.

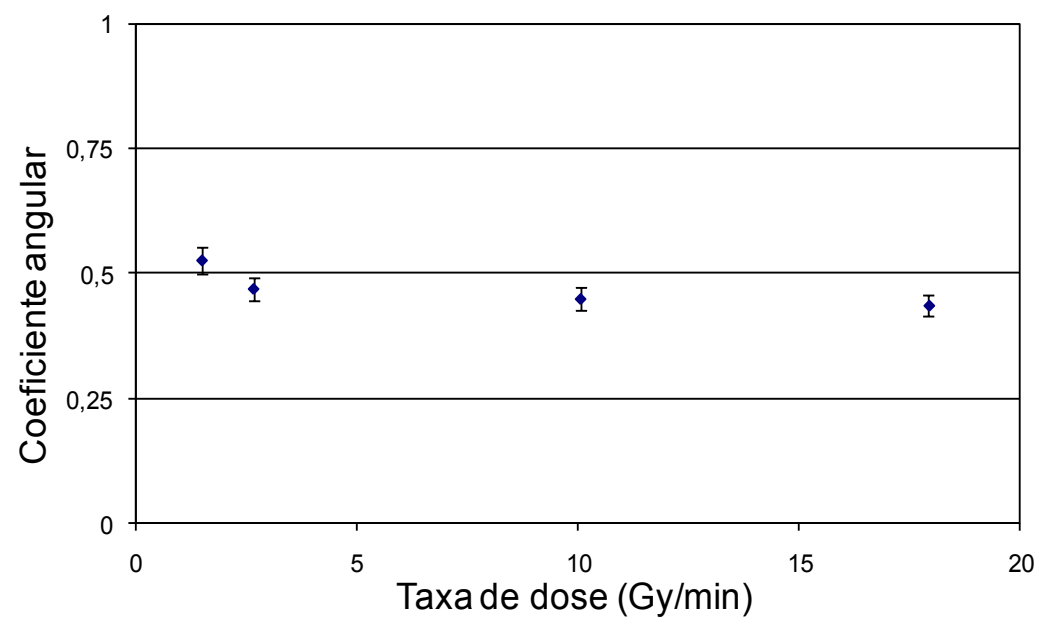

Figura 5.17 - Relação entre os coeficientes angulares das curvas representadas na Figura 5.16 e a taxa de dose absorvida.

O resultado apresentado na Figura 5.17 indica que o dosímetro de gel polimérico utilizado é independende das taxas de dose consideradas neste 
experimento. Porém, devido às oscilações nos valores dos coeficientes angulares, o experimento foi repetido utilizando um número maior de amostras.

\section{Oitavo Experimento - Dose x $\mathbf{R}_{2}$ e Taxa de dose $\times \mathbf{R}_{2}$ : raios gama}

O oitavo experimento consistiu na repetição do sétimo experimento, porém utilizando quatro amostras por dose. Foram preparadas 72 amostras de gel polimérico. Quatro amostras de gel polimérico foram tomadas como controle (não irradiadas). As amostras restantes foram divididas em quatro grupos, correspondentes às diferentes taxas de dose apresentadas na Tabela 5.2. Os grupos foram designados por I, If, II e IIf, como anteriormente. As amostras foram irradiadas 1 dia após a produção, sob condições de equilíbrio eletrônico, com as doses apresentadas na Tabela 5.2.

Tabela 5.2 - Taxas de dose absorvida na água (fornecidas pelo Laboratório Padrão Secundário de Dosimetria do Centro Helmholtz de Munique) e doses absorvidas utilizadas no oitavo experimento.

\begin{tabular}{|c|c|c|}
\hline Irradiador & $\begin{array}{c}\text { Taxa de dose } \\
\text { absorvida } \\
\text { em abril/2011 } \\
(\text { Gy/min })\end{array}$ & $\begin{array}{c}\text { Dose } \\
\text { absorvida } \\
(\text { Gy })\end{array}$ \\
\hline Gamma Cell 220 I & 2,5 & $5 ; 10 ; 15 ; 20$ \\
\hline $\begin{array}{c}\text { Gamma Cell 220 I } \\
\text { com filtro }\end{array}$ & 1,4 & $5 ; 10 ; 15 ; 20$ \\
\hline Gamma Cell 220 II & 15,0 & $15 ; 20 ; 30 ; 40$ \\
\hline $\begin{array}{c}\text { Gamma Cell 220 II } \\
\text { com filtro }\end{array}$ & 8,4 & $10 ; 15 ; 20 ; 30 ; 40$ \\
\hline
\end{tabular}

As amostras foram avaliadas 1 dia após a irradiação utilizando a técnica de ressonância magnética nuclear. A média dos valores de $R_{2}$ do grupo de controle, $R_{2}(0)$, foi subtraída dos valores médios de $R_{2}$ obtidos pelas amostras. Esta diferença foi relacionada à dose absorvida aplicada às amostras, obtendose, então, uma curva de " $R_{2}-R_{2}(0)$ " versus dose absorvida para cada grupo (I, If, II e IIf). Estas curvas estão representadas na Figura 5.18. 
Os dados de cada grupo foram ajustados a uma função linear e os coeficientes angulares dos grupos foram analisados em um gráfico que os relaciona com a taxa de dose.

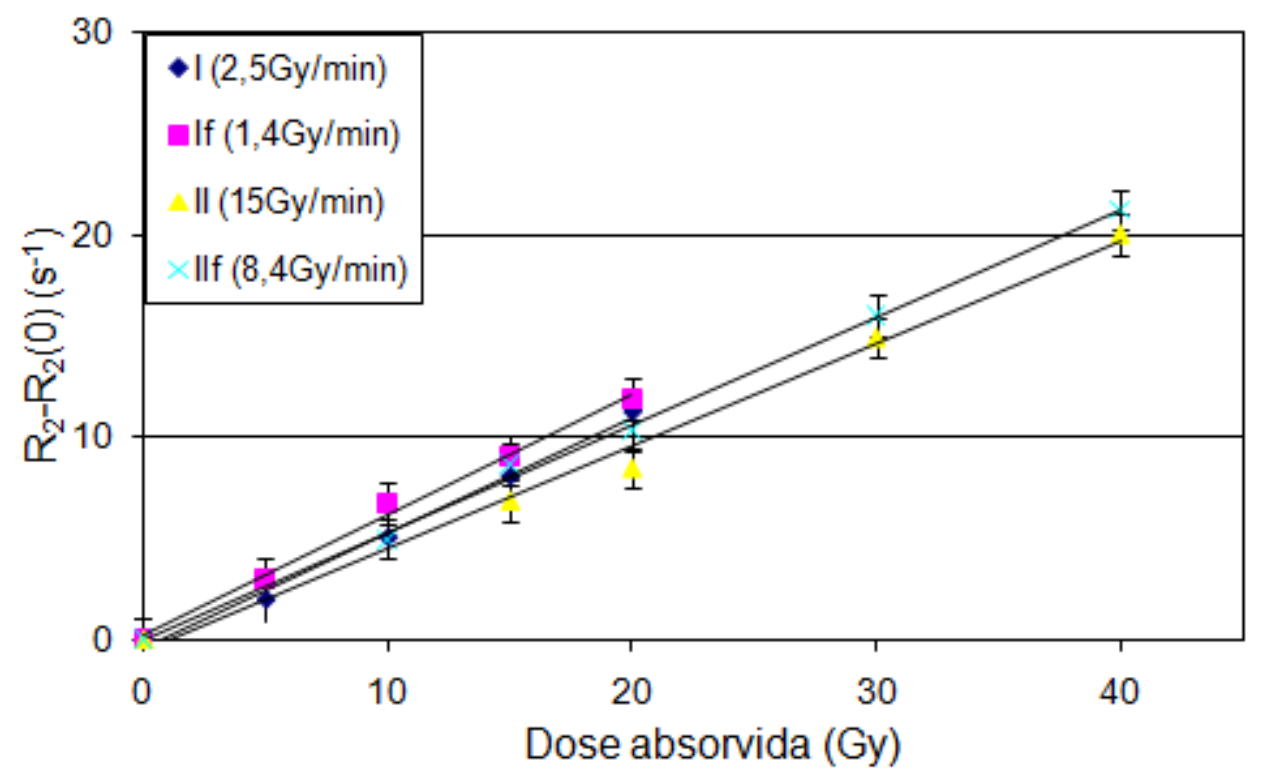

Figura 5.18 - Relações entre $R_{2}-R_{2}(0)$ e a dose absorvida para as diversas taxas de dose e os respectivos ajustes lineares. Cada ponto representa quatro amostras.

Neste caso os coeficientes angulares obtidos dos ajustes lineares também foram relacionados com as taxas de dose e estão apresentados na Figura 5.19.

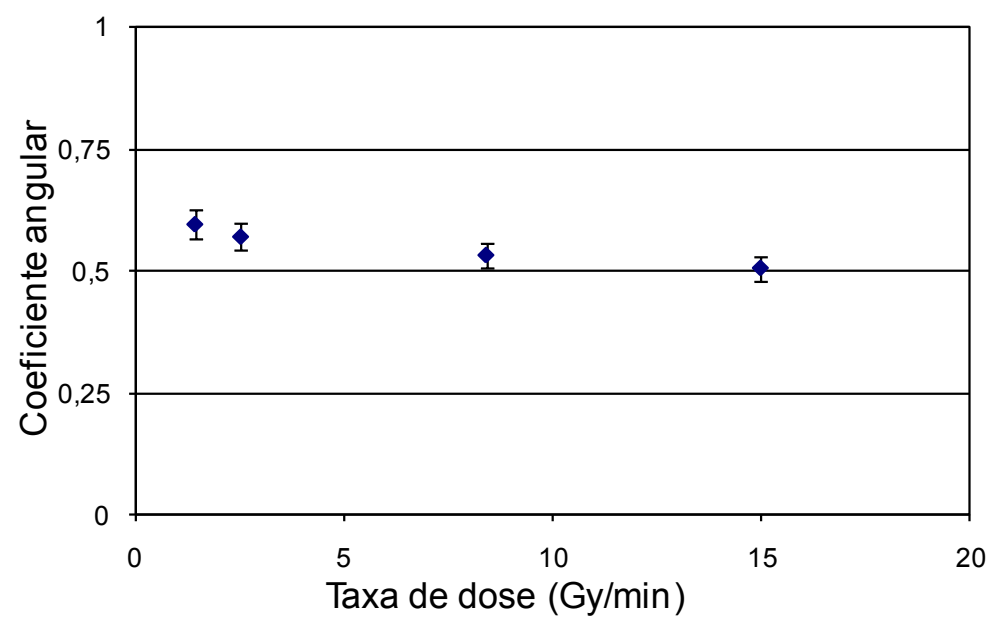

Figura 5.19 - Relação entre os coeficientes angulares das curvas representadas na Figura 5.18 e a taxa de dose absorvida. 
O resultado apresentado na Figura 5.19 mostra que o dosímetro de gel polimérico utilizado é independende das taxas de dose consideradas neste experimento.

Os resultados apresentados até aqui mostram que o gel polimérico possui um comportamento dosimétrico satisfatório para os feixes testados. As curvas de dose-resposta do dosímetro de gel polimérico para diversos feixes de raios $X$ (no intervalo de doses de 0 a $10 \mathrm{~Gy}$ ) e para raios gama (no intervalo de doses de 0 a 40 Gy) apresentaram comportamentos lineares. $O$ gel polimérico utilizado também mostrou comportamento dosimétrico independente da taxa de dose aplicada. 


\subsection{Cálculo do Alcance de Elétrons}

Como mencionado anteriormente, o principal conceito do efeito de aumento de dose em tecido mole adjacente a materiais de número atômico alto é derivado do aumento radical da seção de choque para interação fotoelétrica nesses materiais de número atômico alto, como ouro.

Para estimar o alcance dos fotoelétrons de diversas energias em tecido mole (ou gel polimérico), foi calculado o alcance de elétrons por meio da "aproximação de freamento contínuo" ou CSDA (continuous slowing down approximation), que é uma aproximação do livre caminho médio. Este processo consiste na perda gradativa da energia cinética conforme o elétron interage com os átomos do material atravessado (Turner, 2007).

Este cálculo foi realizado utilizando a base de dados ESTAR do NIST (National Institute of Standards and Technology, 1998). A tabela do alcance em água por aproximação de freamento contínuo para elétrons com energias entre 10 e $350 \mathrm{keV}$ foi utilizada como estimativa do comportamento em gel polimérico, uma vez que o valor de densidade do gel polimérico $\left(1,07 \mathrm{~g} / \mathrm{cm}^{3}\right)$ é muito próximo ao da água $\left(1 \mathrm{~g} / \mathrm{cm}^{3}\right)$. Essa grandeza fornecida pela base de dados ESTAR possui uma relação mássica; portanto, os valores foram multiplicados pela densidade para a obtenção do alcance em unidade de distância percorrida no meio.

O mesmo procedimento foi realizado com o ouro, pois, para energias baixas, a dimensão das partículas de ouro possui a mesma ordem de grandeza do alcance dos elétrons, influenciando na medição real da absorção da energia depositada por estes elétrons, como será discutido no item 5.8.1.

Os valores de alcance dos elétrons para água e ouro estão representados na Figura 5.20. 


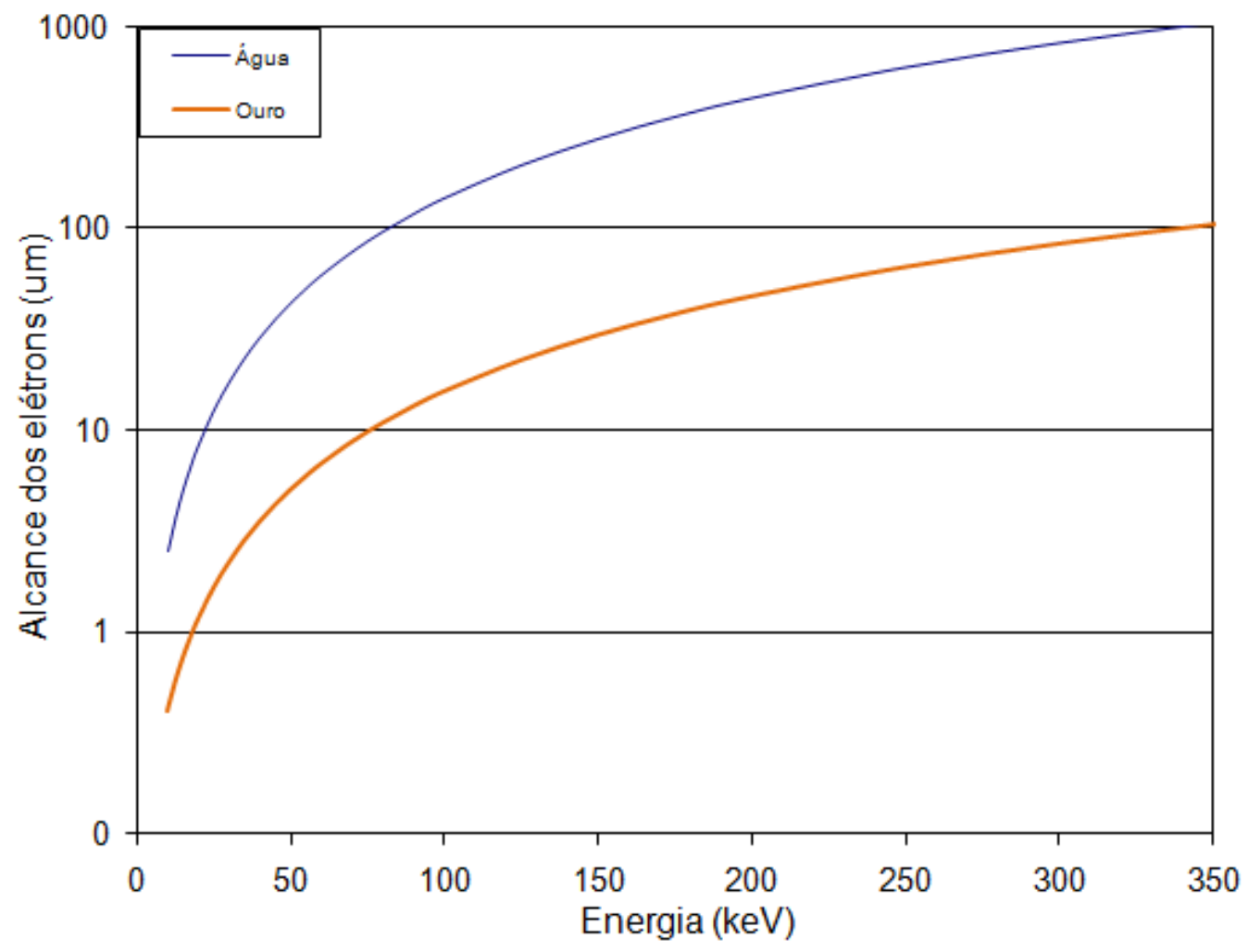

Figura 5.20 - Relação entre o alcance dos elétrons e a energia da radiação incidente, baseado nos dados do ESTAR do NIST (1998).

A Figura 5.20 mostra que os elétrons de uma mesma energia são capazes de percorrer uma distância quase 10 vezes maior em água que em ouro. Portanto, supondo que o gel polimérico se comporte de maneira semelhante à água, os elétrons emitidos de partículas de ouro em contato com o gel polimérico deveriam ser capazes de ionizar o gel polimérico, causando deposição de energia.

As suposições decorrentes destes cálculos levaram aos testes preliminares utilizando folhas de ouro. 


\subsection{Experimentos Preliminares com Folhas de Ouro}

Baseando-se nos cálculos realizados no item 5.2, este primeiro experimento teve como objetivo medir o aumento da dose absorvida causado pela presença de folhas de ouro dentro do gel polimérico, supondo que os elétrons seriam capazes de atravessar as folhas de ouro, ionizando o gel polimérico.

\section{Primeiro Experimento - GP misturado com folhas de ouro}

Dois lotes de gel polimérico foram produzidos: A e B. O lote A foi composto por 28 frascos tipo Eppendorf $(1,5 \mathrm{ml})$ cheios de gel polimérico, dos quais 16 foram parcialmente preenchidos com folhas de ouro de aproximadamente $100 \mathrm{~nm}$ de espessura.

As amostras foram irradiadas 1 dia após a produção em feixes de raios $X$ da qualidade N-200 (ISO 4037) utilizando o sistema Philips MCN 323, com doses absorvidas de 2, 4 e 6 Gy. Para cada valor de dose absorvida foram consideradas 3 amostras sem ouro e 4 amostras com ouro. Sete amostras foram utilizadas como controle (3 sem ouro e 4 com ouro).

O lote B consistiu em 12 frascos tipo Eppendorf $(1,5 \mathrm{ml})$, dos quais 6 continham ouro. As amostras foram irradiadas 1 dia após a produção com o mesmo feixe utilizado para irradiar o lote $A$. As doses absorvidas do lote $B$ foram: 2 e 4 Gy. Para cada dose foram consideradas 2 amostras com ouro e 2 amostras sem ouro. Quatro amostras foram tomadas como controle (2 com ouro e 2 sem ouro).

A avaliação dos dois grupos, A e B, foi realizada 1 dia após a irradiação, utilizando a técnica de ressonância magnética nuclear. A média dos valores de $R_{2}$ do grupo de controle $\left(R_{2}(0)\right)$ foi subtraída dos valores médios de $R_{2}$ obtidos pelas amostras. Esta diferença foi relacionada à dose absorvida aplicada às amostras, obtendo-se, então, um gráfico de "dose absorvida" versus " $\mathrm{R}_{2}$ $\mathrm{R}_{2}(0)$ " para lote $A$ e outro para o lote $B$. Estes resultados estão representados nas Figuras 5.21 para o lote A e 5.22 para o lote B. 


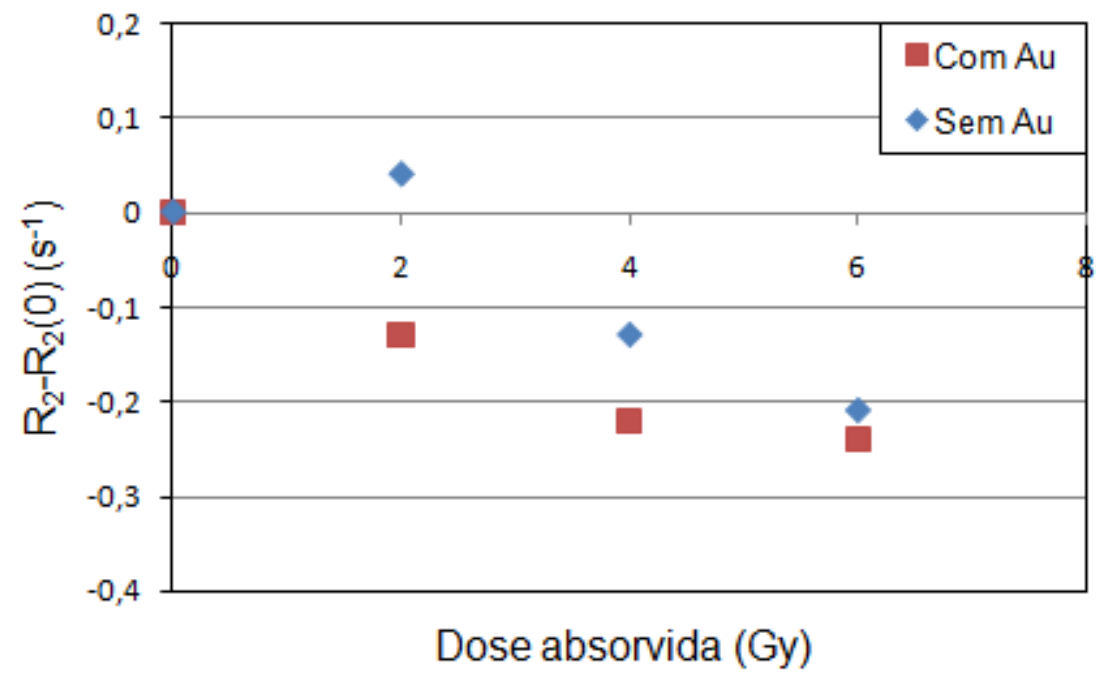

Figura 5.21 - Relação entre $R_{2}-R_{2}(0)$ e a dose absorvida para o lote $A$.

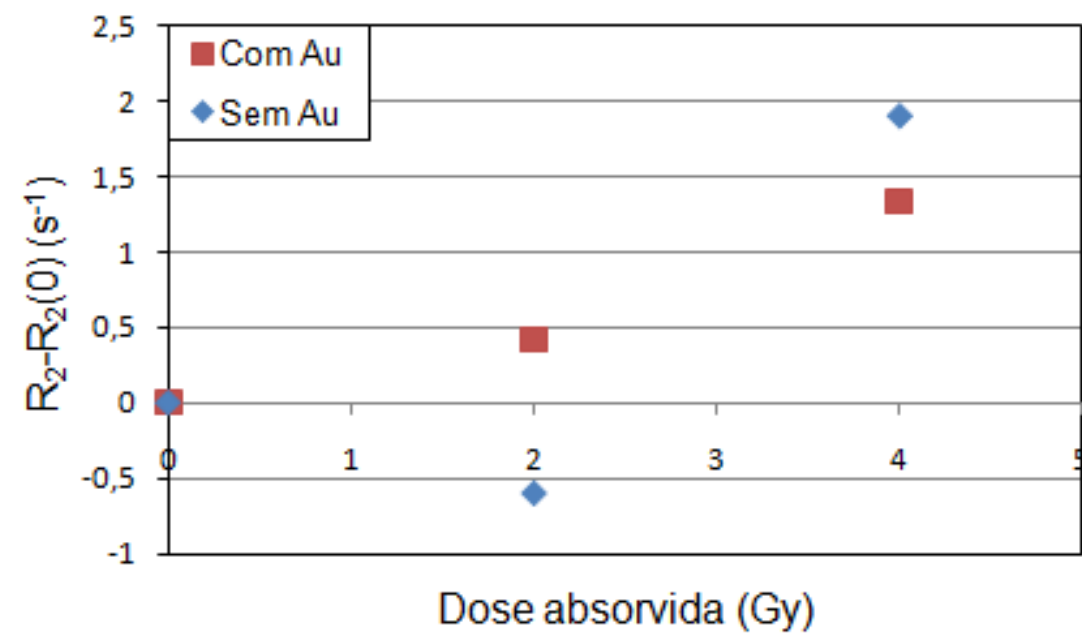

Figura 5.22 - Relação entre $R_{2}-R_{2}(0)$ e a dose absorvida para o lote $B$.

Os resultados apresentados nas Figuras 5.21 e 5.22 não apresentam uma relação clara entre $R_{2}-R_{2}(0)$ e a dose absorvida nem mesmo para as amostras sem ouro. Como verificado nos resultados apresentados na seção 5.1, o gel polimérico utilizado neste trabalho apresenta uma relação linear de aumento da taxa de relaxamento transversal em função da dose absorvida, conferindo, portanto, a capacidade dosimétrica do gel polimérico utilizado. Com isso, foi necessário procurar o motivo pelo qual o experimento não apresentou um comportamento adequado. 
Alguns estudos mencionam que 0 material do frasco onde o gel polimérico está contido pode afetar a sensibilidade do dosímetro devido à permeabilidade ao oxigênio através das paredes dos frascos. Por este motivo, é recomendado o uso de materiais com baixa permeabilidade ao oxigênio, como o plástico Barex ${ }^{\circledR}$ e vidros. Portanto, supõe-se neste caso que o oxigênio tenha permeado através das paredes do frasco e, por isso, o processo de polimerização teria sido inibido, uma vez que oxigênio captura radicais livres (Item 3.3.2).

No caso dos frascos com ouro, também é possível que a própria folha de ouro tenha microbolhas de ar acumuladas na superfície. Outra preocupação é que as folhas de ouro causam artefatos nas imagens de ressonância magnética nuclear, diminuindo a intensidade do sinal na vizinhança destas folhas. Isso ocorre, pois o ouro submetido a campos magnéticos altos modifica localmente a susceptibilidade magnética.

\section{Segundo Experimento - GP coberto com folhas de ouro}

O segundo experimento realizado nesta fase teve como objetivo medir o aumento da dose absorvida causado pela presença de folhas de ouro adjacentes ao gel polimérico, supondo que os elétrons seriam capazes de atravessar as folhas de ouro, alcançando o gel polimérico, como previsto pelos cálculos realizados no item 5.2. Neste experimento foram produzidas 12 amostras de gel polimérico em recipientes de vidro (com $50 \mathrm{ml}$ e $5 \mathrm{~cm}$ de diâmetro). Os recipientes foram preenchidos com gel polimérico, cobertos com filme de PVC (com $14 \pm 2 \mu \mathrm{m}$ de espessura) e posicionados de "ponta-cabeça" na solução capturadora de oxigênio, para prevenir a permeação do oxigênio para dentro do gel através do filme de PVC. Antes da irradiação, metade da superfície de cada amostra foi coberta com uma folha de ouro com $100 \mathrm{~nm}$ de espessura (Figura $5.23)$. 

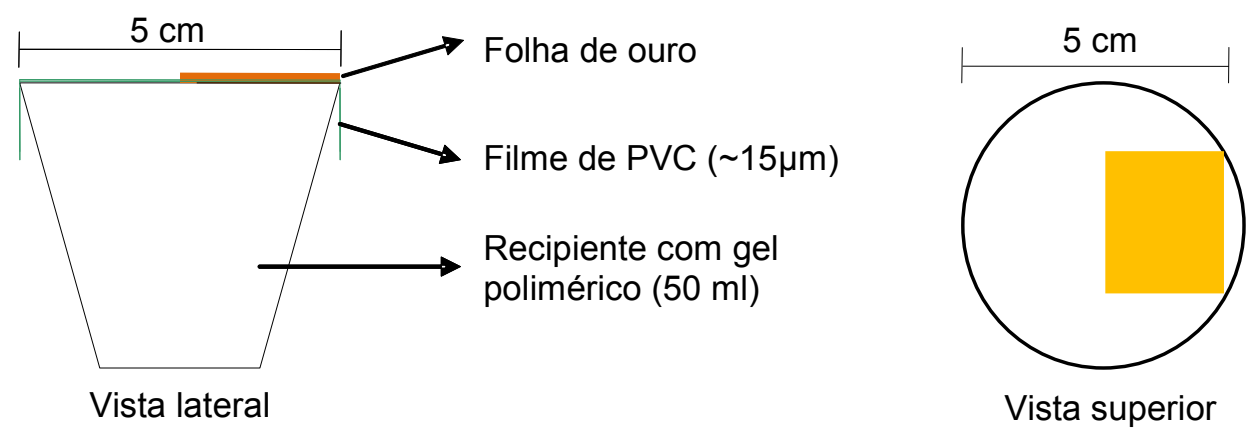

Figura 5.23 - Representação da amostra utilizada neste experimento.

As amostras foram irradiadas 1 dia após a produção em feixes de raios $X$ da qualidade N-200 (ISO 4037) utilizando o sistema Philips MCN 323, com doses absorvidas de 1, 2, 3, 4 e 5 Gy; duas amostras por dose foram utilizadas e duas amostras foram tomadas como controle. As amostras foram posicionadas com a superfície coberta com PVC e ouro perpendicular ao feixe de raios $\mathrm{X}$.

Após a irradiação, as folhas de ouro foram retiradas da superfície das amostras e estas foram avaliadas com a técnica de ressonância magnética nuclear no dia seguinte. Dois valores de $\mathrm{R}_{2}$ foram obtidos para cada amostra: um valor sob a área previamente coberta com ouro e outro valor sob a área livre. $\mathrm{A}$ média dos valores de $R_{2}$ do grupo de controle $\left(R_{2}(0)\right)$ foi subtraída dos valores médios de $R_{2}$ com ouro e sem ouro obtidos pelas amostras. Esta diferença foi relacionada à dose absorvida aplicada às amostras, obtendo-se, então, uma curva de " $R_{2}-R_{2}(0)$ " versus dose absorvida com ouro e outro sem ouro. Estas curvas estão representadas na Figura 5.24. 


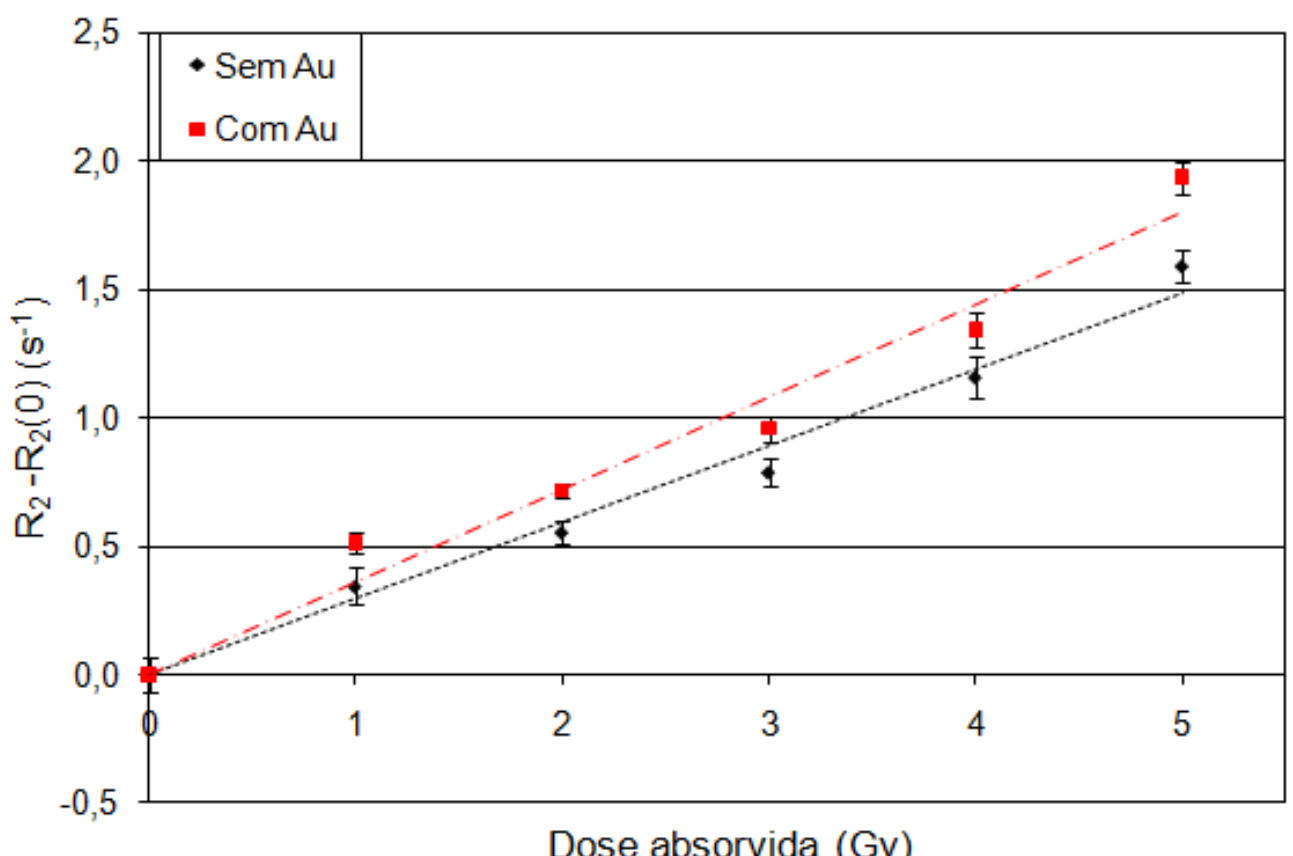

Figura 5.24 - Relações entre $R_{2}-R_{2}(0)$ e a dose absorvida com ouro e sem ouro.

Os resultados apresentados na Figura 5.24 permitem observar que as taxas de relaxamento medidas sob a área coberta com folhas de ouro durante a irradiação são maiores que as taxas medidas sob a área livre de ouro. $O$ coeficiente angular do ajuste linear das medições sob a área com ouro é maior que o coeficiente angular do ajuste linear das medições da área sem ouro. Isto indica que a presença das folhas de ouro sobre a superfície das amostras de gel polimérico causaram um aumento da dose absorvida na vizinhança destas folhas em até $20 \%$. No entanto, este resultando ainda não pôde ser considerado definitivo, pois havia dificuldade em trabalhar com as folhas de ouro que, por serem muito finas $(\sim 100 \mathrm{~nm})$, ocorreram pequenos rasgos, de modo que pequenas áreas não foram perfeitamente cobertas com ouro.

\section{Terceiro Experimento - GP coberto com folhas de ouro}

O terceiro experimento realizado nesta fase consistiu em uma repetição do experimento anterior, porém utilizando uma folha de ouro com $0,1 \mathrm{~mm}$ de espessura para evitar rasgos na folha de ouro, garantindo uma cobertura perfeita da amostra com ouro. 
As curvas de " $R_{2}-R_{2}(0)$ " versus dose absorvida com ouro e outro sem ouro estão representadas na Figura 5.25.

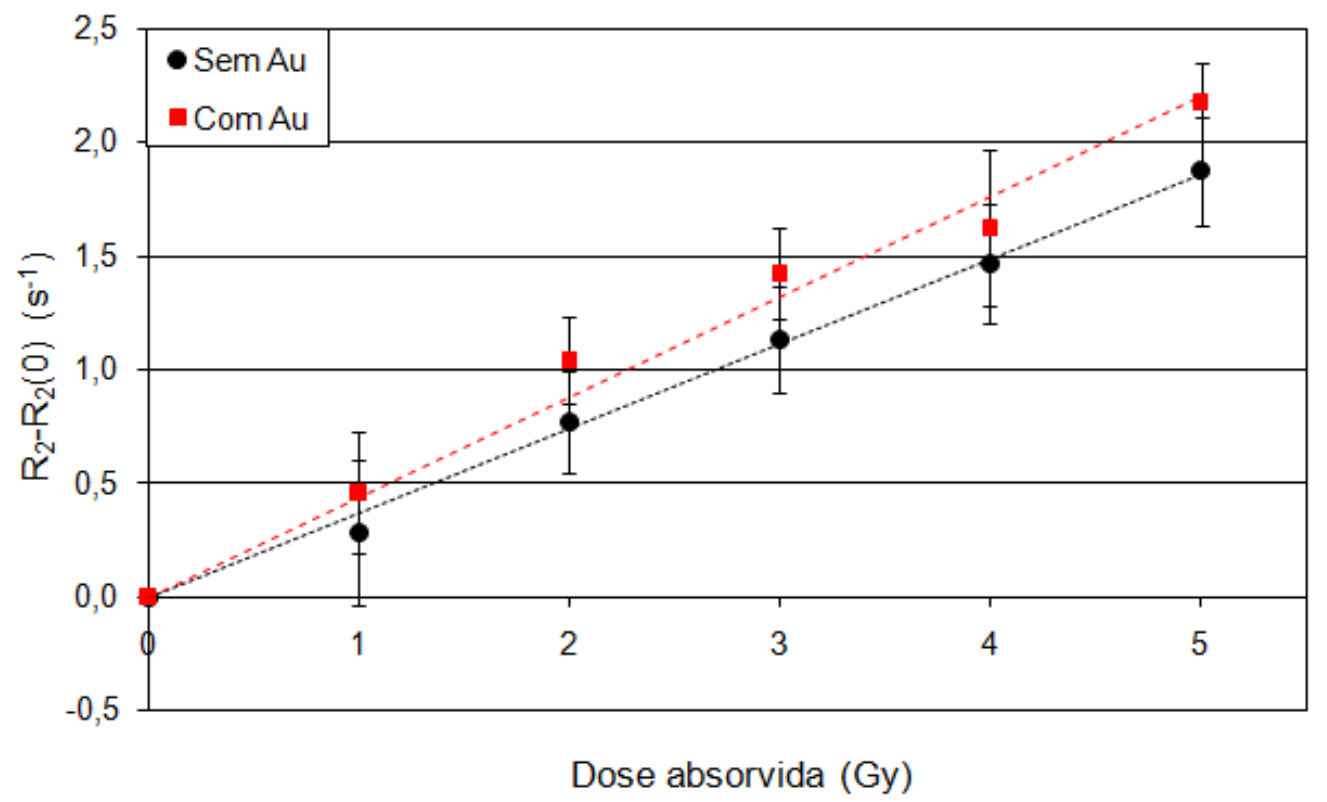

Figura 5.25 - Relações entre $R_{2}-R_{2}(0)$ e a dose absorvida com ouro e sem ouro.

Os resultados apresentados na Figura 5.25 também mostram que as taxas de relaxamento medidas sob a área coberta com folhas de ouro durante a irradiação são maiores que as taxas medidas sob a área livre de ouro. $O$ coeficiente angular do ajuste linear das medições sob a área com ouro é $~ 18 \%$ maior que o coeficiente angular do ajuste linear das medições da área sem ouro. Isto indica que a presença das folhas de ouro sobre a superfície das amostras de gel polimérico causaram um aumento da dose absorvida na vizinhança destas folhas.

As barras de incerteza possivelmente são provenientes de contaminação da superfície com oxigênio atmosférico durante a irradiação. Este experimento ainda não alcança completamente o objetivo principal deste trabalho, portanto as seções seguintes foram necessárias para uma melhor compreensão do fenômeno estudado, pois este depende de outros fatores, como a energia do fóton incidente e a dimensão das partículas de ouro. 


\subsection{Feixes de Raios X que aumentam o Efeito Fotoelétrico}

Conforme discutido anteriormente, a seção de choque para efeito fotoelétrico, isto é, a probabilidade de sua ocorrência, decresce com o aumento da energia do fóton, havendo, no entanto, um aumento abrupto para energias imediatamente maiores que a energia de ligação das camadas eletrônicas dos átomos do material.

Em princípio, a otimização da ocorrência do efeito fotoelétrico poderia ser alcançada irradiando o material de alto número atômico com feixes monenergéticos de energia infinitesimalmente maior que a energia de ligação dos elétrons do átomo. No entanto, em situações reais, os feixes de radiação são compostos por um espectro de energias. Então, a maneira mais eficiente de aumentar a probabilidade de ocorrência do efeito fotoelétrico é buscar espectros de energias que possuam maior intensidade na região da energia de ligação dos elétrons do átomo.

Para este fim, diversos espectros foram simulados utilizando o software SpekCalc (Poludniowski et al, 2009), variando-se o potencial aplicado ao tubo de raios $\mathrm{X}$ e a filtração adicional.

Inicialmente, diversos espectros sugeridos pela norma ISO 4037 (1994) (narrow series) foram simulados. Estes espectros estão representados nas Figuras $5.26,5.27,5.28,5.29,5.30,5.31,5.32$. O espectro $\mathrm{N}-250$ não foi simulado porque o programa SpekCalc não permite inserir filtros de chumbo, necessários para a produção do feixe $\mathrm{N}-250$. 


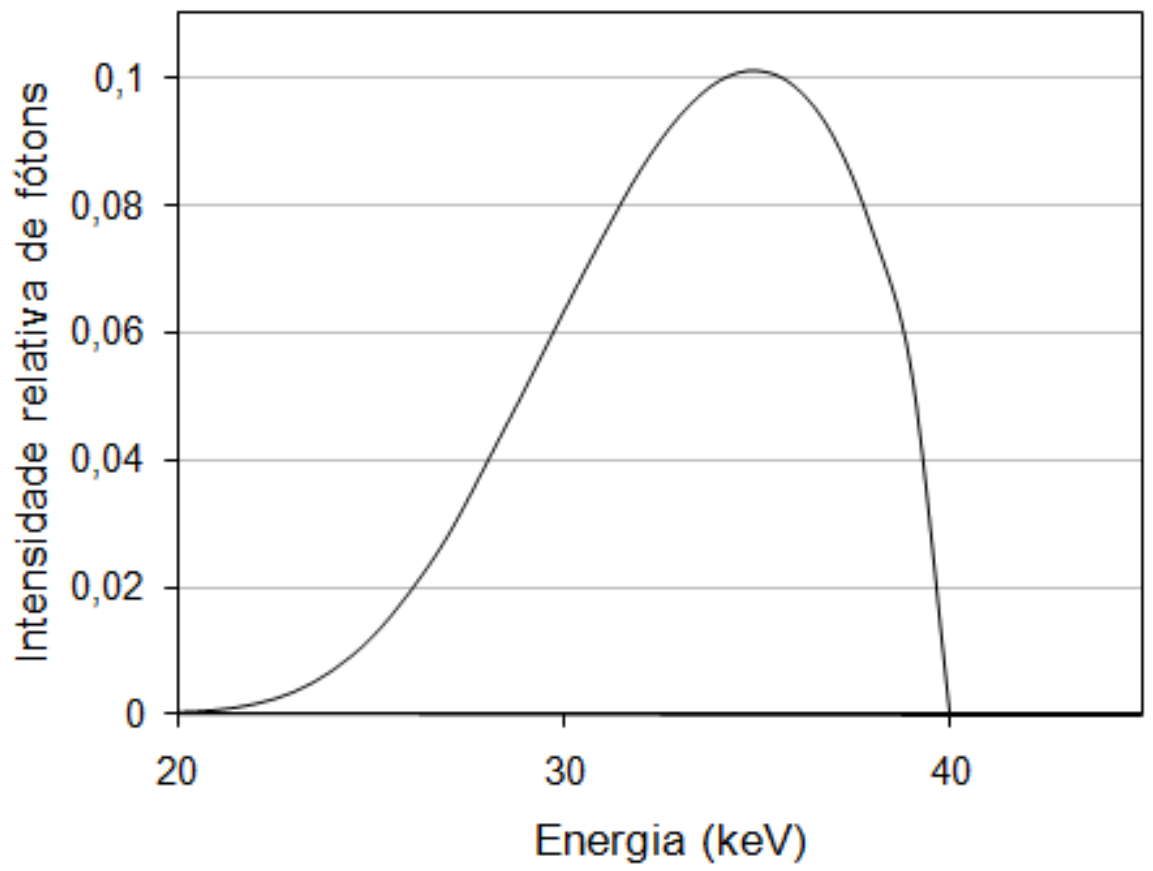

Figura 5.26 - Espectro do feixe N-40 da norma ISO 4037 (1994).

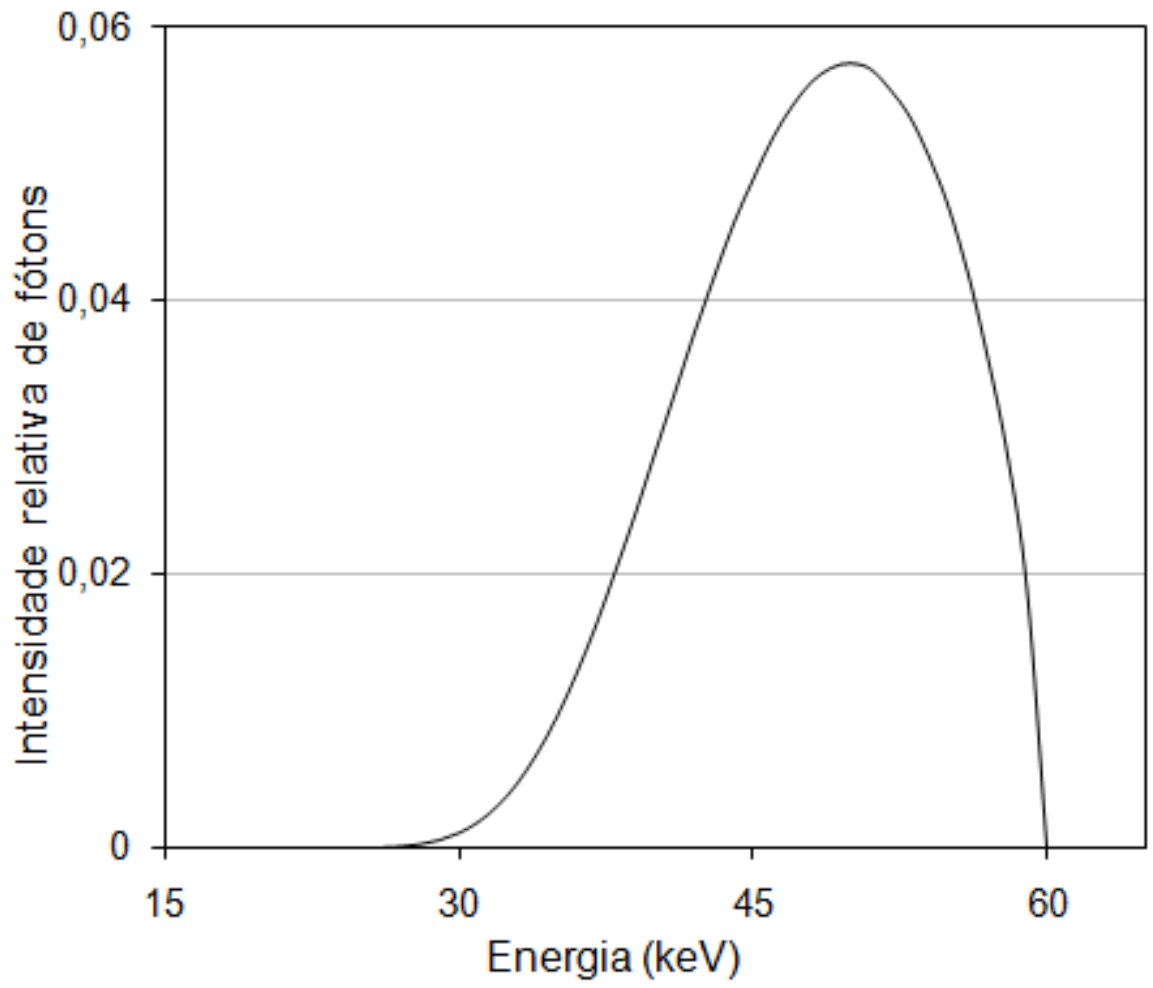

Figura 5.27 - Espectro do feixe N-60 da norma ISO 4037 (1994). 


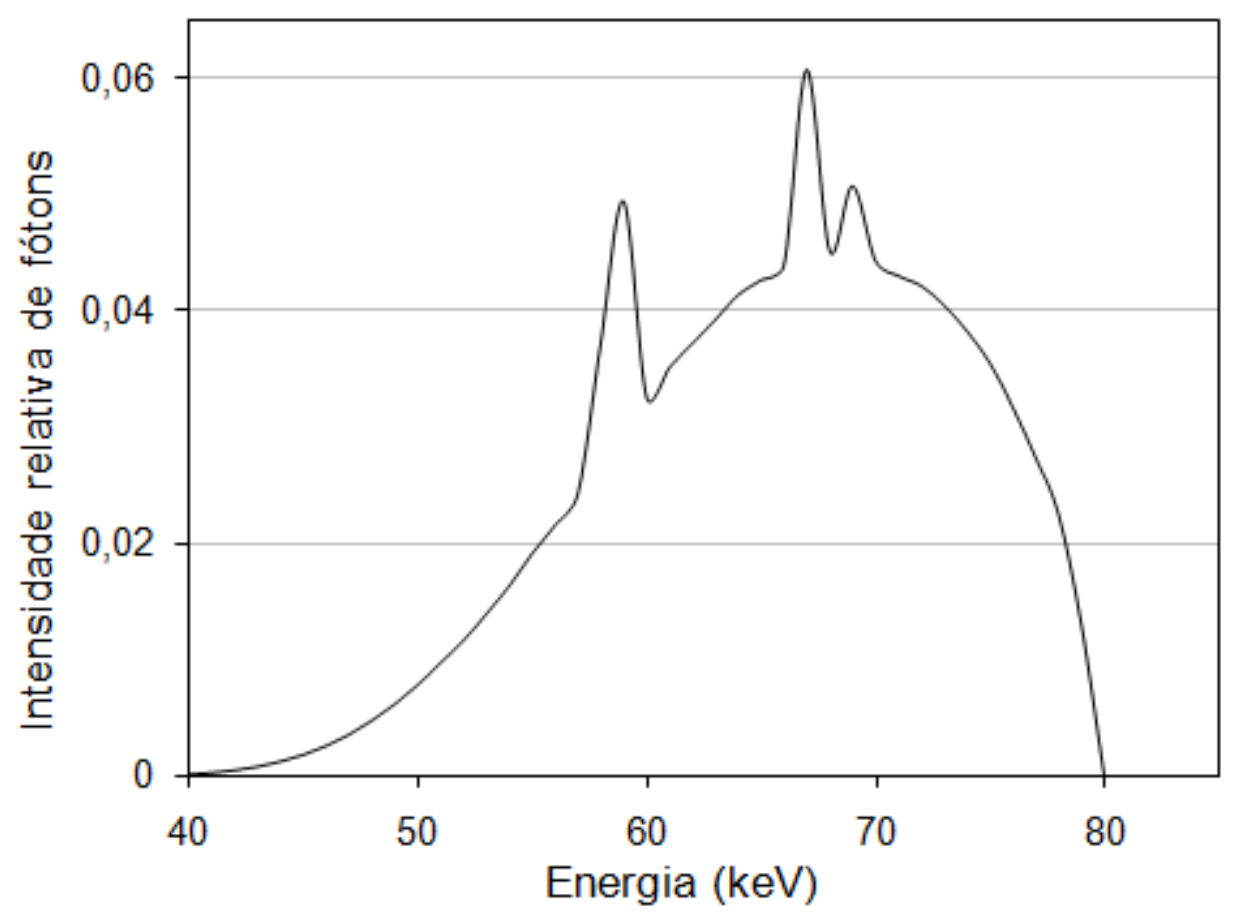

Figura 5.28 - Espectro do feixe N-80 da norma ISO 4037 (1994).

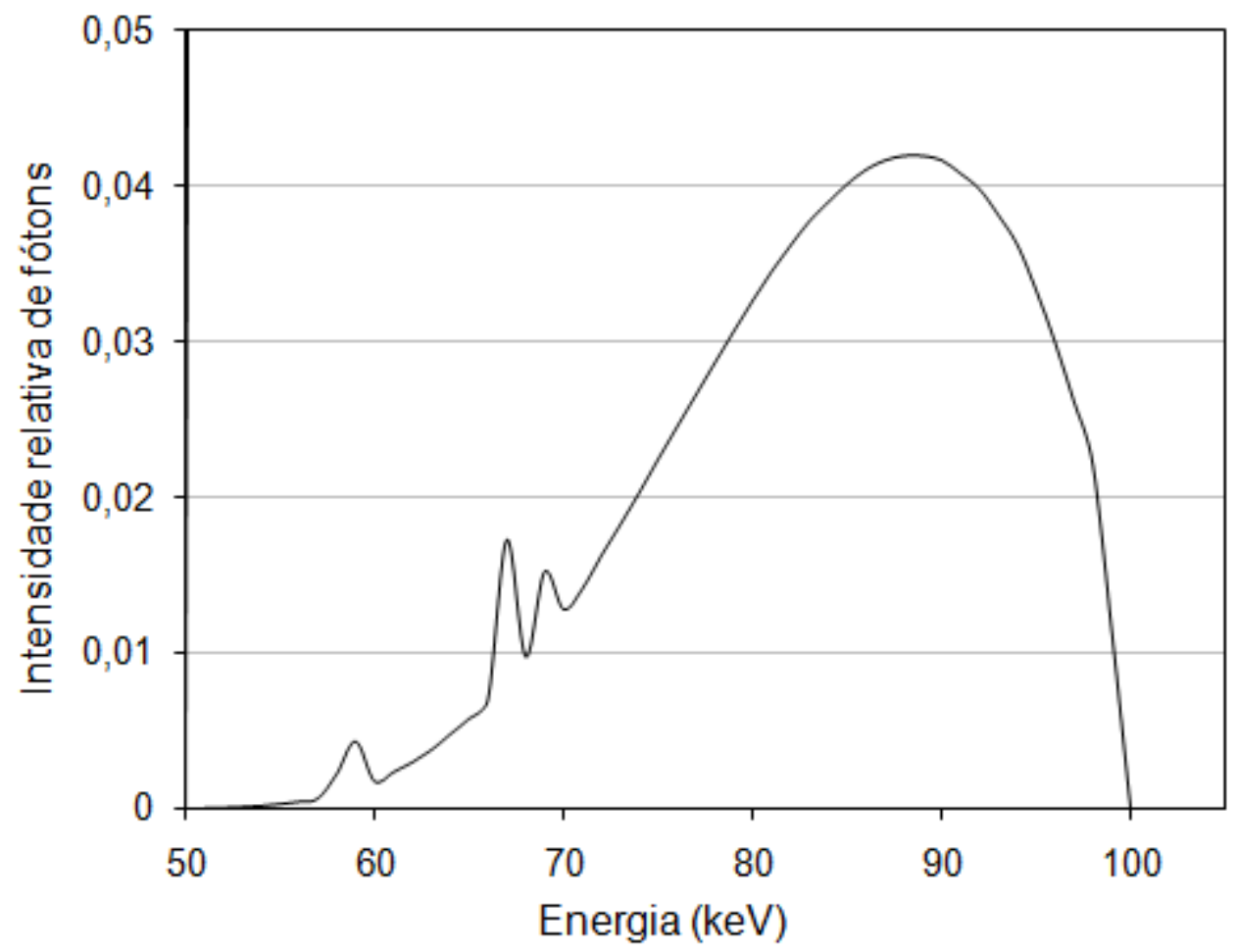

Figura 5.29 - Espectro do feixe N-100 da norma ISO 4037 (1994). 


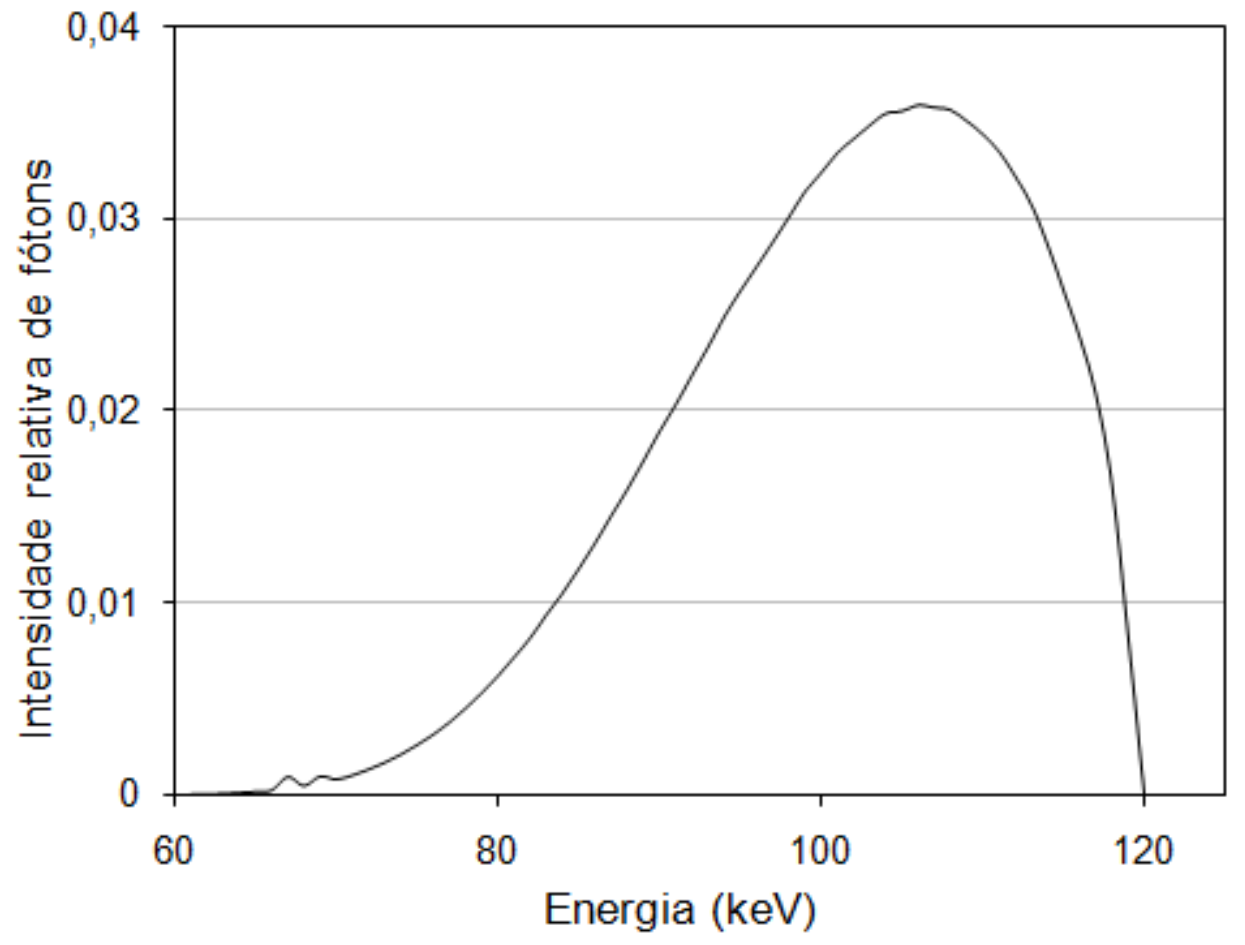

Figura 5.30 - Espectro do feixe N-120 da norma ISO 4037 (1994).

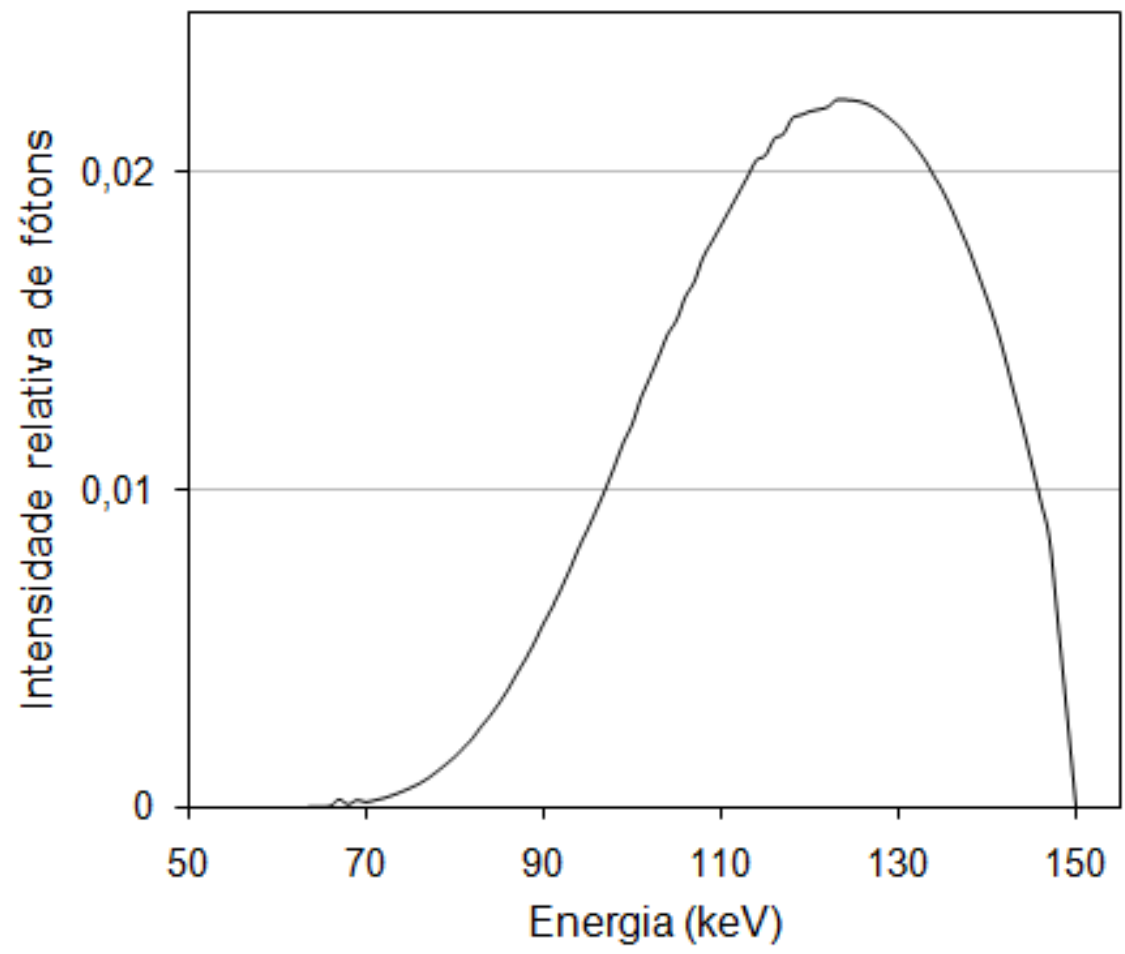

Figura 5.31 - Espectro do feixe N-150 da norma ISO 4037 (1994). 


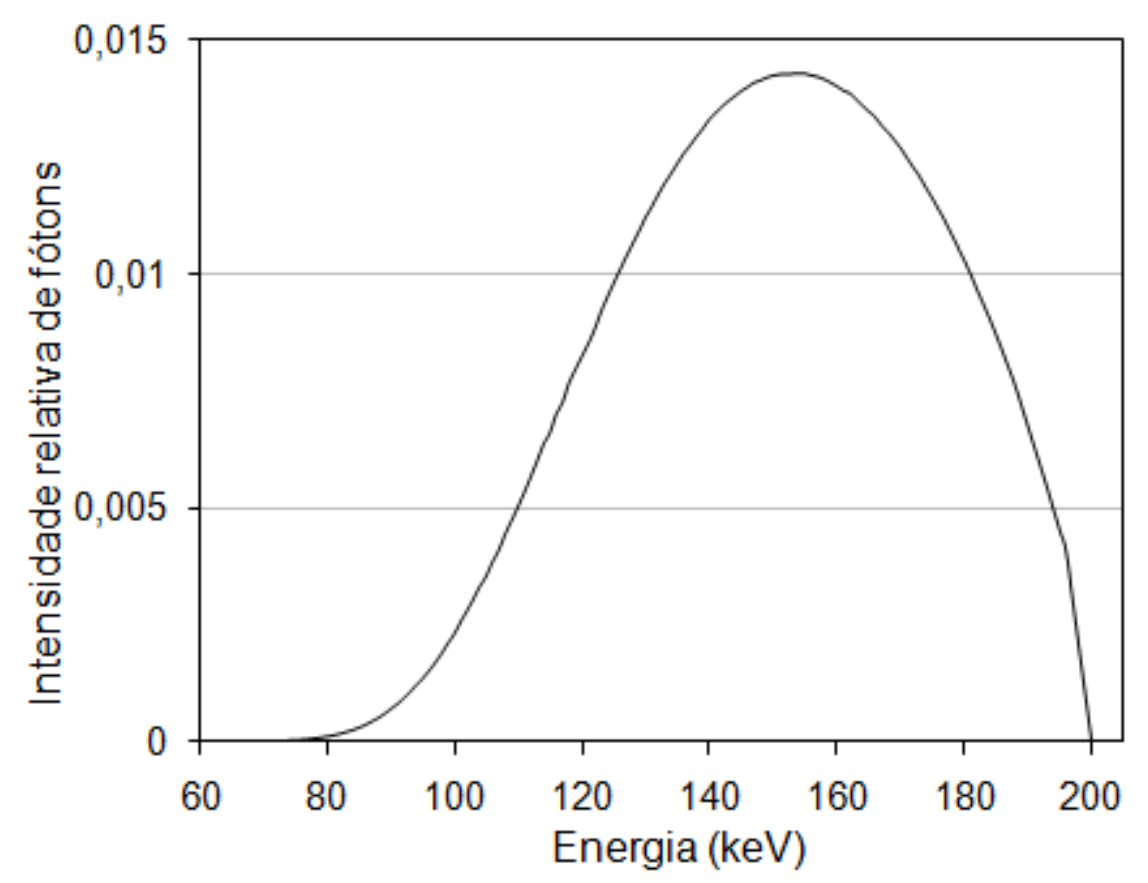

Figura 5.32 - Espectro do feixe N-200 da norma ISO 4037 (1994).

Analisando estes espectros, é possível observar que o espectro $\mathrm{N}-100$ (Figura 5.29) possui a maior intensidade de fótons de energia imediatamente acima da energia de ligação da camada $\mathrm{K}$ do átomo de ouro $(\sim 80,7 \mathrm{keV})$. Portanto, o espectro $\mathrm{N}-100$ possibilitaria um aumento na probabilidade de deposição de energia por efeito fotoelétrico. Entretanto, o espectro N-100 é produzido sob intensa filtração ( $4 \mathrm{mmAl}$ e $5 \mathrm{mmCu}$ ), de modo que a taxa de dose não ultrapassa 0,05 mGy/s nos sistemas MCN 323 e MCN 165. Em vista disso, um espectro produzido com $150 \mathrm{kV}$, com a mesma filtração do espectro $\mathrm{N}-100$ foi simulado. A filtração foi mantida igual àquela utilizada para produzir o N-100 para manter alta a intensidade de fótons imediatamente acima da energia de ligação da camada $\mathrm{K}$ do átomo de ouro.

A possibilidade de utilização dos espectros $\mathrm{N}-120$ e $\mathrm{N}-150$ foi descartada pois ambos apresentam pouca intensidade de fótons na região da energia de ligação da camada $\mathrm{K}$ do átomo de ouro. Além disso, estes espectros também produzem taxas de dose da ordem de $1 \times 10^{-2} \mathrm{mGy} / \mathrm{s}$, o que demandaria longos períodos de irradiação para a realização do experimento.

$\mathrm{O}$ espectro escolhido, produzido por um potencial de $150 \mathrm{kV}$ filtrado com $4 \mathrm{mmAl}$ e $5 \mathrm{mmCu}$ (feixe 150*), produz uma taxa de dose da ordem de 0,5 
mGy/s e está representado na Figura 5.33, juntamente com o espectro N-100 para fins de comparação.

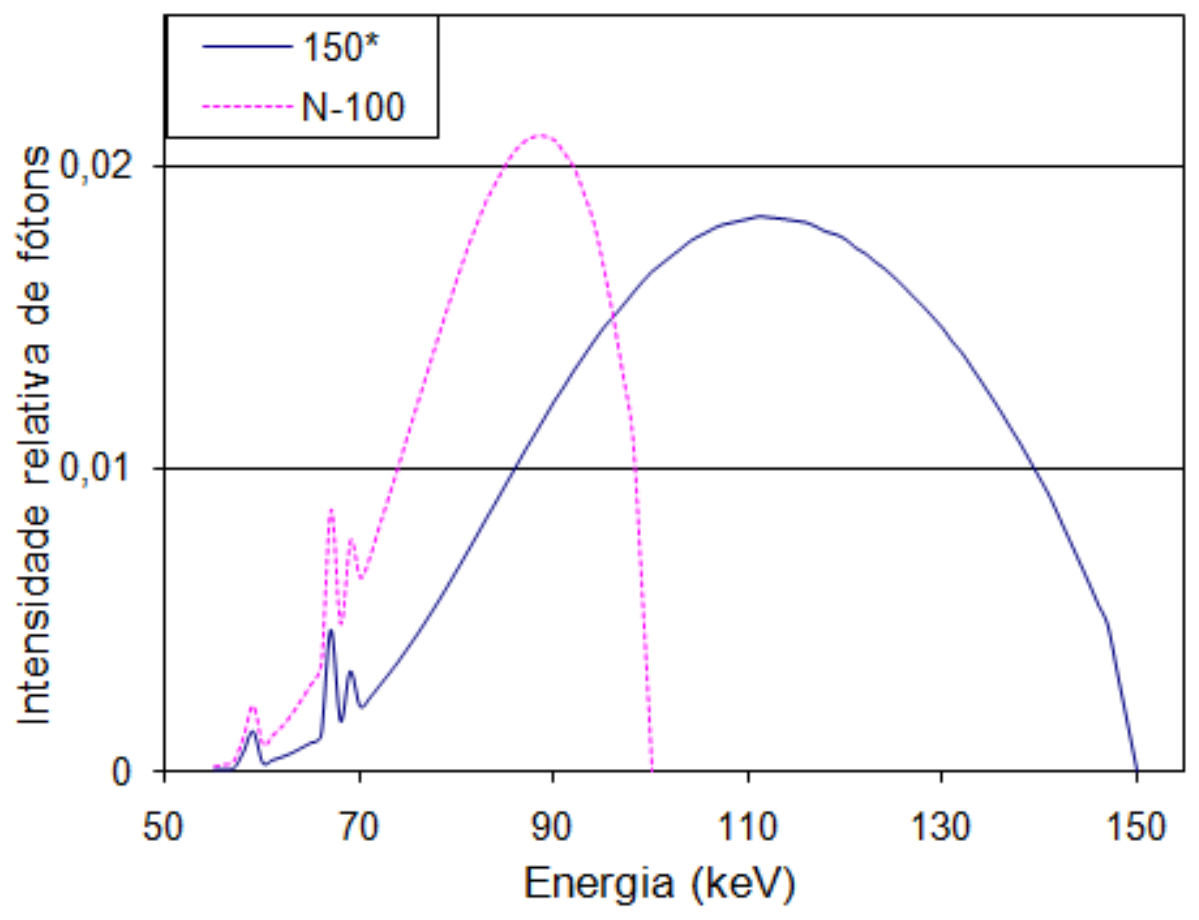

Figura 5.33 - Espectros dos feixes 150* e N-100 da ISO 4037 (1994).

A mesma análise foi realizada para definir um espectro com alta intensidade de fótons na região da energia de ligação da camada $L$ do ouro (com subníveis de 11,9 a 13,7 keV). Os espectros $\mathrm{N}-40$ e $\mathrm{N}-60$ produzem taxas de dose da ordem de $1 \times 10^{-1} \mathrm{mGy} / \mathrm{s}$, portanto um espectro produzido por um potencial de $50 \mathrm{kV}$ filtrado com $4 \mathrm{mmAl}$ foi escolhido (feixe $50^{*}$ ). Este espectro está representado na Figura 5.34 juntamente com os espectros das qualidades $\mathrm{N}$ 40 e N-60 para comparação. 


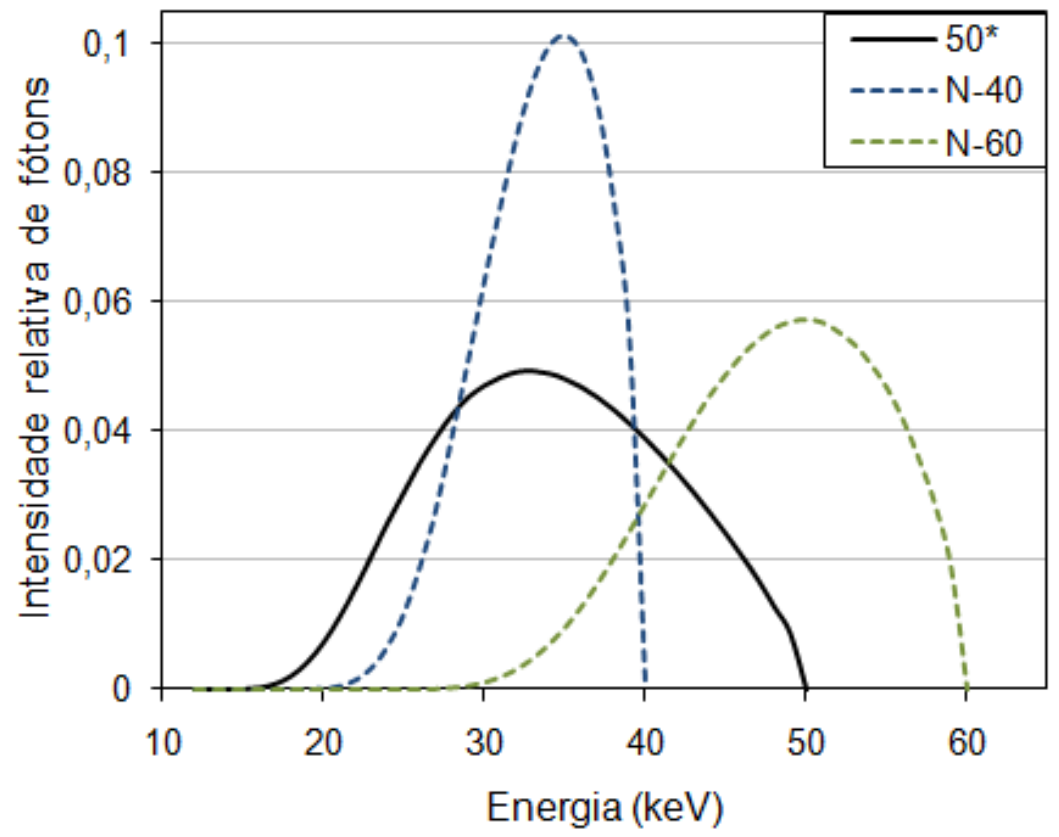

Figura 5.34 - Espectros dos feixes 50*, N-40 e N-60 (ISO 4037, 1994).

As características dos espectros apresentados estão na Tabela 5.3.

Tabela 5.3 - Características dos feixes de raios X apresentados.

\begin{tabular}{|c|c|c|c|c|c|}
\hline Feixe & Tensão & $\begin{array}{c}\text { Filtração } \\
\text { adicional } \\
(\mathrm{mm})\end{array}$ & $\begin{array}{c}\text { Taxa de } \\
\text { kerma no } \mathrm{ar}^{*} \\
(\mu \mathrm{Gy} / \mathrm{s})\end{array}$ & $\begin{array}{c}\text { Camada } \\
\text { semir- } \\
\text { redutora } \\
(\mathrm{mmCu})\end{array}$ & $\begin{array}{c}\text { Energia } \\
\text { média } \\
(\mathrm{keV})\end{array}$ \\
\hline $\mathrm{N}-40$ & $40(\mathrm{~B})$ & $4 \mathrm{Al}+0,21 \mathrm{Cu}$ & 0,90 & 0,08 & 33,3 \\
\hline $50^{*}$ & $50(\mathrm{~B})$ & $4 \mathrm{Al}$ & 16,65 & 0,07 & 34,2 \\
\hline $\mathrm{N}-60$ & $60(\mathrm{~B})$ & $4 \mathrm{Al}+0,6 \mathrm{Cu}$ & 1,42 & 0,24 & 48,1 \\
\hline $\mathrm{N}-80$ & $80(\mathrm{~B})$ & $4 \mathrm{Al}+2 \mathrm{Cu}$ & 0,71 & 0,59 & 65,6 \\
\hline $\mathrm{N}-100$ & $100(\mathrm{~B})$ & $4 \mathrm{Al}+5 \mathrm{Cu}$ & 0,33 & 1,13 & 84,0 \\
\hline $\mathrm{N}-120$ & $120(\mathrm{~B})$ & $4 \mathrm{Al}+5 \mathrm{Cu}+1 \mathrm{Sn}$ & 0,37 & 1,73 & 101,4 \\
\hline $\mathrm{N}-150$ & $150(\mathrm{~B})$ & $4 \mathrm{Al}+2,5 \mathrm{Sn}$ & 2,84 & 2,39 & 119,4 \\
\hline $150^{*}$ & $150(\mathrm{~B})$ & $4 \mathrm{Al}+5 \mathrm{Cu}$ & 5,03 & 2,07 & 110,8 \\
\hline $\mathrm{N}-200$ & $200(\mathrm{~A})$ & $4 \mathrm{Al}+2 \mathrm{Cu}+3 \mathrm{Sn}$ & 7,83 & 3,50 & 150,6 \\
\hline
\end{tabular}

*Taxas de kerma no ar a $1 \mathrm{~m}$ do alvo do sistema de raios $\mathrm{X}$, com corrente de $1 \mathrm{~mA}$. 


\subsection{Cálculo dos Coeficientes de Absorção Mássica de Energia}

O cálculo dos coeficientes de absorção mássica de energia $\left(\mu_{e n} / \rho\right)$ para o gel polimérico puro e para o gel polimérico com ouro foi essencial para o desenvolvimento deste trabalho por possibilitar o cálculo da dose absorvida para diferentes concentrações de ouro.

Estes cálculos representam aproximações analíticas e são provenientes de diversas suposições, uma vez que, em geral, as equações diferenciais para seção de choque não possuem solução analítica, demandando, então, a aplicação de métodos numéricos, como códigos de Monte Carlo.

A base de dados XCOM do NIST (1998) disponibiliza os valores dos coeficientes de absorção mássica de energia para diversos materiais, assim como para elementos químicos puros. O primeiro passo consistiu em determinar a composição química do gel polimérico. Em geral, os trabalhos que analisam o gel polimérico quimicamente desprezam a presença da gelatina. Este desprezo provavelmente ocorre pois a gelatina é o único componente do gel polimérico que não possui uma fórmula química simples. No entanto, a gelatina equilave a $14 \%$ do gel polimérico.

A gelatina utilizada na produção do gel polimérico usado nesse trabalho é fabricada a partir de pele suína e é constituída principalmente de colágeno do tipo I. O colágeno é composto por diversos aminoácidos e, no caso da pele suína, os principais aminoácidos encontrados são glicina, prolina e hidroxiprolina. (Nguyen et al, 1986; Knight et al, 1990)

A fórmula química da hidroxiprolina foi considerada como uma aproximação da composição química da gelatina. Após estas considerações, a Tabela 4.2 foi transformada nas Tabelas 5.4 e 5.5 . 
Tabela 5.4 - Composição detalhada do gel polimérico com as fórmulas químicas dos componentes, considerando a fórmula da hidroxiprolina para a gelatina.

\begin{tabular}{|c|c|c|}
\hline Componente & Fórmula & Massa (\%) \\
\hline Água destilada & $\mathrm{H}_{2} \mathrm{O}$ & 79,97 \\
\hline $\begin{array}{c}\text { Gelatina } \\
\text { (hidroxiprolina) }\end{array}$ & $\mathrm{C}_{5} \mathrm{H}_{9} \mathrm{NO}_{3}$ & 13,99 \\
\hline Ácido metacrílico 99\% & $\mathrm{C}_{4} \mathrm{H}_{6} \mathrm{O}_{2}$ & 5,99 \\
\hline Ácido ascórbico & $\mathrm{C}_{6} \mathrm{H}_{8} \mathrm{O}_{6}$ & 0,035 \\
\hline Sulfato de cobre & $\mathrm{CuSO}_{4}$ & 0,0025 \\
\hline
\end{tabular}

Tabela 5.5 - Composição elementar do gel polimérico obtida utilizando o programa XCOM do NIST (1998).

\begin{tabular}{|c|c|c|}
\hline Número atômico (Z) & Elemento & Massa (\%) \\
\hline 1 & $\mathrm{H}$ & 10,33 \\
\hline 6 & $\mathrm{C}$ & 9,72 \\
\hline 7 & $\mathrm{~N}$ & 1,48 \\
\hline 8 & $\mathrm{O}$ & 78,35 \\
\hline 16 & $\mathrm{~S}$ & 0,0005 \\
\hline 29 & $\mathrm{Cu}$ & 0.001 \\
\hline
\end{tabular}

Os elementos com porcentagem de massa inferior a 1\% (em cinza na Tabela 5.4) não foram considerados nos cálculos analíticos.

\subsubsection{Interpolação dos Coeficientes do NIST}

A base de dados XCOM do NIST (1998) disponibiliza os valores dos coeficientes de absorção mássica de energia $\left(\mu_{e n} / \rho\right)$ para diversos materiais em uma faixa ampla de energia, porém com intervalos muito grandes entre uma energia e outra. Na faixa de energias entre 10 e $150 \mathrm{keV}$, a base de dados XCOM apresenta apenas 11 pontos para os principais elementos que compõem o gel polimérico, deixando clara a necessidade de uma interpolação destes coeficientes para uma aproximação mais precisa da dose absorvida. 
A interpolação é um método de construção de novos pontos de dados dentro do intervalo de uma distribuição discreta de pontos conhecidos. Diversas funções matemáticas foram testadas, como linear, polinomial e exponencial, porém a interpolação mais suave encontrada foi:

$$
\mu_{\text {en }} / \rho=a \cdot E^{b}
$$

em que a e b foram determinados a partir da solução do sistema de equações dado por:

$$
\left\{\begin{array}{l}
{\left[\mu_{e n} / \rho\right]_{i}=a \cdot E_{i}^{b}} \\
{\left[\mu_{e n} / \rho\right]_{i+1}=a \cdot E_{i+1}^{b}}
\end{array}\right.
$$

em que $\left[\mu_{e n} / \rho\right]_{i}$ é o coeficiente do XCOM para a respectiva energia $E_{i}$.

Este método de interpolação foi realizado para os principais elementos presentes no gel polimérico: hidrogênio, carbono, nitrogênio e oxigênio, e para o ouro na faixa de energia entre 10 e $150 \mathrm{keV}$, em intervalos de $1 \mathrm{keV}$.

No caso do ouro foi necessária uma adaptação nesta interpolação na região dos bordas $\mathrm{K}$ e $\mathrm{L}$ por causa das descontinuidades abruptas, quando a energia do fóton se iguala à energia de ligação dessas camadas eletrônicas. Os coeficientes de absorção mássica de energia obtidos para o ouro estão representados nas Figuras 5.35 e 5.36, sobrepostos aos dados do XCOM (NIST, 1998).

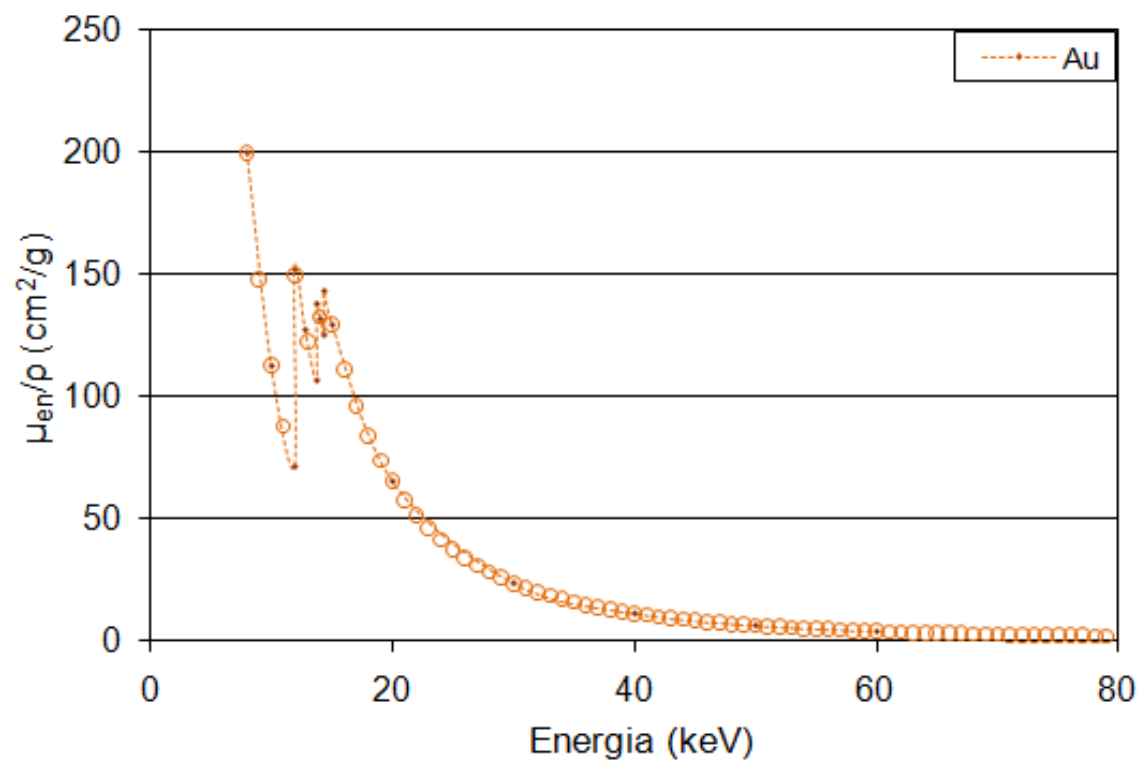

Figura 5.35 - Coeficiente de absorção mássica de energia em relação à energia do fóton para o elemento ouro entre 10 e $80 \mathrm{keV}$. 


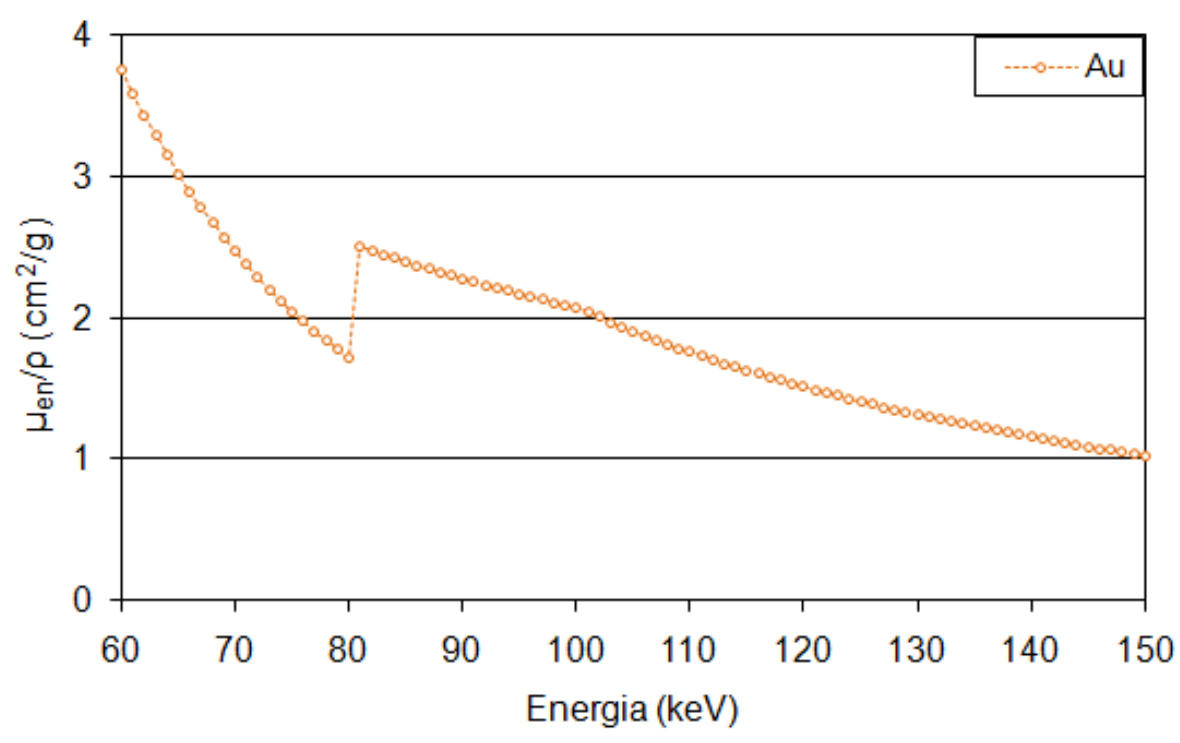

Figura 5.36 - Coeficiente de absorção mássica de energia em relação à energia do fóton para o elemento ouro entre 60 e $150 \mathrm{keV}$.

Os coeficientes de absorção mássica de energia para o gel polimérico foram obtidos por meio da combinação linear (soma ponderada) dos coeficientes dos elementos individuais de acordo com a porcentagem de massa apresentados na Tabela 5.4. Os valores dos coeficientes de absorção mássica de energia para o gel polimérico (GP) foram obtidos entre 10 e $150 \mathrm{keV}$, em intervalos de $1 \mathrm{keV}$. Os dados obtidos por meio da interpolação para os elementos individuais (hidrogênio, carbono, oxigênio e nitrogênio) e o resultado da combinação linear para o gel polimérico estão representados nas Figuras 5.37 e 5.38 . 


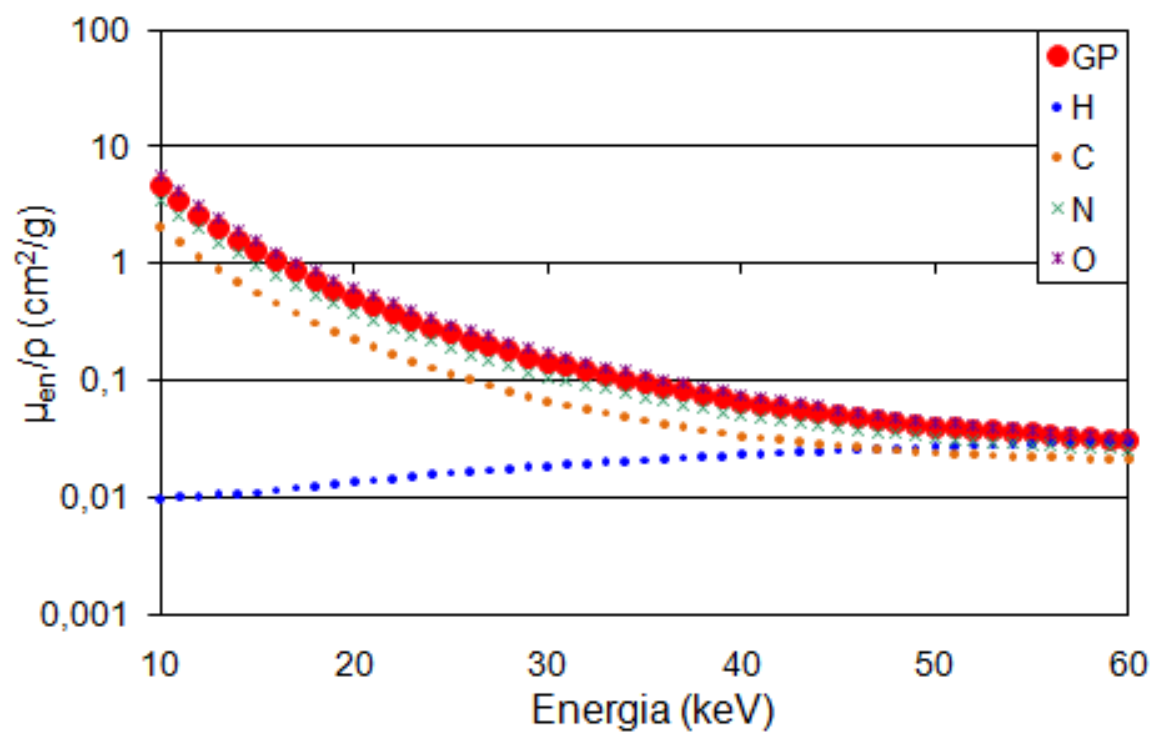

Figura 5.37 - Coeficiente de absorção mássica de energia em relação à energia do fóton incidente para energias de 10 a $60 \mathrm{keV}$, para diferentes elementos presentes no gel polimérico e para o gel polimérico (GP).

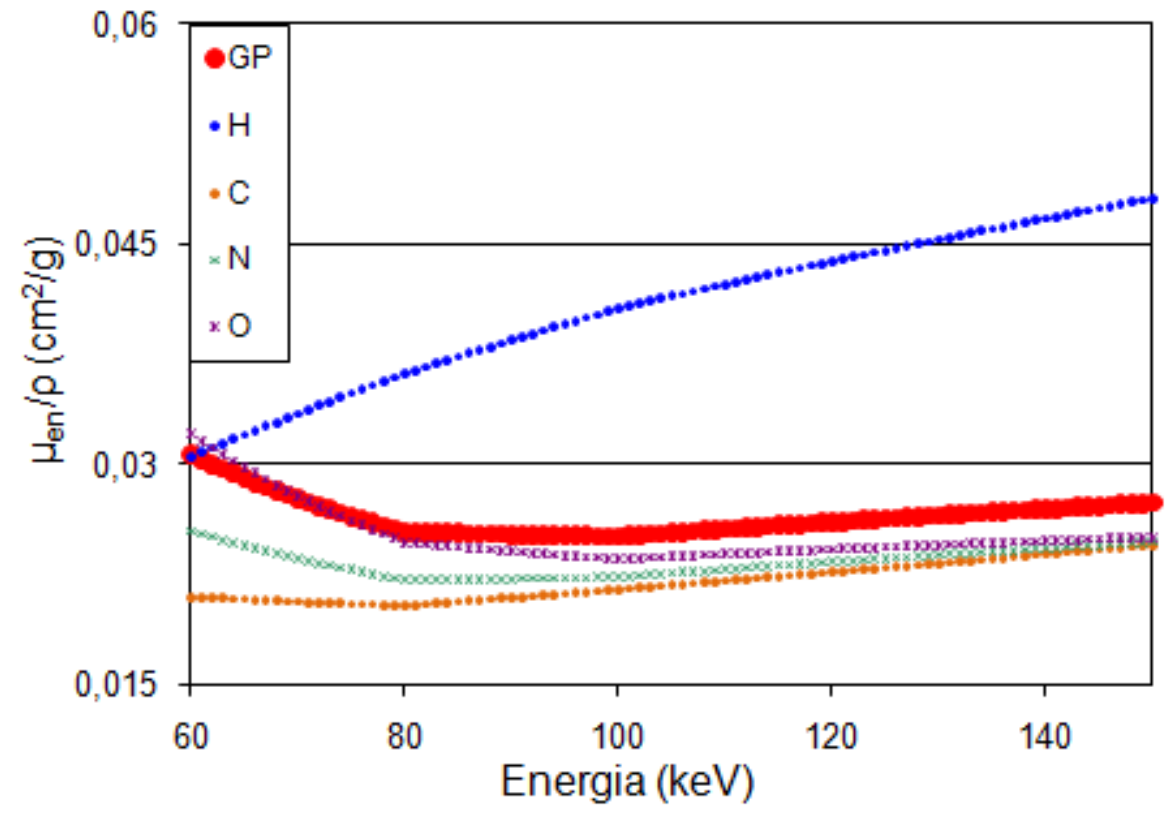

Figura 5.38 - Coeficiente de absorção mássica de energia em relação à energia do fóton incidente para energias de 60 a $150 \mathrm{keV}$, para diferentes elementos presentes no gel polimérico e para o gel polimérico (GP).

Os coeficientes de absorção mássica de energia obtidos para o gel polimérico (GP) foram comparados com os coeficientes de absorção mássica de energia para o tecido mole padrão da ICRP (2002) (Figura 5.39). Os coeficientes 
para o tecido mole padrão da ICRP (2002) também foram obtidos por meio da interpolação dos dados fornecidos pela base de dados XCOM do NIST (1998).

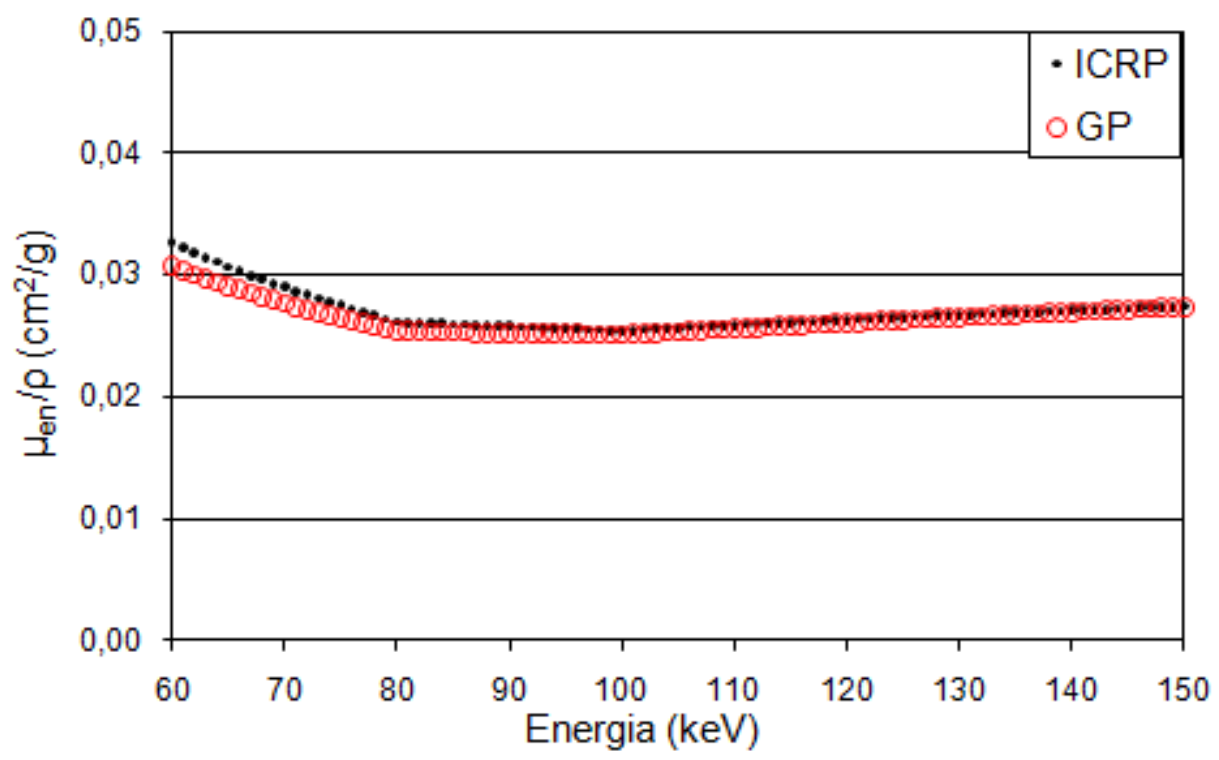

Figura 5.39 - Coeficiente de absorção mássica de energia em relação à energia do fóton incidente para o gel polimérico (GP) e para o tecido mole padrão da ICRP (2002).

Este resultado mostra uma variação máxima de $6 \%$ entre o coeficiente de absorção mássica de energia do gel polimérico e o coeficiente de absorção mássica de energia do tecido mole padrão da ICRP (2002), conferindo, então, a característica de tecido-equivalência do gel polimérico.

\subsubsection{Cálculo dos Coeficientes de Absorção Mássica de Energia para o Gel Polimérico Puro e para o Gel Polimérico com Ouro}

Após a obtenção dos coeficientes de absorção mássica de energia para o gel polimérico, o processo de combinação linear foi repetido inserindo as seguintes concentrações de ouro (em gramas de ouro por grama de gel polimérico, gAu/gGP): 0,00001; 0,0001; 0,001; 0,005 e 0,01.

Os coeficientes obtidos para algumas combinações de gel polimérico com ouro em relação à energia estão representados nas Figuras 5.40 e 5.41 . 


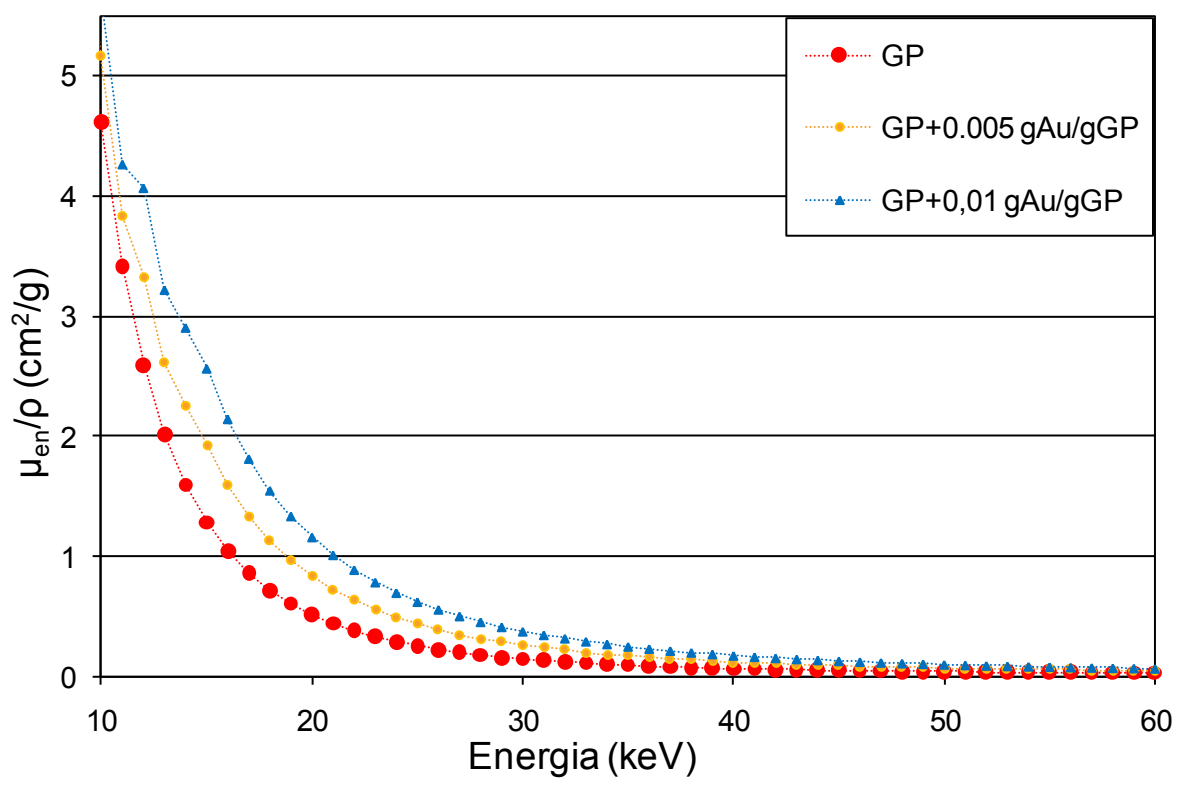

Figura 5.40 - Coeficiente de absorção mássica de energia em relação à energia do fóton incidente para o gel polimérico com duas concentrações de ouro, entre 10 e $60 \mathrm{keV}$.

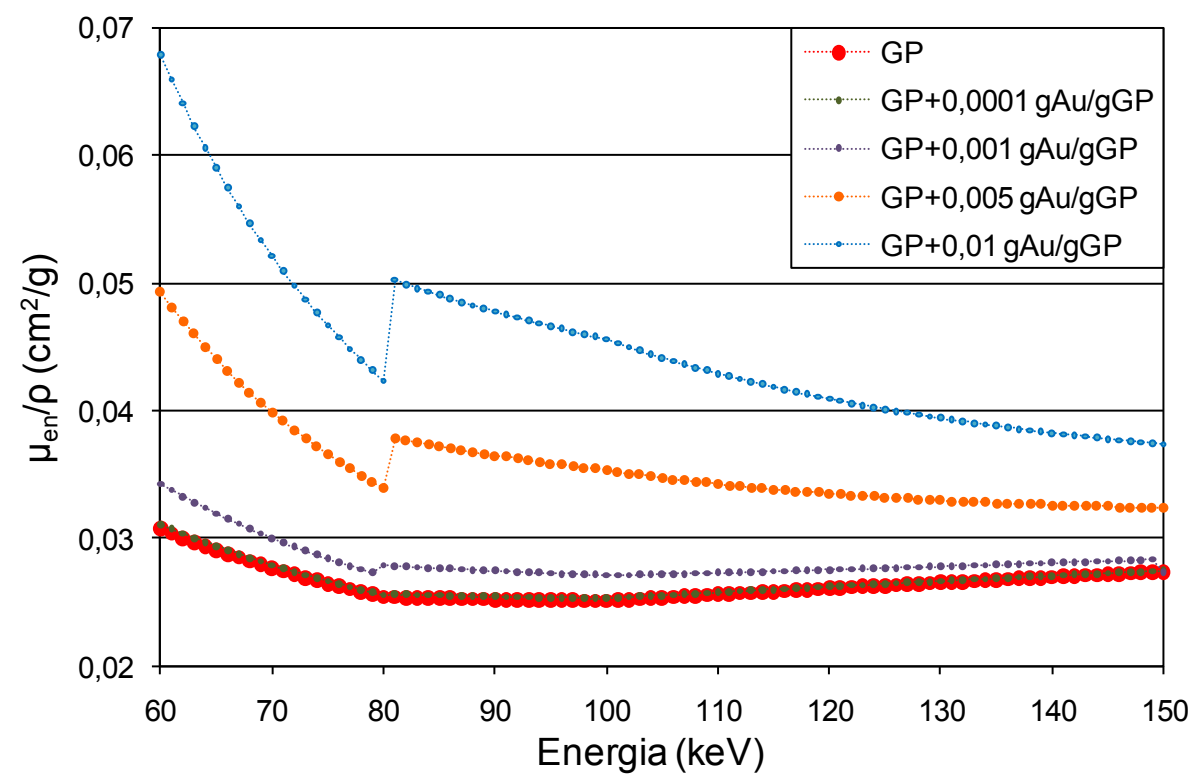

Figura 5.41 - Coeficiente de absorção mássica de energia em relação à energia do fóton incidente para o gel polimérico com diversas concentrações de ouro, entre 60 e $150 \mathrm{keV}$.

A análise dos resultados apresentados nas Figuras 5.40 e 5.41 mostra que há um aumento no coeficiente de absorção mássica de energia quando a concentração de ouro é aumentada. Em cerca de $20 \mathrm{keV}$, o gel polimérico com 
0,005 gAu/gGP apresenta um aumento de aproximadamente $63 \%$ do coeficiente de absorção mássica de energia em relação àquele referente ao gel polimérico puro. Para $81 \mathrm{keV}$, este aumento representa aproximadamente 50\%. Estes resultados são provenientes principalmente do aumento da absorção de energia por efeito fotoelétrico pelos átomos de ouro. 


\subsection{Cálculo da Dose Absorvida}

A dose absorvida foi calculada em uma fatia de $1 \mathrm{~mm}$ de espessura adjacente à entrada do feixe de raios $X$ (Figura 5.42 ) para as amostras de gel polimérico puro e gel polimérico com diferentes concentrações de ouro. A amostra considerada consiste em um tubo de ensaio de vidro com $100 \mathrm{~mm}$ de comprimento e $12 \mathrm{~mm}$ de diâmetro interno, com uma parede de vidro de $2 \mathrm{~mm}$. A parede de vidro foi desconsiderada nos cálculos.
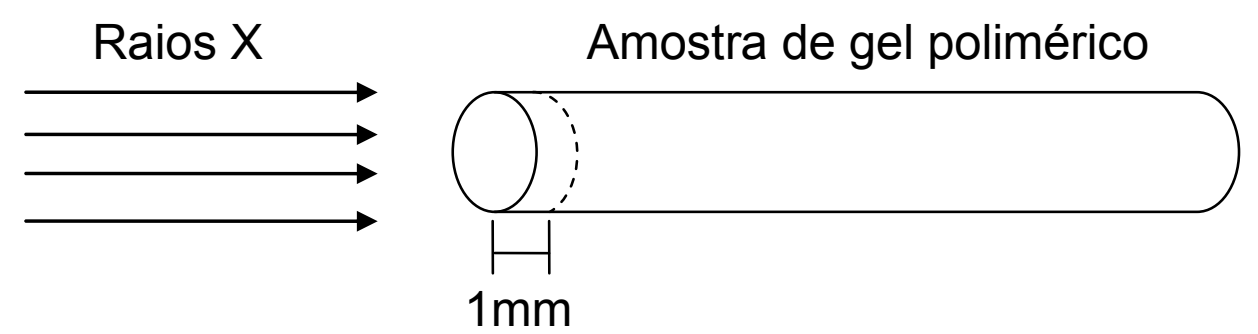

Figura 5.42 - Representação da fatia da amostra utilizada no cálculo da dose absorvida.

A dose absorvida foi calculada para: espectro N-100 (ISO 4037), espectro de $150 \mathrm{kV}$ filtrado com $4 \mathrm{mmAl}$ e $5 \mathrm{mmCu}\left(150^{*}\right)$ e espectro de $50 \mathrm{kV}$ filtrado com $4 \mathrm{mmAl}\left(50^{*}\right)$, todos gerados utilizando o programa SpekCalc. $\mathrm{O}$ cálculo da dose foi realizado utilizando a fórmula representada pela Eq. 3.26, somando a contribuição de cada energia do espectro em intervalos de $1 \mathrm{keV}$. A equação em função da energia resulta em:

$$
D_{\text {total }}=\sum_{E} D(E)=\sum_{E} \frac{\psi(E)\left(1-e^{\left.-\frac{\mu_{e n}(E) \cdot \rho \cdot x}{\rho}\right)}\right.}{\rho \cdot A \cdot x}
$$

em que $\psi(E)$ é a intensidade de fótons de energia $E$ proveniente do programa SpekCalc e $\mu_{e n} / \rho(E)$ é o coeficiente de absorção mássica de energia para a energia $E$ obtido no item 5.5 .

O cálculo da dose absorvida não foi realizado para espessuras maiores da amostra por supor que o espectro do feixe de raios $\mathrm{X}$ não se altera ao longo da amostra (pelo menos em espessuras como $1 \mathrm{~mm}$ de gel polimérico). Esta suposição pode ser considerada na entrada do feixe, porém levaria a erros muito grandes em profundidades maiores. 
Os valores de dose absorvida obtidos para o gel polimérico puro e para o gel polimérico com 0,00001; 0,0001; 0,001; 0,005 e 0,01 gAu/gPG foram comparados, resultando em uma relação entre o fator de aumento da dose (DEF, dose enhancement factor, razão entre a dose com ouro e a dose sem ouro) e a concentração de ouro na amostra ([Au]) para os três espectros de raios $X$ considerados $\left(\mathrm{N}-100,150^{*}\right.$ e 50*). Estas relações estão apresentadas na Figura 5.43 .

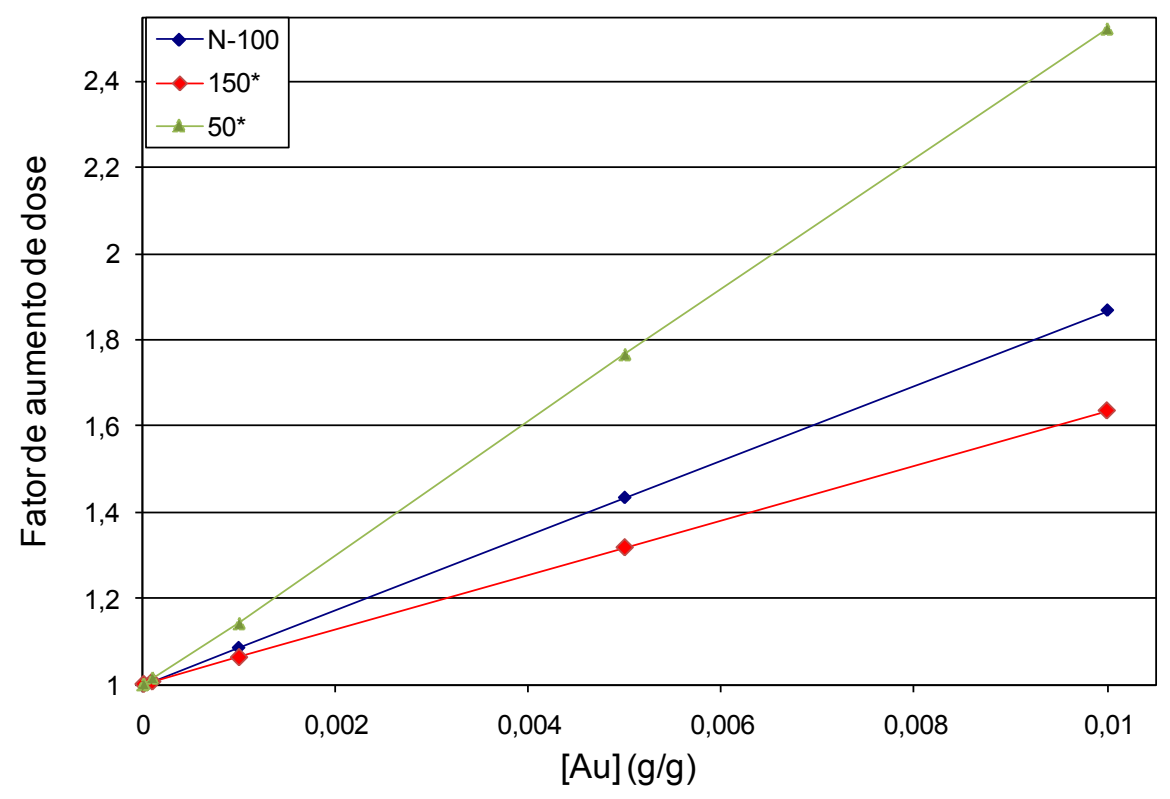

Figura 5.43 - Relação entre o aumento de dose e a concentração de ouro no gel polimérico para os espectros dos feixes N-100 (ISO 4037, 1994), 150* e $50^{*}$.

Estes resultados mostram que, para a concentração de 0,005 gAu/gGP, o fator de aumento de dose absorvida na entrada da amostra é $43 \%$ para o feixe $\mathrm{N}-100,32 \%$ para o feixe $150^{*}$ e $76 \%$ para o feixe $50^{*}$. 


\subsection{Simulações por Método de Monte Carlo}

Nesta parte do trabalho, um programa para dosimetria de fótons previamente desenvolvido pelo Prof. Dr. Alessio Mangiarotti (Universidade de Coimbra, Portugal) foi utilizado. O programa em questão foi desenvolvido utilizando Geant 3.21 (Brun et al, 1987).

O Geant é um programa desenvolvido pelo CERN (Organização Europeia para Pesquisa Nuclear, Brun et al, 1987) que simula a passagem de partículas elementares pela matéria. Embora tenha sido originalmente desenvolvido para simular experimentos em Física das altas energias, atualmente o programa é aplicado nas áreas de ciências médicas e biológicas, radioproteção e astronáutica.

O programa desenvolvido pelo Prof. Dr. Alessio Mangiarotti foi testado e comparado com outros códigos de Monte Carlo utilizados para dosimetria. As Figuras 5.44 e 5.45 mostram que o programa criado em Geant 3.21 possui características compatíveis com os demais códigos comumemente utilizados para dosimetria.

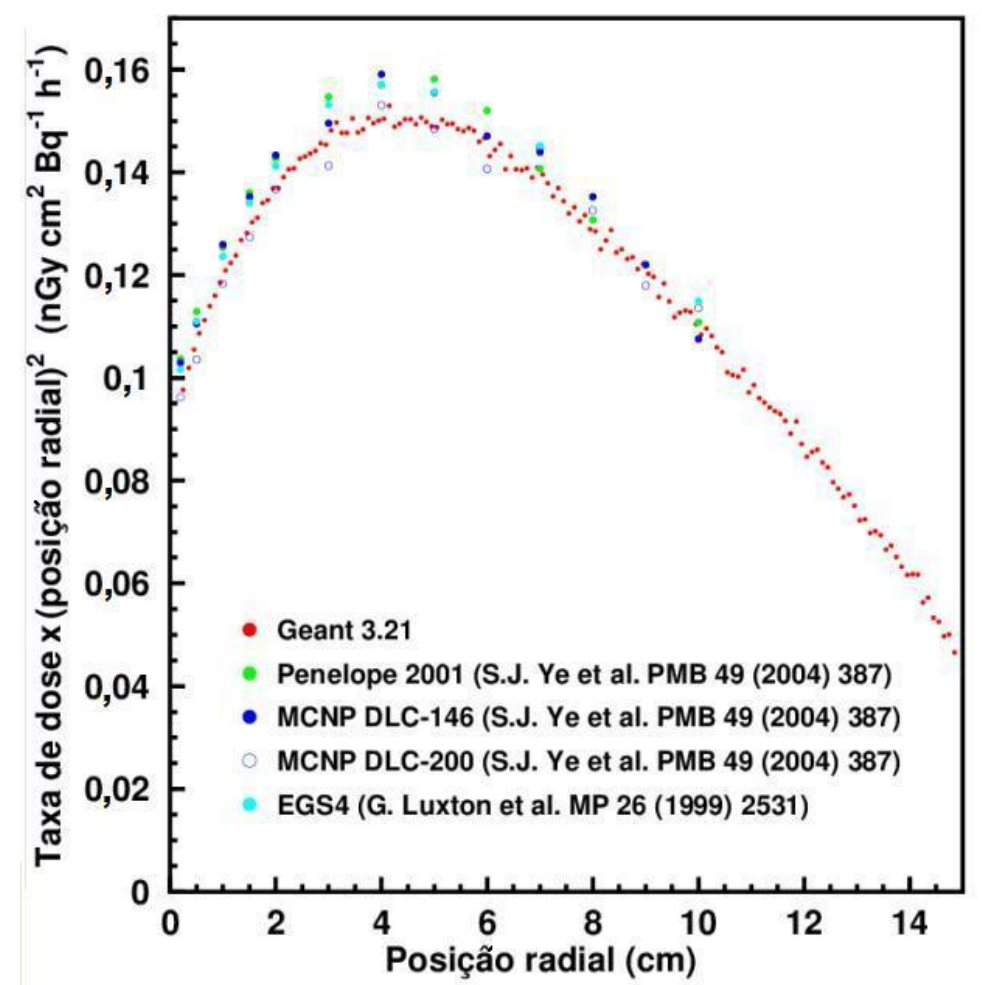

Figura 5.44 - Distribuição da taxa de dose de um feixe monoenergético de $50 \mathrm{keV}$ em relação à distância radial para cinco códigos diferentes de Monte Carlo. (Figura gentilmente cedida pelo Prof. Dr. Alessio Mangiarotti) 


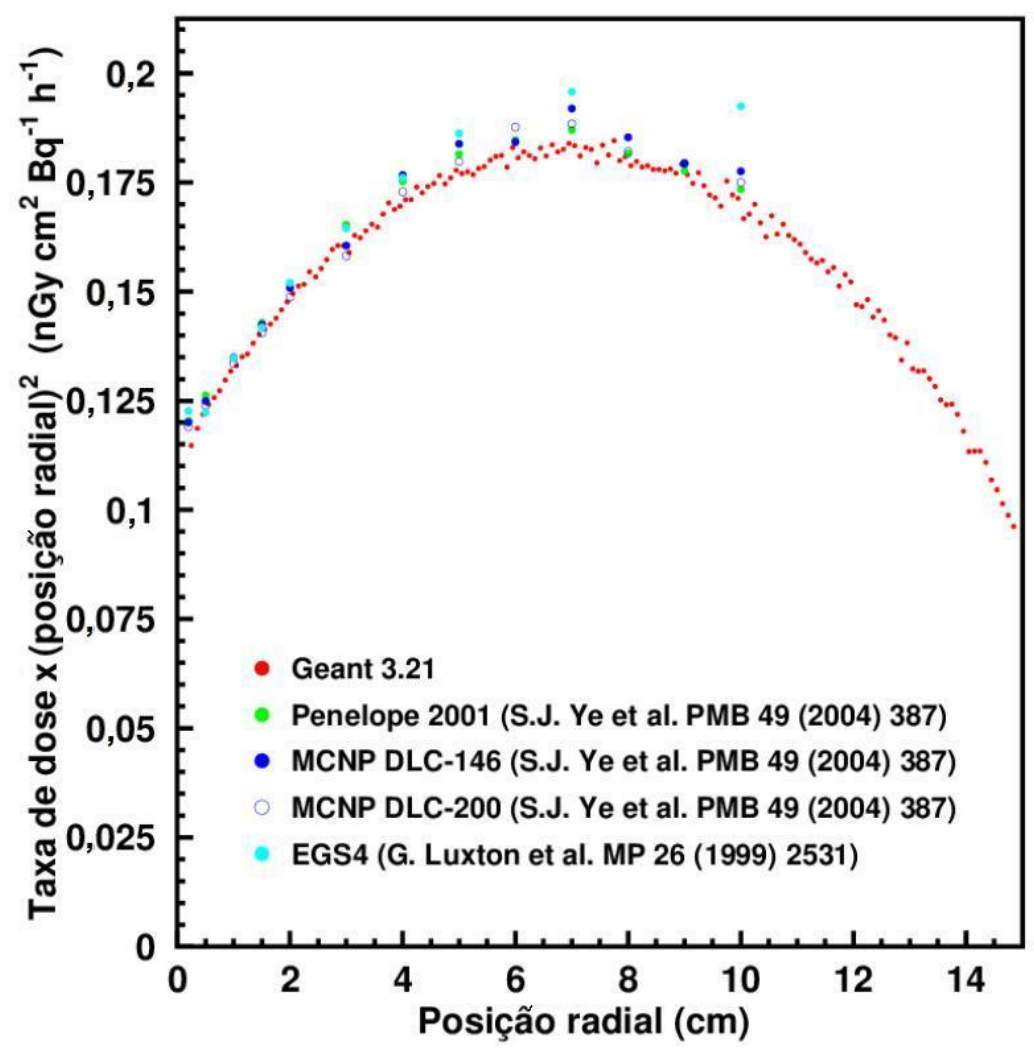

Figura 5.45 - Distribuição da taxa de dose de um feixe monoenergético de $100 \mathrm{keV}$ em relação à distância radial para cinco códigos diferentes de Monte Carlo. (Figura gentilmente cedida pelo Prof. Dr. Alessio Mangiarotti)

O programa foi alterado para se adequar às características dos experimentos realizados neste trabalho. A geometria da amostra foi inserida no programa como sendo um tubo de ensaio de vidro com $100 \mathrm{~mm}$ de comprimento e $12 \mathrm{~mm}$ de diâmetro interno, com uma parede de vidro de $2 \mathrm{~mm}$. O gel polimérico também foi simulado como sendo uma mistura homogênea dos elementos químicos que o compoem (Tabelas 5.3 e 5.4 ) e, posteriomente, foram adicionados $5 \mathrm{mg}$ de ouro por grama de gel polimérico. Diversos feixes de radiação calculados na seção 5.4 foram inseridos no programa, sendo eles: N-40, $\mathrm{N}-60, \mathrm{~N}-80, \mathrm{~N}-100, \mathrm{~N}-120, \mathrm{~N}-200$ e N-250 da ISO 4037 (1994) e, adicionalmente, os feixes de $50 \mathrm{keV}$ filtrado com $4 \mathrm{mmAl}\left(50^{*}\right)$ e de $150 \mathrm{keV}$ filtrado com $4 \mathrm{mmAl} \mathrm{e}$ $5 \mathrm{mmCu}\left(150^{*}\right)$, utilizados no item 5.6.

O programa trilhou a trajetória da radiação incidente, contabilizando informações sobre as interações sofridas no percurso, como tipo de interação (absorção fotoelétrica, espalhamento Compton, Rayleigh) e a quantidade de 
energia depositada, levando ao cálculo da dose absorvida pela amostra. Este procedimento foi realizado para a amostra de gel polimérico puro e para a amostra de gel polimérico com ouro (0,005 gAu/gPG), utilizando os feixes de raios $\mathrm{X}$ citados.

As Figuras 5.46 e 5.47 mostram a dose absorvida em relação à profundidade da amostra de gel polimérico com 0,005 gAu/gGP e de gel polimérico puro para diversos feixes de raios $\mathrm{X}$.

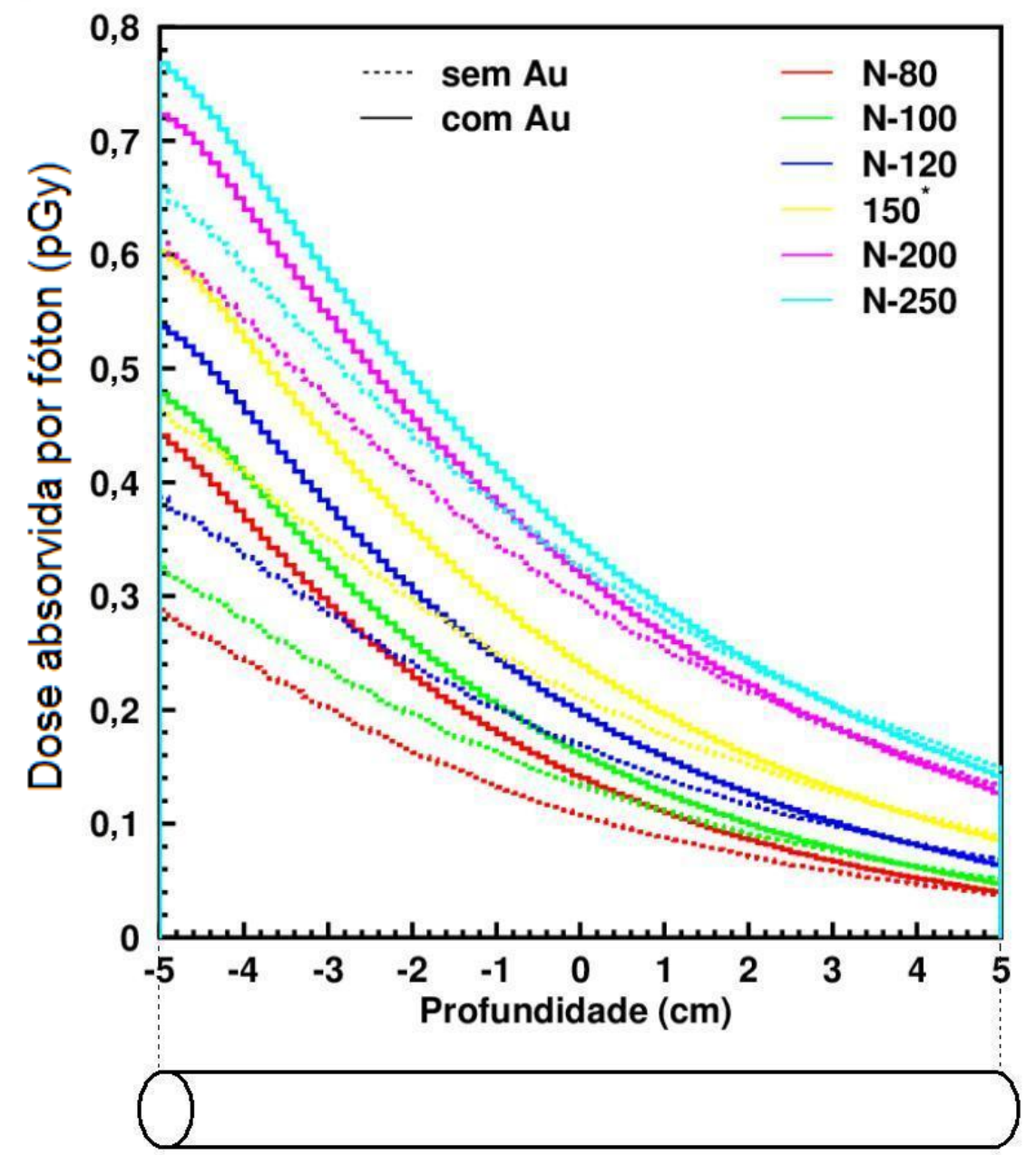

Figura 5.46 - Relação entre a dose absorvida e a profundidade da amostra de gel polimérico com e sem ouro para os feixes $\mathrm{N}-80, \mathrm{~N}-100, \mathrm{~N}-120$, $150^{*}, \mathrm{~N}-200$ e N-250. 


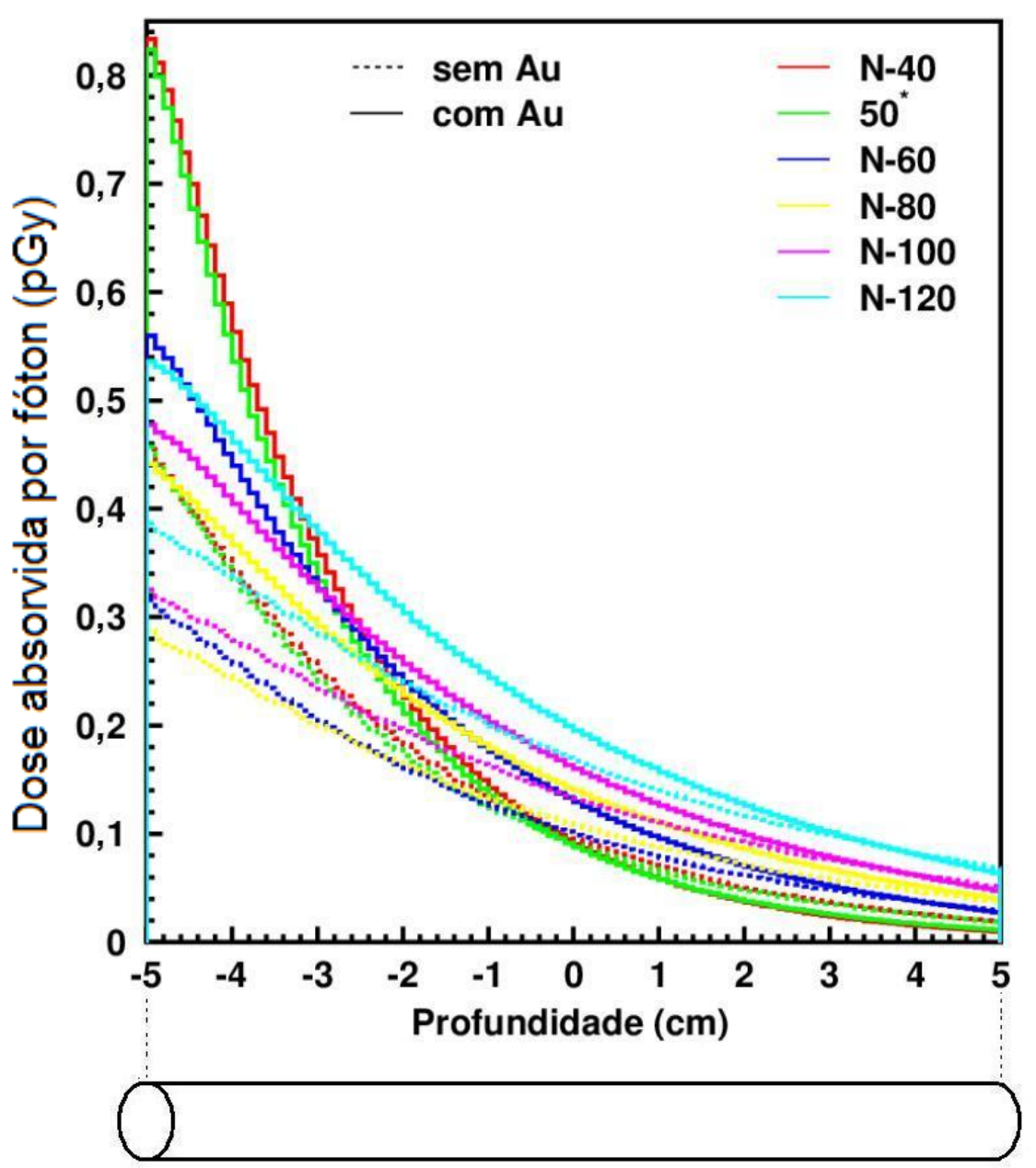

Figura 5.47 - Relação entre a dose absorvida e a profundidade da amostra de gel polimérico com e sem ouro para os feixes $\mathrm{N}-40,50^{*}, \mathrm{~N}-60, \mathrm{~N}-80$, $\mathrm{N}-100$ e $\mathrm{N}-120$.

Para melhor visualização dos resultados apresentados nas Figuras 5.46 e 5.47, o aumento percentual da dose absorvida pelo gel polimérico com ouro $(0,005 \mathrm{gAu} / \mathrm{gGP})$ em relação à dose absorvida pelo gel polimérico puro foi representado nas Figuras 5.48 e 5.49 . 


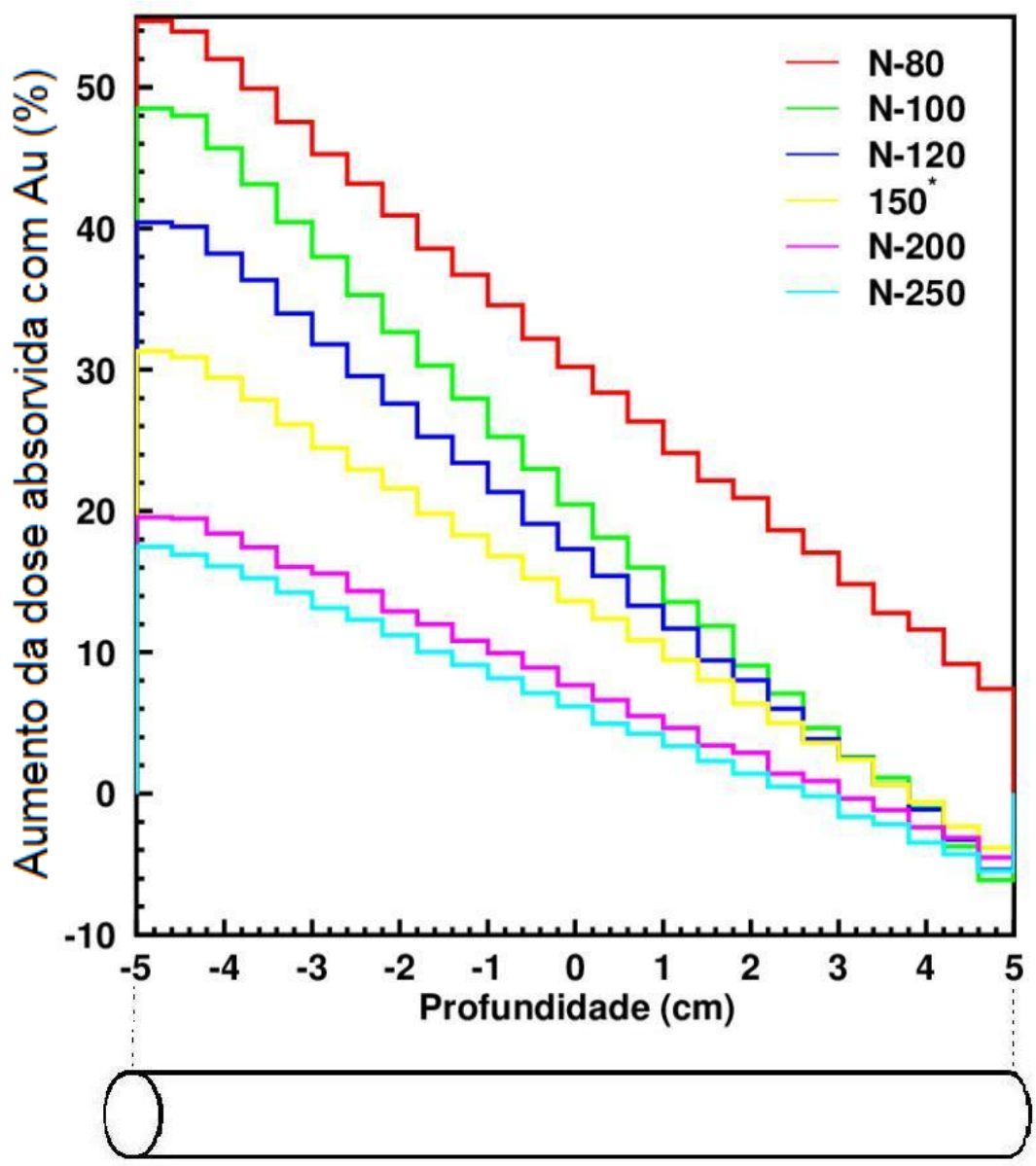

Figura 5.48 - Aumento da dose absorvida pela amostra de gel polimérico com 0,005 gAu/gGP em relação à dose absorvida pela amostra de gel polimérico puro para os feixes $\mathrm{N}-80, \mathrm{~N}-100, \mathrm{~N}-120,150 *$, N-200 e N-250. 


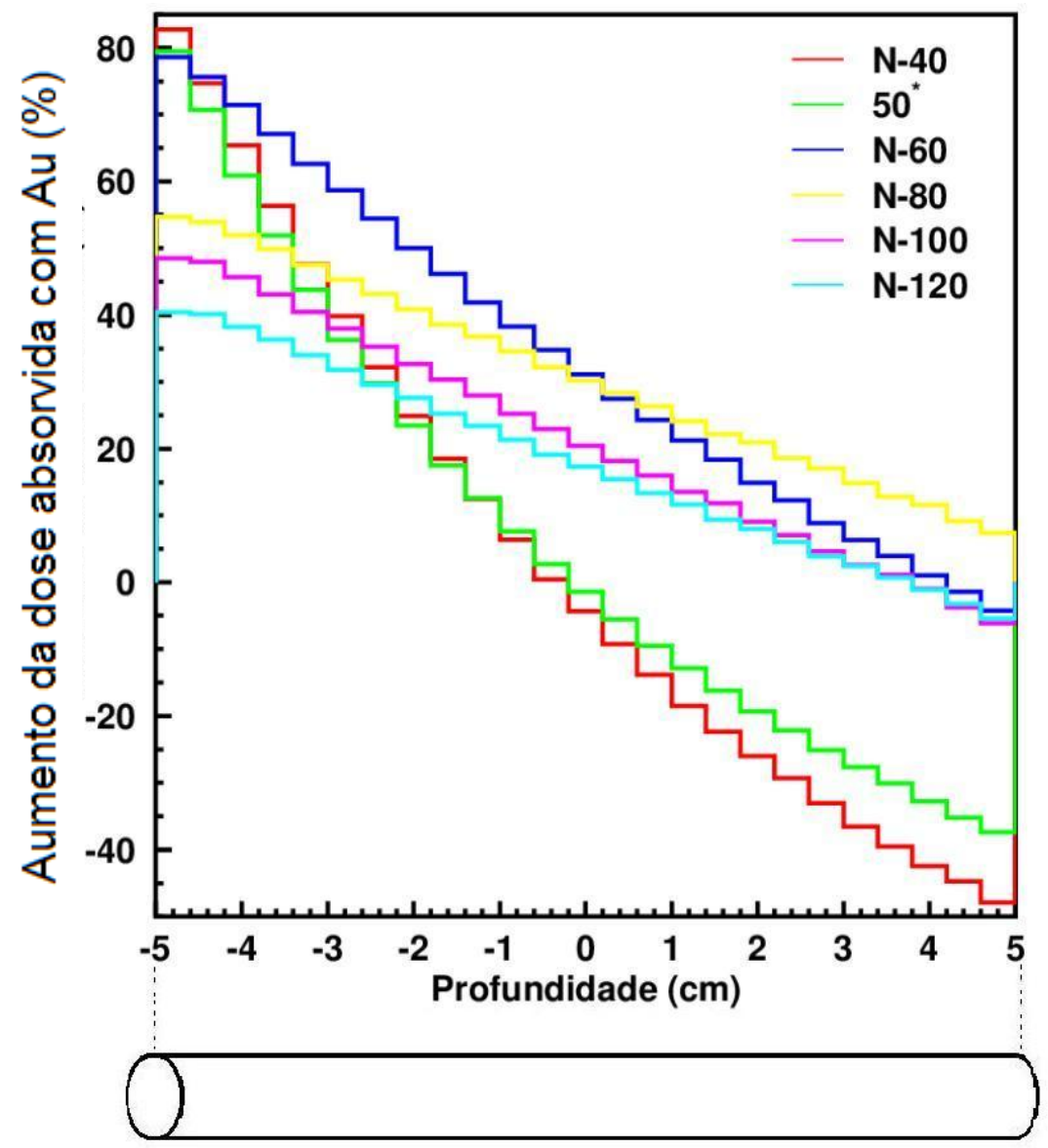

Figura 5.49 - Aumento da dose absorvida pela amostra de gel polimérico com $0,005 \mathrm{gAu} / \mathrm{gGP}$ em relação à dose absorvida pela amostra de gel polimérico puro para os feixes N-40, 50*, N-60, N-80, N-100 e N-120.

As Figuras 5.48 e 5.49 mostram que há um aumento significativo na dose absorvida na entrada da amostra de gel polimérico com 0,005 gAu/gGP em relação à dose absorvida na entrada da amostra de gel polimérico puro para todos os feixes de raios $X$ considerados. Os aumentos da dose absorvida na entrada da amostra em relação ao feixe de raios $X$ utilizado estão representados na Figura 5.50. 


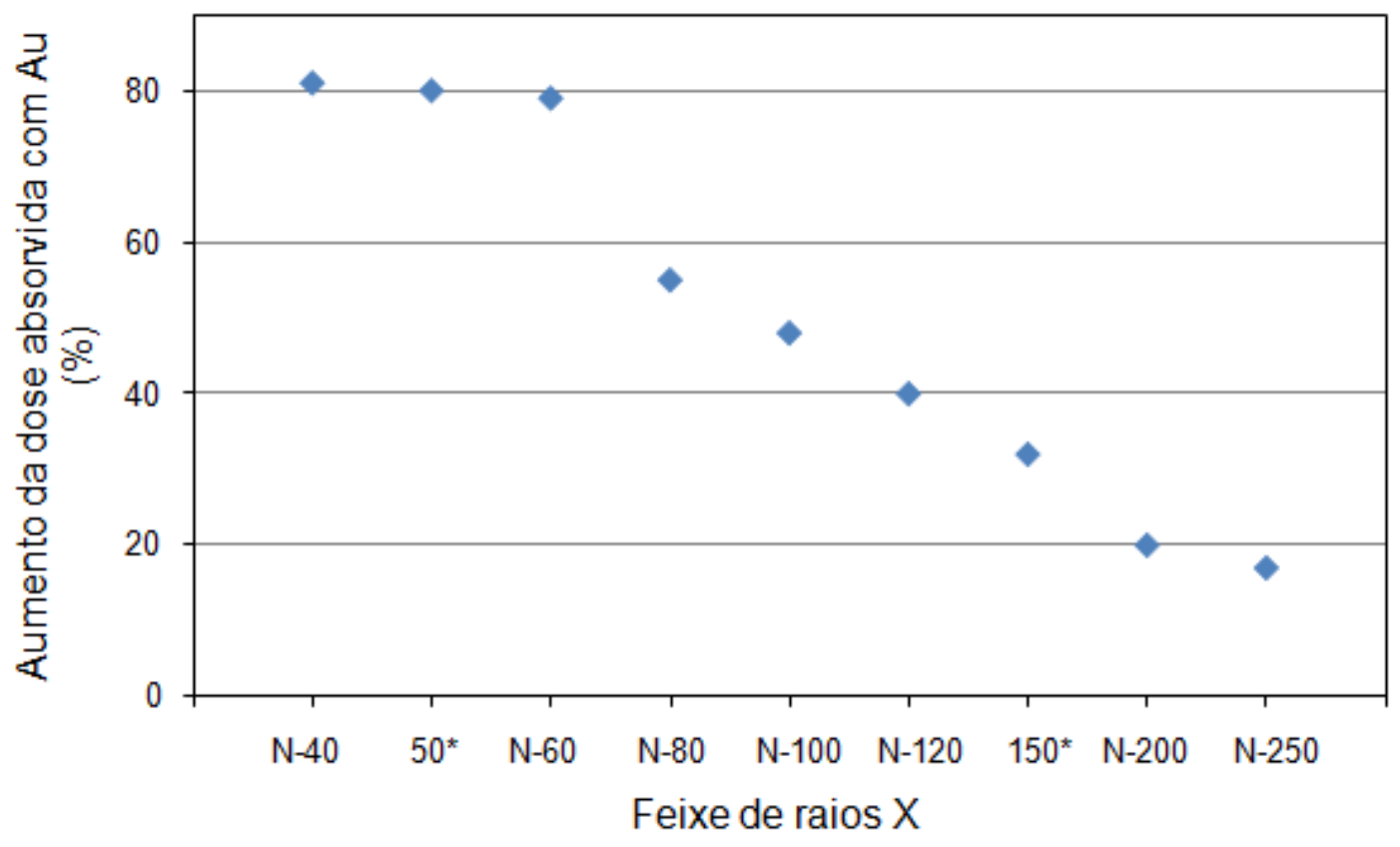

Figura 5.50 - Aumento da dose absorvida pela amostra de gel polimérico com 0,005 gAu/gGP em relação à dose absorvida pela amostra de gel polimérico puro.

Na Figura 5.50 é possível observar que o fator de aumento da dose absorvida diminui à medida que a energia dos raios $\mathrm{X}$ aumenta. Este resultado era esperado, pois, como discutido no item 3.2.1.2, a probabilidade de interação da radiação com a matéria por efeito fotoelétrico decresce com o aumento da energia do fóton incidente.

Tomando os espectros N-100 e 150*, o programa Geant 3.21 também permitiu analisar os espectros de raios $\mathrm{X}$ de saída, ou seja, após interagir com a amostra de gel polimérico puro e com a amostra de gel polimérico com 0,005 gAu/gGP. Estes resultados estão representados na Figura 5.51. 


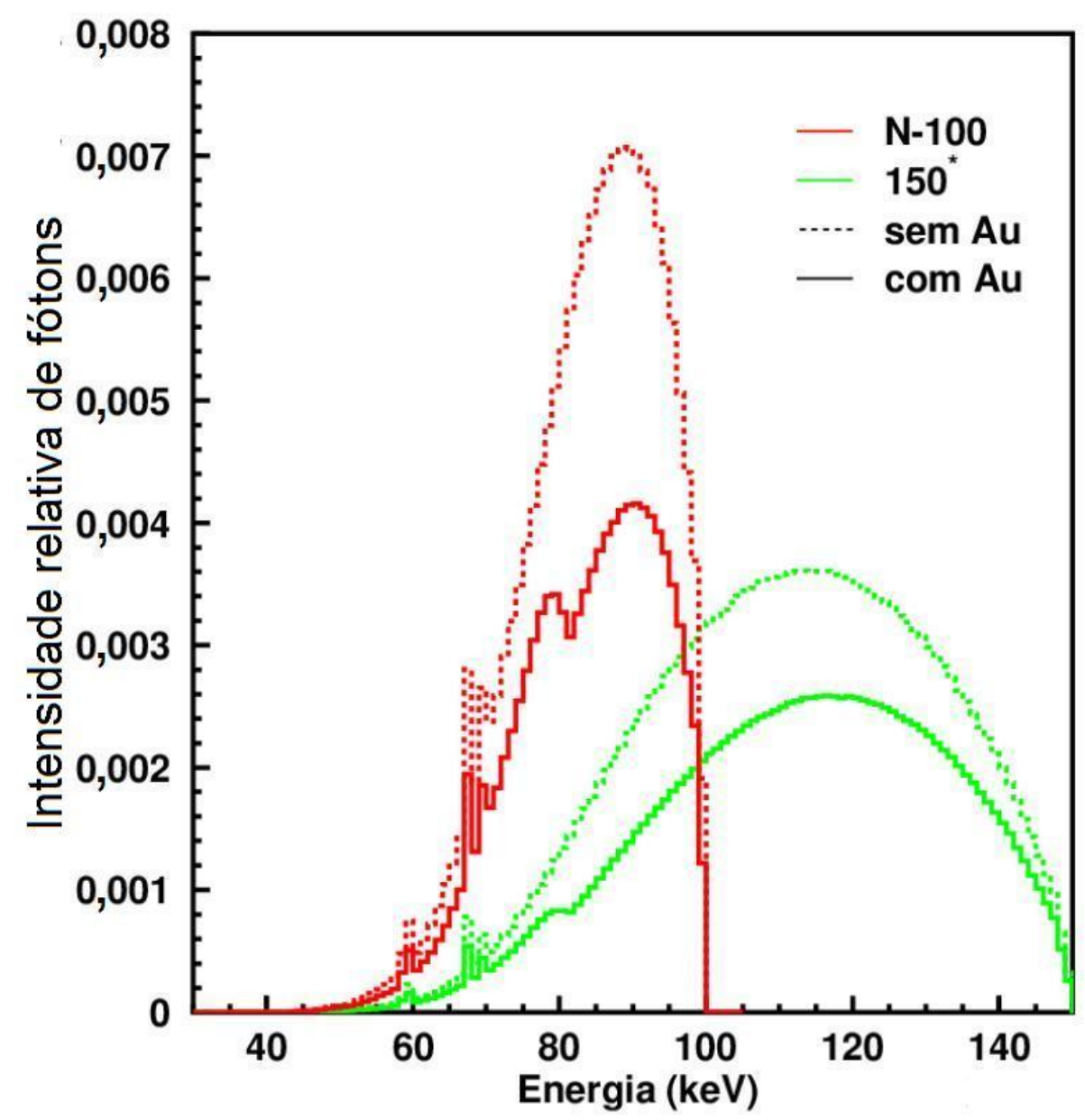

Figura 5.51 - Espectros dos feixes N-100 e 150* após interação com a amostra com ouro e sem ouro.

O principal resultado observado na Figura 5.51 é a intensa absorção de fótons na região de energias próximas à energia de ligação da camada $\mathrm{K}$ do átomo de ouro ( $81 \mathrm{keV})$. Além deste resultado, o espectro como um todo é mais absorvido pela amostra de gel polimérico com ouro, levando, consequentemente, a um aumento da dose absorvida pela amostra de gel polimérico com ouro em relação àquela de gel polimérico puro. 


\subsection{Gel Polimérico com Microesferas de Ouro}

$\mathrm{Na}$ fase final deste trabalho, as informações obtidas nas seções anteriores foram combinadas e dois experimentos foram realizados. Ambos experimentos tiveram como objetivo medir o aumento da dose absorvida causado pela presença de microesferas de ouro suspensas no gel polimérico.

\subsubsection{Irradiação com o Espectro de Raios X do Feixe 50*}

Para o primeiro experimento foram produzidas 56 amostras de gel polimérico em tubos de ensaio de vidro com $100 \mathrm{~mm}$ de comprimento e $12 \mathrm{~mm}$ de diâmetro interno, com uma parede de vidro de $2 \mathrm{~mm}$. O gel polimérico de metade das amostras foi misturado com microesferas de ouro com $1 \mu \mathrm{m}$ de diâmetro, de modo que a concentração ficasse $0,005 \mathrm{gAu} / \mathrm{gGP}$. Uma amostra com ouro e outra sem ouro estão representadas na Figura 5.52.

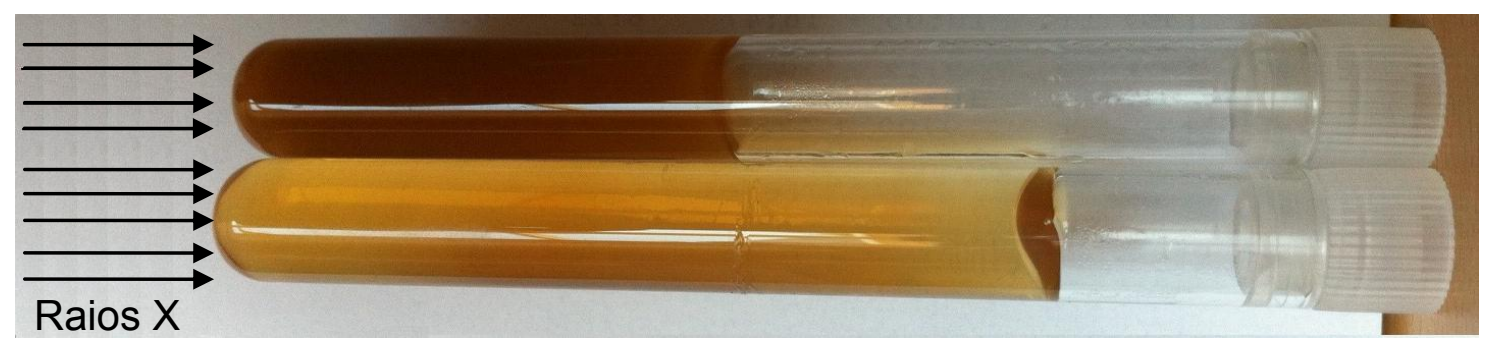

Figura 5.52 - Tubos de ensaio com gel polimérico puro e com gel polimérico com ouro, com irradiação pelo lado esquerdo.

As amostras foram irradiadas 1 dia após a produção utilizando o sistema Philips MCN $165 \mathrm{com}$ um feixe de raios $\mathrm{X}$ produzido por $50 \mathrm{kV}$ filtrado com $4 \mathrm{mmAl}\left(50^{*}\right)$, com doses absorvidas de 0,$25 ; 0,5 ; 0,75 ; 1 ; 2$ e 3 Gy. Para cada valor de dose absorvida foram consideradas 4 amostras sem ouro e 4 amostras com ouro. Oito amostras foram utilizadas como controle (4 sem ouro e 4 com ouro).

A avaliação das amostras foi realizada 1 dia após a irradiação utilizando a técnica de ressonância magnética nuclear. As medições foram realizadas tomando uma fatia de $1 \mathrm{~mm}$ de espessura, como representado na Figura 5.42 do item 5.6. A média dos valores de $R_{2}$ do grupo de controle $\left(R_{2}(0)\right)$ sem ouro foi subtraída dos valores médios de $R_{2}$ obtidos pelas amostras sem ouro irradiadas. 
Esta diferença foi relacionada à dose absorvida aplicada às amostras, obtendose, então, um gráfico de " $R_{2}-R_{2}(0)$ " versus dose absorvida (Figura 5.53). $O$ mesmo procedimento foi realizado com as amostras de gel polimérico com microesferas de ouro (Figura 5.53). Os gráficos obtidos foram ajustados por funções lineares.

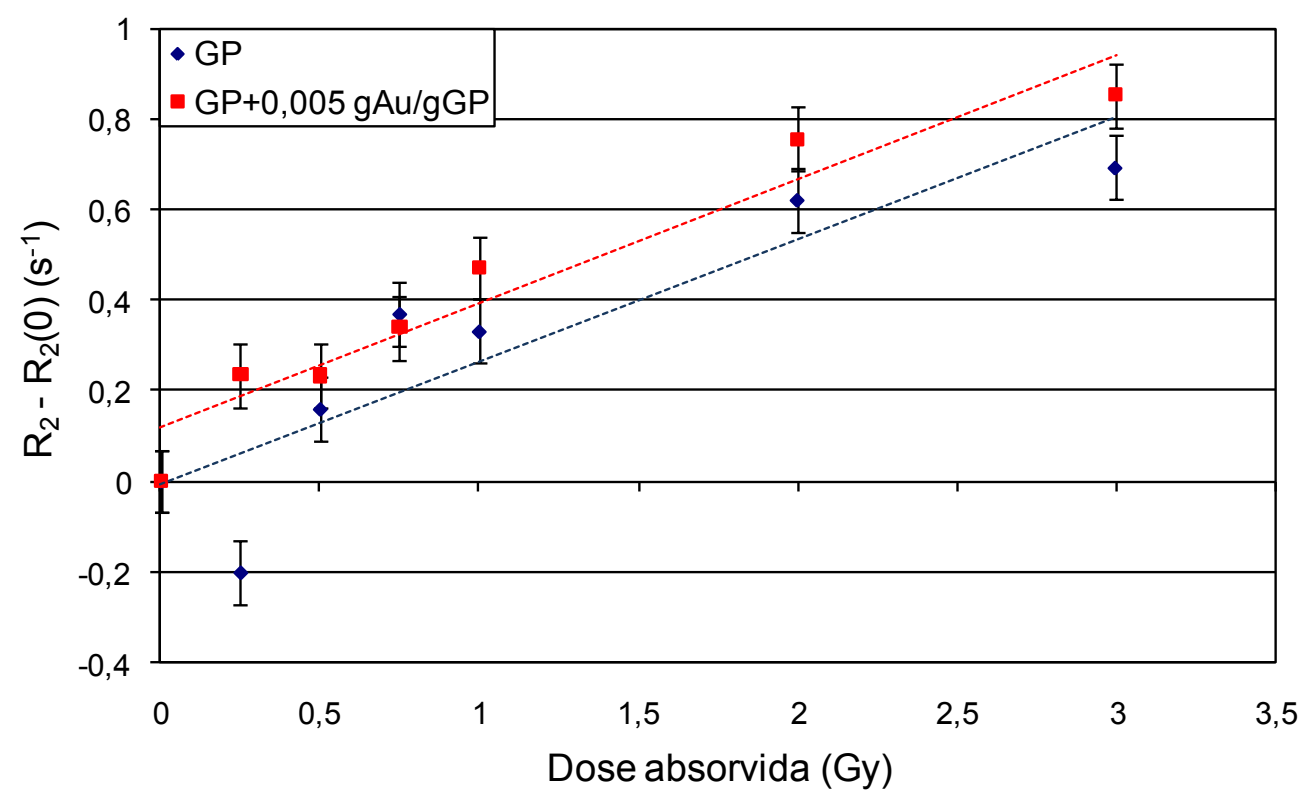

Figura 5.53 - Relações entre $R_{2}-R_{2}(0)$ e a dose absorvida das amostras de gel polimérico puro e com ouro para o feixe $50^{*}$.

A Figura 5.53 não mostra uma relação de aumento de dose absorvida pelas amostras com ouro, pois os ajustes lineares apresentam coeficientes angulares praticamente iguais, enquanto o esperado seria um aumento de até $80 \%$. No entanto, ao analisar os valores absolutos medidos de $R_{2}$, é possível observar um aumento na sensibilidade do gel polimérico com ouro em relação ao gel polimérico puro, como representado na Figura 5.54. 


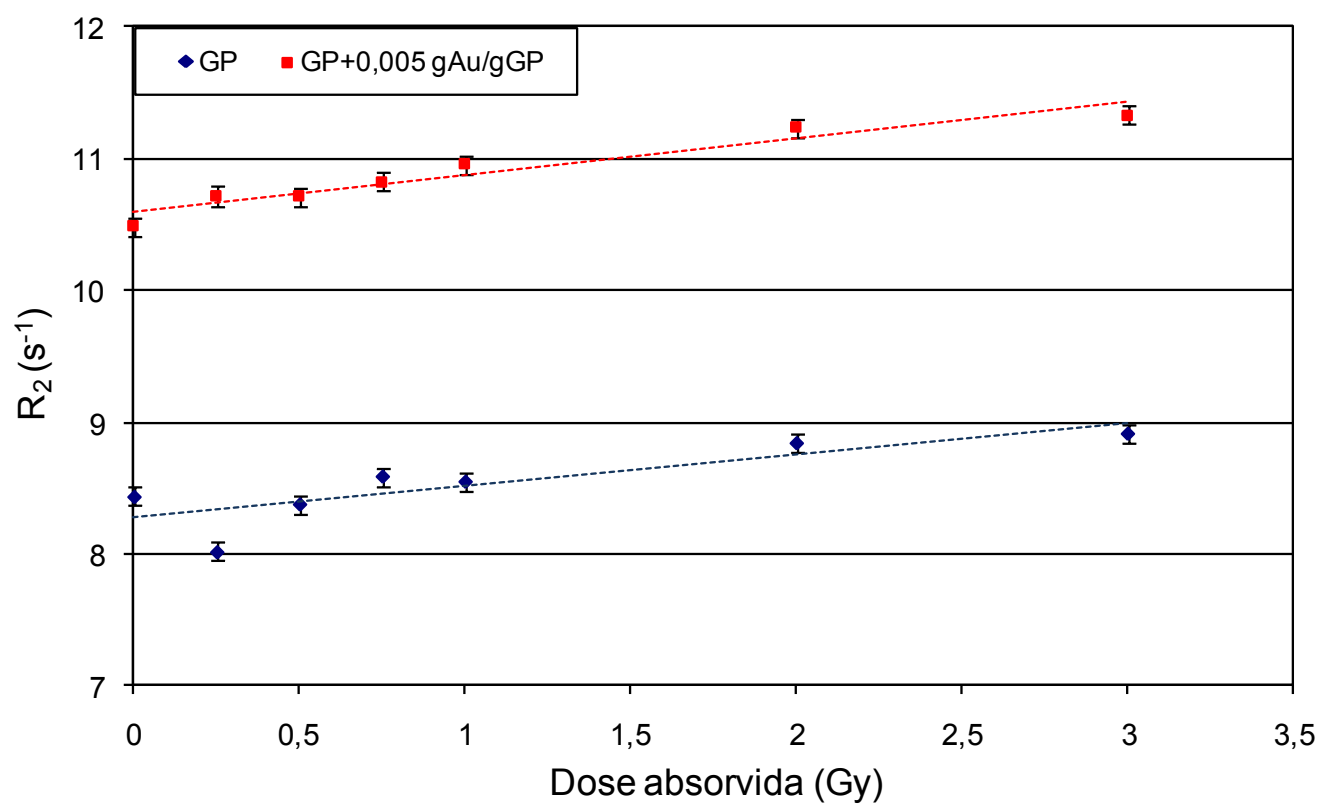

Figura 5.54 - Relações entre $R_{2}$ e a dose absorvida das amostras de gel polimérico puro e com ouro para o feixe $50^{*}$.

$\mathrm{O}$ espectro do feixe de raios $\mathrm{X}$ utilizado neste experimento $\left(50^{*}\right)$ possui energia média de $34 \mathrm{keV}$. Supondo que essa energia de $34 \mathrm{keV}$ seja absorvida por efeito fotoelétrico pela camada $L$ do átomo de ouro, com $\sim 13 \mathrm{keV}$ de energia de ligação, o alcance máximo do fotoelétron de energia $21 \mathrm{keV}(34 \mathrm{keV}-13 \mathrm{keV}$ ) seria de $\sim 10 \mu \mathrm{m}$ em água (aproximadamente igual ao gel polimérico) ou 1,5 $\mu \mathrm{m}$ em ouro. Como a interação de elétrons com a matéria consiste em um processo de perda gradativa da energia cinética conforme o elétron interage com os átomos do material atravessado, o elétron atinge o gel polimérico com uma energia muito baixa, dificultando a medição do aumento de dose.

No próximo caso, experimento utilizando o feixe $150^{*}$, esta limitação deve ser menos pronunciada.

\subsubsection{Irradiação com o Espectro de Raios X do Feixe 150*}

De maneira similar ao experimento anterior, o segundo experimento consistiu de um lote de 48 amostras de gel polimérico em tubos de ensaio de vidro com $100 \mathrm{~mm}$ de comprimento e $12 \mathrm{~mm}$ de diâmetro interno, com uma parede de vidro de $2 \mathrm{~mm}$. O gel polimérico de metade das amostras foi misturado 
com microesferas de ouro com aproximadamente $1 \mu \mathrm{m}$ de diâmetro, de modo que a concentração ficasse 0,005 gAu/gPG.

As amostras foram irradiadas 1 dia após a produção utilizando 0 sistema Philips MCN 165 com um feixe de raios $X$ produzido por $150 \mathrm{kV}$ filtrado com $4 \mathrm{mmAl}$ e $5 \mathrm{mmCu}\left(150^{*}\right)$, com doses absorvidas de 1; 2; 3; 5 e 6 Gy. Para cada valor de dose absorvida foram consideradas 4 amostras sem ouro e 4 amostras com ouro. Oito amostras foram utilizadas como controle (4 sem ouro e 4 com ouro).

A avaliação das amostras foi realizada 1 dia após a irradiação utilizando a técnica de ressonância magnética nuclear. As medições foram realizadas tomando uma fatia de $1 \mathrm{~mm}$ de espessura, como representado na Figura 5.42 do item 5.6. A média dos valores de $R_{2}$ do grupo de controle $\left(R_{2}(0)\right)$ sem ouro foi subtraída dos valores médios de $\mathrm{R}_{2}$ obtidos pelas amostras sem ouro irradiadas. Esta diferença foi relacionada à dose absorvida aplicada às amostras, obtendose, então, um gráfico de " $R_{2}-R_{2}(0)$ " versus dose absorvida (Figura 5.55). $O$ mesmo procedimento foi realizado com as amostras de gel polimérico com microesferas de ouro (Figura 5.55). Os gráficos obtidos foram ajustados por funções lineares.

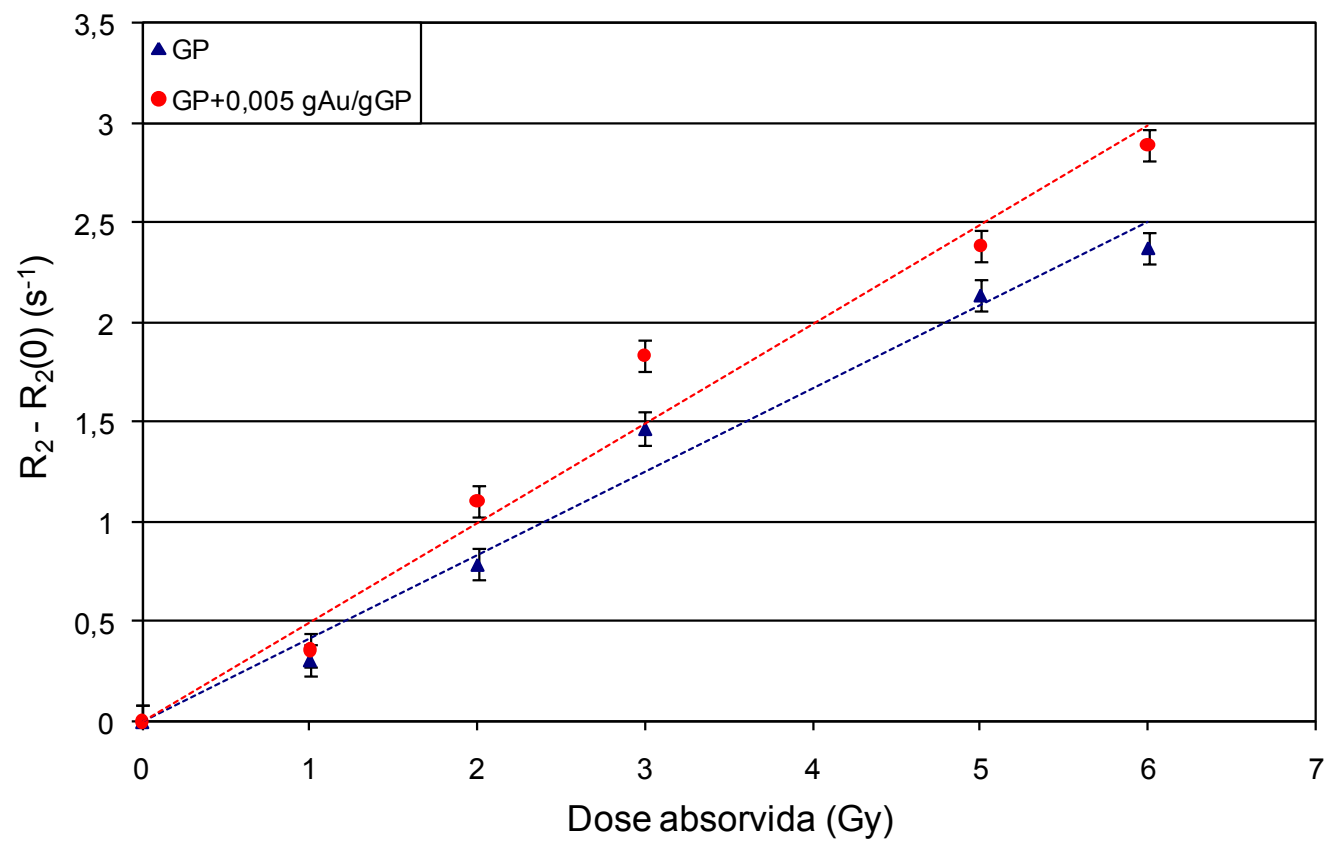

Figura 5.55 - Relações entre $R_{2}-R_{2}(0)$ e a dose absorvida das amostras de gel polimérico puro e com ouro para o feixe $150^{*}$. 
Na Figura 5.55 é possível observar que o coeficiente angular do ajuste linear das medições do gel polimérico com ouro é maior que o coeficiente angular do ajuste linear das medições do gel polimérico puro. Os coeficientes angulares obtidos foram 0,4985 para o gel polimérico com ouro e 0,417 para o gel polimérico puro. Isto significa que houve um aumento de $19,5 \%$ do coeficiente angular do gel polimérico com ouro em relação ao gel polimérico puro.

O aumento previsto pelos cálculos analíticos apresentados no item 5.6 e pelos resultados da simulação por método de Monte Carlo no item 5.7 foi de $32 \%$. O resultado do presente experimento está compatível com o esperado, uma vez que a energia depositada por aqueles elétrons de energias mais baixas são difíceis de mensurar, podendo então, representar esta diferença de $12 \%$ entre o aumento de dose previsto e o aumento de dose medido utilizando a técnica de dosimetria com gel polimérico.

Para fins de comparação com os resultados do item anterior, a Figura 5.56 representa os valores absolutos medidos de $R_{2}$ em relação à dose absorvida.

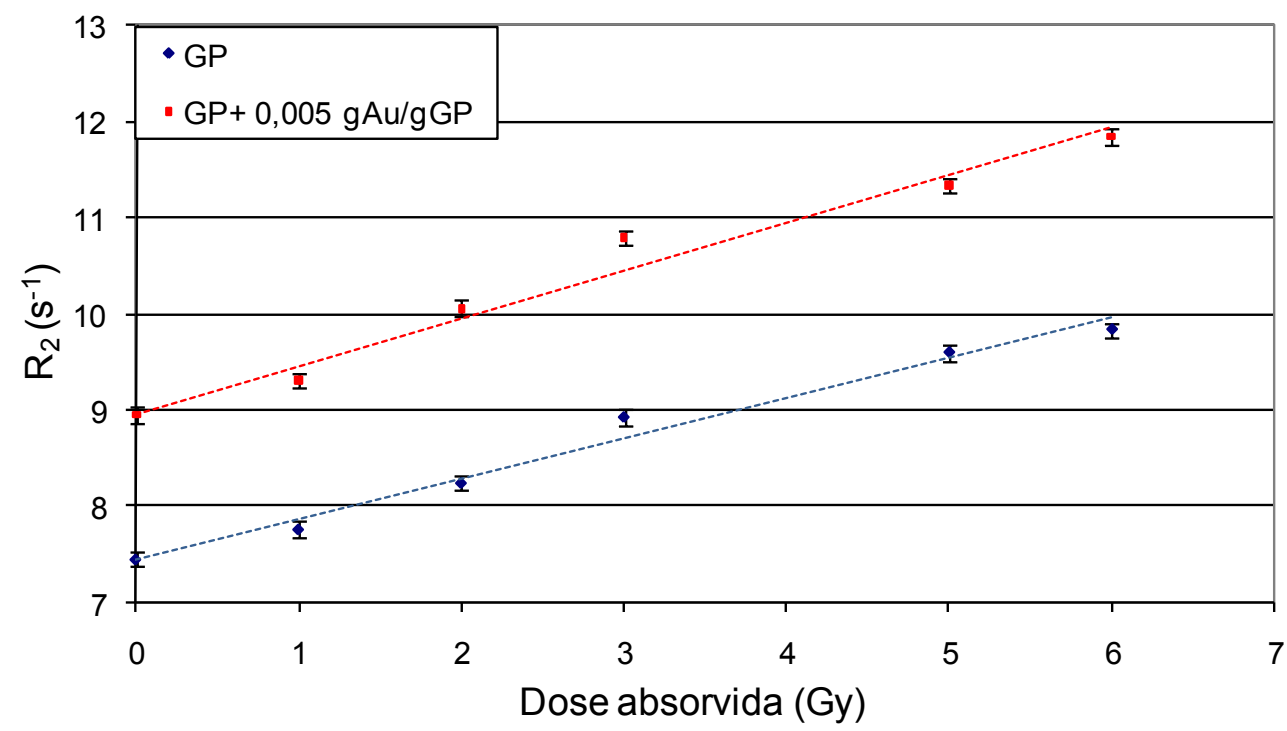

Figura 5.56 - Relações entre $R_{2}$ e a dose absorvida das amostras de gel polimérico puro e com ouro para o feixe $150^{*}$.

Como no item anterior, a Figura 5.56 também mostra um aumento na sensibilidade do gel polimérico com ouro em relação ao gel polimérico puro. Este aumento na sensibilidade do gel polimérico devido à presença de ouro não foi 
previsto, porém este efeito pode ser explorado em aplicações da técnica de ressonância magnética nuclear em contraste de imagens para diagnóstico.

As amostras de gel polimérico puro e com ouro irradiadas com 2 Gy foram analisadas em relação à profundidade. $A$ relação entre o valor de $R_{2}$ da amostra de gel polimérico com ouro e o valor de $R_{2}$ da amostra de gel polimérico puro foram comparadas com o fator de aumento de dose obtido a partir da simulação com o método de Monte Carlo. Estes valores estão representados na Figura 5.57 com os respectivos ajustes exponenciais.

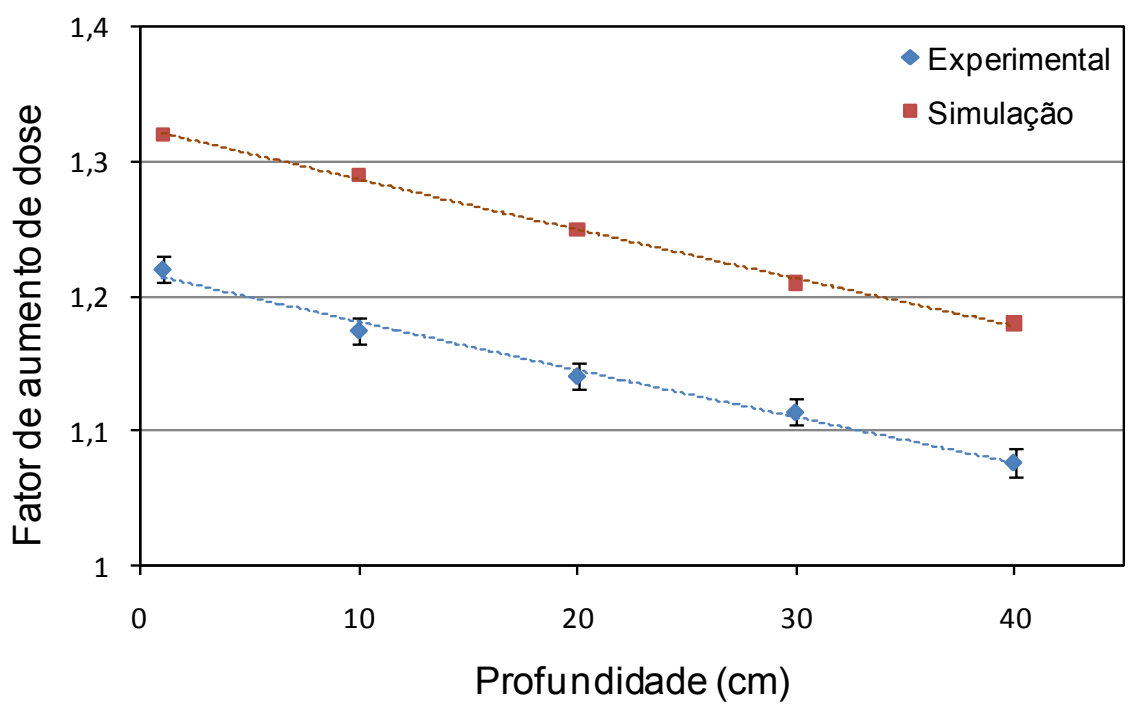

Figura 5.57 - Aumento da dose absorvida pela amostra de gel polimérico com $0,005 \mathrm{gAu} / \mathrm{gGP}$ em relação à dose absorvida pela amostra de gel polimérico puro, para o feixe $150^{*}$.

Os ajustes exponenciais dos resultados apresentados na Figura 5.57 foram $y=1,32 \cdot e^{-0,003 \cdot x}$ para os dados da simulação e $y=1,22 \cdot e^{-0,003 \cdot x}$ para os dados experimentais, sendo $\mathrm{x}$ a profundidade e y o fator de aumento de dose. Os expoentes obtidos $(0,003)$ mostram que as curvaturas dos ajustes exponenciais são iguais, apenas defasados por um fator multiplicativo. Esta defasagem se deve possivelmente à dificuldade em mensurar a energia depositada por aqueles elétrons de energias mais baixas. 


\section{CONCLUSÕES E CONSIDERAÇÕES FINAIS}

O objetivo principal proposto neste trabalho foi mensurar o aumento da dose absorvida causado pela presença de ouro em tecido mole devido ao efeito fotoelétrico. Para alcançar este objetivo foram realizadas diversas etapas.

Inicialmente foi elaborado um procedimento padrão para o uso do dosímetro de gel polimérico utilizando a técnica de ressonância magnética nuclear. Foram realizados estudos da resposta dos dosímetros sob irradiação com diferentes doses, taxas de dose e energias de fótons de raios $\mathrm{X}$ e raios gama. O comportamento do gel polimérico mostrou-se satisfatório para aplicação neste trabalho.

Os alcances em ouro e em água dos fotoelétrons emitidos pelo ouro foram estimados para energias da faixa de quilovoltagem. Baseado nesta estimativa foi realizado um experimento para medir o aumento de dose absorvida causado pela presença de folhas de ouro dentro do gel polimérico, cujo resultado foi negativo provavelmente devido à contaminação com oxigênio atmosférico impedindo a polimerização do gel. Após esta falta de êxito, foram realizados experimentos posicionando folhas de ouro adjacentes ao gel polimérico, perpendicularmente ao feixe de radiação. Os resultados indicaram que a presença das folhas de ouro sobre a superfície das amostras de gel polimérico causaram um aumento da dose absorvida na vizinhança destas folhas.

Diversos espectros de raios $\mathrm{X}$ foram simulados utilizando o programa SpekCalc para buscar espectros com maior intensidade na região da energia de ligação dos elétrons do átomo de ouro. Um espectro produzido por um potencial de $150 \mathrm{kV}$ filtrado com $4 \mathrm{mmAl}$ e $5 \mathrm{mmCu}$ (feixe 150*) foi escolhido. Este espectro apresenta uma intensidade elevada de fótons imediatamente acima da energia de ligação da camada $\mathrm{K}$ do átomo de ouro. Adicionalmente, foi escolhido um espectro produzido por um potencial de $50 \mathrm{kV}$ filtrado com $4 \mathrm{mmAl}$ (feixe $50^{*}$ ) para estudar o efeito dos elétrons da camada $L$ do átomo de ouro. 
Os coeficientes de absorção mássica de energia para o gel polimérico puro e para o gel polimérico com ouro foram calculados por meio da combinação linear dos coeficientes dos elementos químicos individuais que compõem o gel polimérico. Os coeficientes de absorção mássica de energia obtidos para o gel polimérico foram comparados com os coeficientes para o tecido mole padrão da ICRP, apresentando uma variação máxima de $6 \%$, conferindo, então, a característica de tecido-equivalência do gel polimérico.

Utilizando os coeficientes de absorção mássica de energia, calculou-se a dose absorvida em uma fatia de $1 \mathrm{~mm}$ de espessura adjacente à entrada do feixe de raios $X$ para as amostras de gel polimérico puro e gel polimérico com diferentes concentrações de ouro. Estes cálculos resultaram em um fator de aumento de dose absorvida na entrada da amostra de $32 \%$ para o feixe $150^{*} \mathrm{e}$ $76 \%$ para o feixe $50^{*}$, para a concentração de $0,005 \mathrm{gAu} / \mathrm{gGP}$.

Um programa de dosimetria utilizando o método de Monte Carlo foi utilizado para se deteminar a dose absorvida em amostras de gel polimérico puro e de gel polimérico com 0,005 gAu/gGP para diversos feixes de raios X. A simulação resultou em um aumento significativo da dose absorvida na entrada da amostra de gel polimérico com 0,005 gAu/gGP em relação à dose absorvida pelo gel polimérico puro para todos os feixes de raios $X$ considerados.

Os resultados da simulação também permitiram analisar os espectros de raios $X$ de saída, após a interação com a amostra de gel polimérico (puro e com 0,005 gAu/gGP). Os espectros de saída apresentaram uma intensa absorção de fótons na região de energias próximas à energia de ligação da camada $\mathrm{K}$ do átomo de ouro ( $\sim 81 \mathrm{keV})$. Além disso, o espectro como um todo foi mais absorvido pela amostra de gel polimérico com ouro.

Os experimentos com gel polimérico misturado com 0,005 gAu/gGP irradiados com os feixes $50^{*}$ e $150^{*}$ apresentaram um aumento da sensibilidade na resposta utilizando a técnica de ressonância magnética nuclear. As amostras com ouro irradiadas com o feixe $50^{*}$ não apresentaram aumento de dose absorvida em relação àquelas sem ouro. Isto ocorreu pois os fotoelétrons emitidos pelo ouro possuem energias baixas, de modo que o alcance é curto, dificultando a medição do aumento de dose utilizando gel polimérico. 
No caso das amostras com ouro irradiadas com o feixe de $150^{*}$ houve um aumento de $19,5 \%$ da dose absorvida em relação àquelas sem ouro. Este resultado está compatível com aqueles obtidos pelo método de Monte Carlo (32\%) e pelos cálculos analíticos com os coeficientes de absorção mássica de energia (32\%), uma vez que a energia depositada por aqueles fotoelétrons de energias mais baixas são difíceis de mensurar, podendo, então, representar esta diferença de $12 \%$ entre o aumento de dose previsto e o aumento de dose medido utilizando a técnica de dosimetria com gel polimérico. Confirmando esta hipótese, as medições em função da profundidade também apresentaram uma defasagem de $10 \%$ em relação aos resultados obtidos pelo método de Monte Carlo.

Para a continuidade deste trabalho e para a futura aplicação em seres humanos, é necessário desenvolver métodos (químicos ou cirúrgicos) para armazenar as partículas de ouro no tumor, sem que haja deposição de ouro em tecido saudável. Também seria recomendável realizar testes in vivo utilizando camundongos. 


\section{REFERÊNCIAS}

AFONSO, L.C.; SCHÖFER, F.; HOESCHEN, C. 2009. Absorbed dose enhancement caused by gold particles in polymer gels. Proceedings of World Congress on Medical Physics, September 2009, Munich, Germany.

AFONSO, L.C.; GREITER, M.; SCHÖFER, F.; HOESCHEN, C. 2010. Dose enhancement caused by gold particles on polymer gels. Proceedings of the 6th International Conference on 3D Radiation Dosimetry, August 2010, Hilton Head Island, USA. pp. 457-461.

ALEXANDER, P.; CHARLESBY, A.; ROSS, M. 1954. The degradation of solid polymethyl-methacrylate by ionizing radiations. Proceedings of the Royal Society, pp. 392-404.

ATTIX, F.H. 2005. Introduction to Radiological Physics and Radiation Dosimetry. Wiley-VCH Verlag GmbH \& Co., Weinheim.

BALDOCK, C.; BURFORD, R.P.; BILLINGHAM, N.; WAGNER, G.S.; PATVAL, S.; BADAWI, R.D.; KEEVIL, S.F. 1998. Experimental procedure for the manufacture and calibration of polyacrylamide gel (PAG) for magnetic resonance imaging (MRI) Radiation Dosimetry. Physics in Medicine and Biology, 43, pp. 695-702.

BALDOCK, C. 2006. Historical overview of the development of gel dosimetry: a personal perspective. Fourth International Conference on Radiotherapy Gel Dosimetry. Journal of Physics: Conference Series 56, pp. 14-22.

BALDOCK, C.; DE DEENE, Y.; DORAN, S.; IBBOTT, G.; JIRASEK, A.; LEPAGE, M.; MCAULEY, K.B.; OLDHAM, M.; SCHREINER, L.J. 2010. Polymer gel dosimetry. Topical review. Physics in Medicine and Biology, 55, pp. R1-R63.

BAYREDER, C.; GEORG, D.; MOSER, E.; BERG, A. 2006. Basic investigations on the performance of a normoxic polymer gel with tetrakis-hydroxy-methylphosphonium chloride as an oxygen scavenger: Reproducibility, Accuracy, Stability, and Dose Rate Dependence. Medical Physics, 33(7), pp. 2506-2518.

BERG, A. 2009. Magnetic-resonance-imaging based polymer gel dosimetry: methodology, spatial resolution, applications. Proceedings of World Congress on Medical Physics, September 2009, Munich, Germany.

Bruker Biospin $\mathrm{GmbH}, 2003$. Avance ${ }^{\mathrm{tm}}$. Beginners Guide. Ettlingen, Germany.

BRUN, R.; BRUYANT, F.; MAIRE, M.; MCPHERSON, A.C.; ZANARINI, P. 1987. Geant 3. CERN Data Handling Division, DDD/EE/84-1.

COWAN, G. 1998. Statistical Data Analysis. Clarendon Press, Oxford. 
DE DEENE, Y.; HURLEY, C.; VENNING, A.; MATHER, M.; HEALY, B.; WHITTAKER, A.; BALDOCK, C.A. 2002. A basic study of some normoxic polymer gel dosimeters. Physics in Medicine and Biology, 47, pp. 3441-3463.

HOECKER, F.E.; WATKINS, I.W. 1958. Radiation polymerization dosimetry. International Journal of Applied Radiation and Isotopes, 3, pp. 31-36.

HORNAK, J.P. The Basics of MRI (c) 1996-2010. Livro eletrônico. http://www.cis.rit.edu/htbooks/mri/ , acesso em 15/06/2011.

ICRP, International Commission on Radiological Protection. Basic Anatomical and Physiological Data for Use in Radiological Protection Reference Values. Publication 23, 2002.

ICRU, International Commission on Radiation Units and Measurements. Fundamental Quantities and Units for lonizing Radiation. Report 60, 2007.

ISO, International Organization for Standardization. ISO 4037. X and Gamma Reference Radiations for Calibrating Dosemeters and Dose Ratemeters and for Determining their Response as a Function of Photon Energy. PART 1: Characteristics of the Radiation and their Methods of Production. Jan. 1994.

INCA, Instituto Nacional do Câncer. website: http://www.inca.gov.br/conteudo view.asp?ID=100 , acesso em 7/06/2011.

JONES, B.L.; KRISHNAN, S.; CHO, S.H. 2010. Estimation of microscopic dose enhancement factor around gold nanoparticles by Monte Carlo calculations. Medical Physics, 37(7), pp. 3809-3816.

KNIGHT, K.R.; MCCANN, J.J.; VANDERKOLK, C.A.; COE, S.A.; O'BRIEN, B.MCC. 1990. The redistribution of collagen in expanded pig skin. British Journal of Plastic Surgery, 43, pp. 565-570.

KRAUSE, M.O. 1979. Atomic Radiative and Radiationless Yields for $\mathrm{K}$ and $\mathrm{L}$ Shells. Journal of Physical and Chemical Reference Data. 8(2), pp. 307-327.

LEO, W.R. 1987. Techniques for Nuclear and Particle Physics Experiments. Springer-Verlag Berlin, Heidelberg.

LUXTON, G.; JOZSEF, G. 1999. Radial dose distribution, dose to water and dose rate constant for monoenergetic photon point sources from $10 \mathrm{keV}$ to $2 \mathrm{MeV}$ : EGS4 Monte Carlo model calculation. Medical Physics, 26, pp. 2531-2538.

MARYANSKI, M.J.; GORE, J.C.; SCHULZ, R.J. 1992. 3-D Radiation dosimetry by MRI: solvent proton relaxation enhancement by radiation-controlled polymerisation and cross-linking in gels. Proceedings of International Society of Magnetic Resonance in Medicine. 
MARYANSKI, M.J.; GORE, J.C.; KENNAN, R.P.; SCHULZ, R.J. 1993. NMR relaxation enhancement in gels polymerized and cross-linked by ionizing radiation: a new approach to 3D dosimetry by MRI. Magnetic Resonance Imaging, 11, pp. 253-258.

MARYANSKI, M.J.; SCHULZ, R.J.; IBBOTT, G.S.; GATENBY, J.C.; XIE, J.; HORTON, D.; GORE, J.C. 1994a. Magnetic resonance imaging of radiation dose distributions using a polymer-gel dosimeter. Physics in Medicine and Biology, 39 , pp. $1437-1455$.

MARYANSKI, M.J.; GORE, J.C.; SCHULZ, R.J. 1994b. Three-dimensional detection, dosimetry and imaging of an energy field by formation of a polymer in a gel. US Patent 5,321,357.

MCMAHON, S.J.; MENDENHALL, M.H.; JAIN, S.; CURRELL, F. 2008. Radiotherapy in the presence of contrast agents: a general figure of merit and its application to gold nanoparticles. Physics in Medicine and Biology, 53, pp. 5635-5651.

NGUYEN, Q.; FANOUS, M.A.; KAMM, L.H.; KHALILI, A.D.; SCHUEPP, P.H.; ZARKADAS, C.G. 1986. Comparison of the amino acid composition of two commercial porcine skins (rind). Journal of Agricultural and Food Chemistry, 34 , pp. $565-572$.

NIST - ESTAR, 1998, National Institute of Standards and Technology. StoppingPower and Range Tables for Electrons, Protons, and Helium lons. http://www.nist.gov/pml/data/star/index.cfm , acesso em 22/07/2011.

NIST - XCOM, 1998, National Institute of Standards and Technology. XCOM: Photon Cross Sections Database. http://www.nist.gov/pml/data/xcom/index.cfm , acesso em 22/07/2011.

NORMAN, A.; ADAMS, F.H.; RILEY, R.F. 1978. Cytogenetic effects of contrast media and triiodobenzoic acid derivatives in human lymphocytes. Radiology, 129, 199-203.

PODGORSAK, E.B. 2005. Radiation Oncology Physics: A Handbook for Teachers and Students. International Atomic Energy Agency. Vienna.

POLUDNIOWSKI, G.; LANDRY, G.; DEBLOIS, F.; EVANS, P.M.; VERHAEGEN, F. 2009. SpekCalc: a program to calculate photon spectra from tungsten anode $X-$ ray tubes. Physics in Medicine and Biology, 54(19), pp. 433-438.

SCHABERLE, F.A.; SILVA, N.C. Introdução à Física da Radioterapia. http://www.fsc.ufsc.br/ canzian/intrort/radioterapia.html, acesso em $7 / 06 / 2011$.

TURNER, J.E., 2007. Atoms, Radiation, and Radiation Protection. Terceira Edição. Wiley-VCH Verlag GmbH \& Co., Weinheim. 
YE, S.J.; BREZOVICH, I.A.; PAREEK, P.; NAQVI, S.A. 2004. Benchmark of PENELOPE code for low-energy photon transport: dose comparisons with MCNP4 and EGS4. Physics in Medicine and Biology, 49, pp. 387-397. 
Anexo: Trabalhos publicados em anais de congressos. 


\title{
Absorbed dose enhancement caused by gold particles in polymer gels
}

\author{
L.C. Afonso, F. Schöfer and C. Hoeschen \\ Institute of Radiation Protection, Helmholtz Zentrum, Munich, Germany
}

\begin{abstract}
Previous studies showed that the presence of high- $Z$ materials adjacent to soft tissues, when submitted to irradiation, enhances the absorbed dose in these tissues. This effect is due to the outscattering of photoelectrons from the high- $\mathrm{Z}$ materials. The aim of the present work was to measure the absorbed dose enhancement caused by the presence of different concentrations of gold particles in polymeric gels.
\end{abstract}

Keywords - polymer gel, three-dimensional dosimetry, NMR, gold particles.

\section{INTRODUCTION}

It is known from previous studies that the presence of high-Z materials adjacent to soft tissues, when submitted to irradiation, enhances the absorbed dose in these soft tissues. This is due to the outscattering of photoelectrons from the high-Z materials. [1,2]

The concern about the effect of dose enhancement arose after discovering that oral cavity radiation therapy treatments on patients that had golden tooth replacements resulted in an increased damage of the soft tissues surrounding these gold replacements. It was found that the absorbed dose could reach an enhancement of two orders of magnitude in the microscope vicinity of gold replacements, when exposing the patient to diagnostic X-ray examinations. [1]

In experiments with human lymphocytes covered with a thin gold film and then irradiated with diagnostic X-ray beams, it was found that the dose absorbed by the cells was increased by a factor of 45.4. The number of chromosomic aberrations was also in accordance to this dose enhancement. [2]

Thereby, the aim of the present work was to measure the absorbed dose enhancement caused by the presence of different concentrations of gold particles in polymeric gels, which the main characteristic is the soft tissue equivalence. The polymer gel dosimetry technique allows the absorbed dose to be measured with high three-dimensional resolution, which is essential to analyze the enhancement distribution due to photoelectrons outscattered by the gold particles.

\section{DOSIMETRIC METHOD}

\section{A. Polymer gel}

Polymeric Systems began to be studied in relation to their dosimetric capacity in the fifties, by evaluating the radiation effects in poly-methyl-methacrylate [3]; and studying radio-induced polymerization in liquids [4]. Later, works combined these properties as the first polymer gel developed by Maryanski et al [5, 6], which had formulation that was composed by acrylamide, bis-acrylamide and nitrous oxide diluted in an agarose aqueous matrix. The polymerization reaction in this gel was based on the crosslinking of acrylamide monomers.

Further gel formulations were developed by changing the gel matrix (agarose to gelatin), the monomer (acrylamide to methacrylic acid, for example), etc. However, the working principle of any polymer gel dosimeter is based on the radiation-induced polymerization of the monomers present in the gel. When the gel is irradiated, the water radiolysis is induced. The polymerization process is mainly initiated by free radical reactions. The polymerization degree depends on the number of free radicals created by the incident radiation, which depends on the absorbed dose; therefore, originating spatial dose resolution. $[7,8]$

The polymer gel used for this work is known as MAGIC (Methacrylic Ascorbic in Gelatin Initiated by Copper), foremost developed by Fong et al [9]. Its formulation is composed by methacrylic acid, ascorbic acid, gelatin and copper sulfate. As the gel polymerization process is initiated by free radical reactions, and molecular oxygen is an efficient "scavenger" of free radicals, its presence inhibits gel polymerization. Therefore, the ascorbic acid, in a process initiated by the copper sulfate, is responsible for capturing oxygen in the gel solution.

\section{B. Nuclear Magnetic Resonance}

Nuclear Magnetic Resonance (NMR) is a technique that allows determining the properties of a substance by correlating the absorbed energy and the frequency, in the radiofrequency range of the electromagnetic spectrum. The technique uses the transitions between the rotational energy 
levels of the compound's nucleus (atoms or ions) contained in the sample. This occurs necessarily under a magnetic field influence and under the concomitant irradiation with radiofrequency waves.

In dosimetric gels, the scanning process is based on the measurement of the longitudinal and the transversal relaxation rates (R1 and R2), from which dose maps may be determined. Traditionally, the corresponding relaxation times (T1 and T2) are measured, then, the rates are determined. The longitudinal relaxation time, $\mathrm{T} 1$, or spin-net relaxation time, is associated with the interaction of the spins with the net. The longitudinal relaxation is responsible for the return of the magnetization to the thermal equilibrium state. The transversal relaxation time, T2, or spin-spin relaxation time, is associated to the interactions between the spins. Due to the transversal relaxation, the magnetic moments lose coherence, which makes them precess with lightly different frequencies. The relaxation times are measured by applying radiofrequency pulses to excite the magnetization of the spin system, and then, samples are collected during the return to equilibrium. The transversal relaxation time ( $\mathrm{T} 2=1 / \mathrm{R} 2)$ is measured by adjusting the collected data of the transversal relaxation curve after excitation. $[10,11]$

\section{METHODOLOGY}

The samples of polymeric gels (30 ml flasks), with and without gold particles were irradiated with X-rays and $\gamma$ rays beams. Then, these samples were scanned with a Nuclear Magnetic Resonance system and the resultant transversal relaxation rate (T2) distribution was analyzed and associated to the absorbed dose.

Further results are under analysis.

\section{REFERENCES}

1. Regulla D, Friedland W, Hieber L et al (2000) Spatially Limited Effects of Dose and LET Enhancement Near Tissue/Gold Interfaces at Diagnostic X Ray Qualities. Radiation Protection Dosimetry, 90, Nos 1-2, pp. 159-163

2. Regulla D, Panzer W, Schmid E et al (2001) Detection of Elevated RBE in Human Lymphocytes Exposed to Secondary Electrons Released from X-Irradiated Metal Surfaces. Ratiation Research, 155, pp. 744-747

3. Alexander P, Charlesby A, Ross M (1954) The Degradation of Solid Polymethyl-methacrylate by Ionizing Radiations. Proceedings of the Royal Society, pp. 392-404

4. Hoecker FE, Watkins IW (1958) Radiation Polymerization Dosimetry. International Journal of Applied Radiation and Isotopes, 3, pp. 31-36

5. Maryanski MJ, Gore JC, Schulz RJ (1992) 3-D Radiation Dosimetry by MRI: Solvent Proton Relaxation Enhancement by RadiationControlled Polymerisation and Cross-Linking in Gels. Proc. Intl. Soc. Mag. Reson. Med.

6. Maryanski MJ, Gore JC, Kennan RP et al (1993) NMR Relaxation Enhancement in Gels Polymerized and Cross-Linked by Ionizing Radiation: a New Approach to 3D Dosimetry by MRI. Magn. Reson. Imaging, 11, pp. 253-258

7. Berg A, Ertl A, Moser E (2001) High Resolution Polymer Gel Dosimetry by Parameter Selective MR-Microimaging on a Whole Body Scanner at 3 T. Medical Physics, 28(5), pp. 833-843

8. Bayreder C, Georg D, Moser E et al (2006) The spatial resolution in dosimetry with normoxic polymer-gels investigated with the dose modulation transfer approach. Medical Physics, 35(5), pp. 1756-1769

9. Fong PM, Keil DC, Does MD, Gore JC (2001) Polymer Gels for Magnetic Resonance Imaging of Radiation Dose Distributions at Normal Room Atmosphere. Physics in Medicine and Biology, 46, pp. 3105-3113

10. Baustert IC, Oldham M, Smith TAD et al (2000) Optimized MR Imaging for Polyacrylamide Gel Dosimetry. Physics in Medicine and Biology, 45, pp. 847-858

11. McJury M, Oldham M, Cosgrove VP et al (2000) Radiation Dosimetry Using Polymer Gels: Methods and Applications. The British Journal of Radiology, 73, pp. 919-929

Author: L. C. Afonso

Institute: Helmholtz Zentrum München

Street: Ingolstaedter Landstrasse 1

City: Neuherberg

Country: Germany

Email: Luciana.afonso@helmholtz-muenchen.de 


\title{
Dose enhancement caused by gold foils on polymer gels
}

\author{
L.C. Afonso; M. Greiter; F. Schoefer; C. Hoeschen \\ Helmholtz Center Munich, Ingolstaedter Landstrasse 1, 85764 Neuherberg, Germany \\ luciana.afonso@helmholtz-muenchen.de
}

\begin{abstract}
The presence of high- $Z$ materials adjacent to soft tissues, when submitted to irradiation, locally enhances the absorbed dose in these tissues. This effect is due to the outscattering of photoelectrons from the high- $\mathrm{Z}$ materials. The aim of the present work was to measure the absorbed dose enhancement caused by gold foils on polymeric gel.
\end{abstract}

\section{Introduction}

Previous studies showed that the presence of high- $Z$ materials adjacent to soft tissues, when submitted to irradiation, enhances the absorbed dose in these soft tissues. Such effects happen due to the outscattering of photoelectrons from the high- $\mathrm{Z}$ materials. $[1,2,3]$

The concern about the effect of dose enhancement arose after discovering that oral cavity radiation therapy treatments on patients that had golden tooth replacements resulted in an increased damage of the soft tissues surrounding these gold replacements. It was found that the absorbed dose could reach an enhancement of two orders of magnitude in the microscopic vicinity of gold replacements, when exposing the patient to diagnostic X-ray examinations. [1]

In experiments with human lymphocytes covered with a thin gold film and then irradiated with diagnostic X-ray beams, it was found that the dose absorbed by the cells was increased by a factor of 45.4. The number of chromosomic aberrations was also in accordance to this dose enhancement. [2]

Thereby, the aim of the present work was to measure the absorbed dose enhancement caused by the presence of gold foils on the surface of polymeric gel samples, whose main characteristic is the soft tissue equivalence. The polymer gel dosimetry associated to the Nuclear Magnetic Resonance technique allows the absorbed dose to be measured with high three-dimensional resolution, providing the spatial distribution of the dose enhancement caused by the photoelectrons outscattered from the gold foil.

\section{Dosimetric Method}

In order to resolve local dose distributions in soft tissue equivalent material close to high-Z materials polymer gel dosimetry was used.

Polymeric systems were first studied in relation to their dosimetric capacity in the fifties, by evaluating the radiation effects in poly-methyl-methacrylate [4]; and studying radioinduced polymerization in liquids [5]. Later works combined these properties as the first polymer gel developed by Maryanski et al [6,7], which used a formulation that was composed by acrylamide, bisacrylamide and nitrous oxide diluted in an agarose aqueous matrix. 
Further gel formulations were developed by changing the gel matrix (agarose to gelatin), the monomer (acrylamide to methacrylic acid, for example), etc. However, the working principle of any polymer gel dosimetry is based on the radiation-induced polymerization of the monomers present in the gel. When the gel is irradiated, water radiolysis is induced. The polymerization process is mainly initiated by free radical reactions. The polymerization degree depends on the number of free radicals created by the incident radiation, which depends on the absorbed dose; therefore, originating spatial dose resolution. [8, 9]

The polymer gel used for this work is known as MAGIC (Methacrylic Ascorbic in Gelatin Initiated by Copper), foremost developed by Fong et al [10]. Its formulation is composed by methacrylic acid, ascorbic acid, gelatin and copper sulfate. As the gel polymerization process is initiated by free radical reactions, and molecular oxygen is an efficient "scavenger" of free radicals, its presence inhibits gel polymerization. The ascorbic acid, in a process initiated by the copper sulfate, is responsible for capturing oxygen in the gel solution.

\section{Methodology}

\subsection{Polymer Gel Preparation}

The polymer gel samples used in this study were produced using deionized water, gelatin (swine skin, 300 bloom, Sigma Aldrich), methacrylic acid (99\%, Sigma Aldrich), copper (II) sulfate penta-hydrate, and ascorbic acid (extra pure, Merck).

At room temperature, $140 \mathrm{~g}$ of gelatin were added to $700 \mathrm{ml}$ of water. After the water has been absorbed by the gelatin, the mixture was heated to $55{ }^{\circ} \mathrm{C}$ in a water bath and was let to liquefy for approximately 1 hour. The ascorbic acid $(0.3522 \mathrm{~g})$ was added; then, copper (II) sulfate (0.025 g); and finally the methacrylic acid. After each reagent has been added, the gel was mixtured thoroughly. The mixture was kept in the water bath for more approximately 1 hour. Afterwards the gel was poured into 12 glasses $(50 \mathrm{ml}, 5 \mathrm{~cm}$ of diameter), which were previously immersed in an oxygen scavenger solution (water, ascorbic acid and copper (II) sulfate) for 6 hours. The filled glasses were covered with cling film $(14 \pm 2 \mu \mathrm{m})$ and were positioned upside down in an oxygen scavenger solution, in order to prevent oxygen penetration through the cling film into the polymer gel.

\subsection{Irradiation}

The polymer gel samples were irradiated 24 hours after production. A Philips Industrial X-rays (now Yxlon International) system with a MCN 323 tube was used to generate x-rays at $200 \mathrm{kV}, 15 \mathrm{~mA}$ filtered with $0.96 \mathrm{~mm} \mathrm{Cu}$ and $4.05 \mathrm{~mm} \mathrm{Al}$. A PTW ionization chamber (type 23361, $30 \mathrm{~cm}^{3}$ sensitive volume) coupled with a PTW Unidos electrometer was used for the dose measurement.

Gold foils (thickness about $100 \mathrm{~nm}$ ) were placed on the cling film surface of each sample, covering half of the surface area (Figure 1). The polymer gel samples were individually positioned with the cling film surface perpendicular to the beam at the reference point at $70 \mathrm{~cm}$ from the $\mathrm{x}$-ray focal spot (Figure 2). Irradiation doses, measured as air kerma at the reference point, were 0, 1, 2, 3, 4, and 5 Gy, attained at a constant dose rate of $4.52 \mathrm{mGy} / \mathrm{s}$ ( $\pm 1.5 \%$ combined uncertainty; including positioning, calibration factors, instrumental stability, and corrections for air density). Two samples per dose were used.

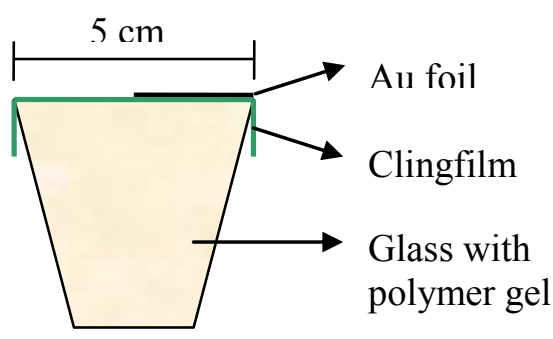

Figure 1: Schematic representation of a sample. 


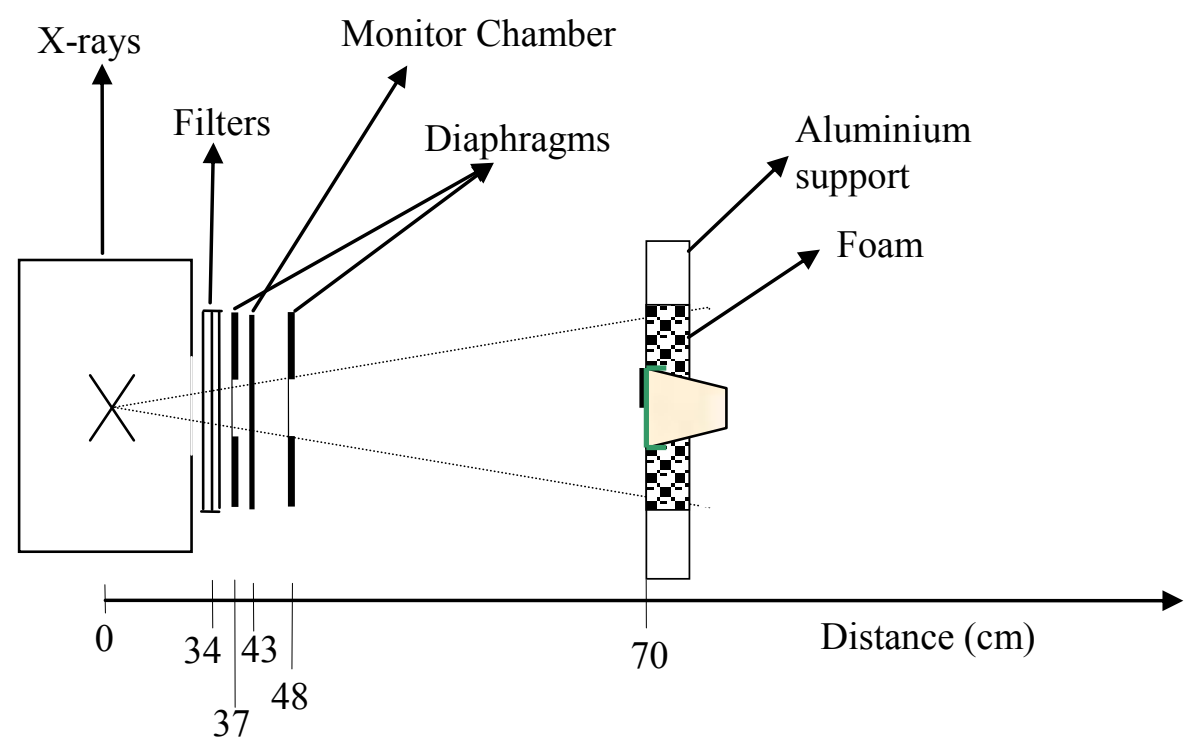

Figure 2: Irradiation set-up (not to scale).

\subsection{NMR Scanning}

After approximately 17 hours the samples were scanned using a Bruker BioSpin system (BioSpec 94/20 USR, 9.4 T). A Multi Slice Multi Echo sequence (MSME) was used with FOV $=6 \times 6 \mathrm{~cm}^{2}$, echo times of $20,40, \ldots, 320 \mathrm{~ms}$ and a repetition time of $2500 \mathrm{~ms}$. One slice with $1 \mathrm{~mm}$ thickness was measured in the surface of each sample. The T2 values were obtained by fitting all signal echoes to a monoexponential function. Then, the transversal relaxation rates $(\mathrm{R} 2=1 / \mathrm{T} 2)$ were related to the doses. Two R2 in different regions of interest (ROI) per sample were measured; one under the area covered by the gold foil and the other out of the area covered with gold. The gold foils were removed before the scanning.

\section{Results and Discussion}

The relation between R2 and the dose is represented in the Figure 3. It is observed that the relaxation rates measured under the gold foils are greater than those measured in the area free of gold. One can observe that the slope from the linear regression of the measurements in the area with gold is greater than the slope obtained from the measurements in the area without gold. This indicates that the presence of gold foils on the surface of the samples caused a dose enhancement in the vicinity of these gold foils by $16 \%$. This result can serve just as an estimate because of two important factors: the thickness of the gold foils was not known exactly; and the gold foils were very flexible and easily torn, so the difficulty of dealing with such foils caused that some small areas were not well covered. 


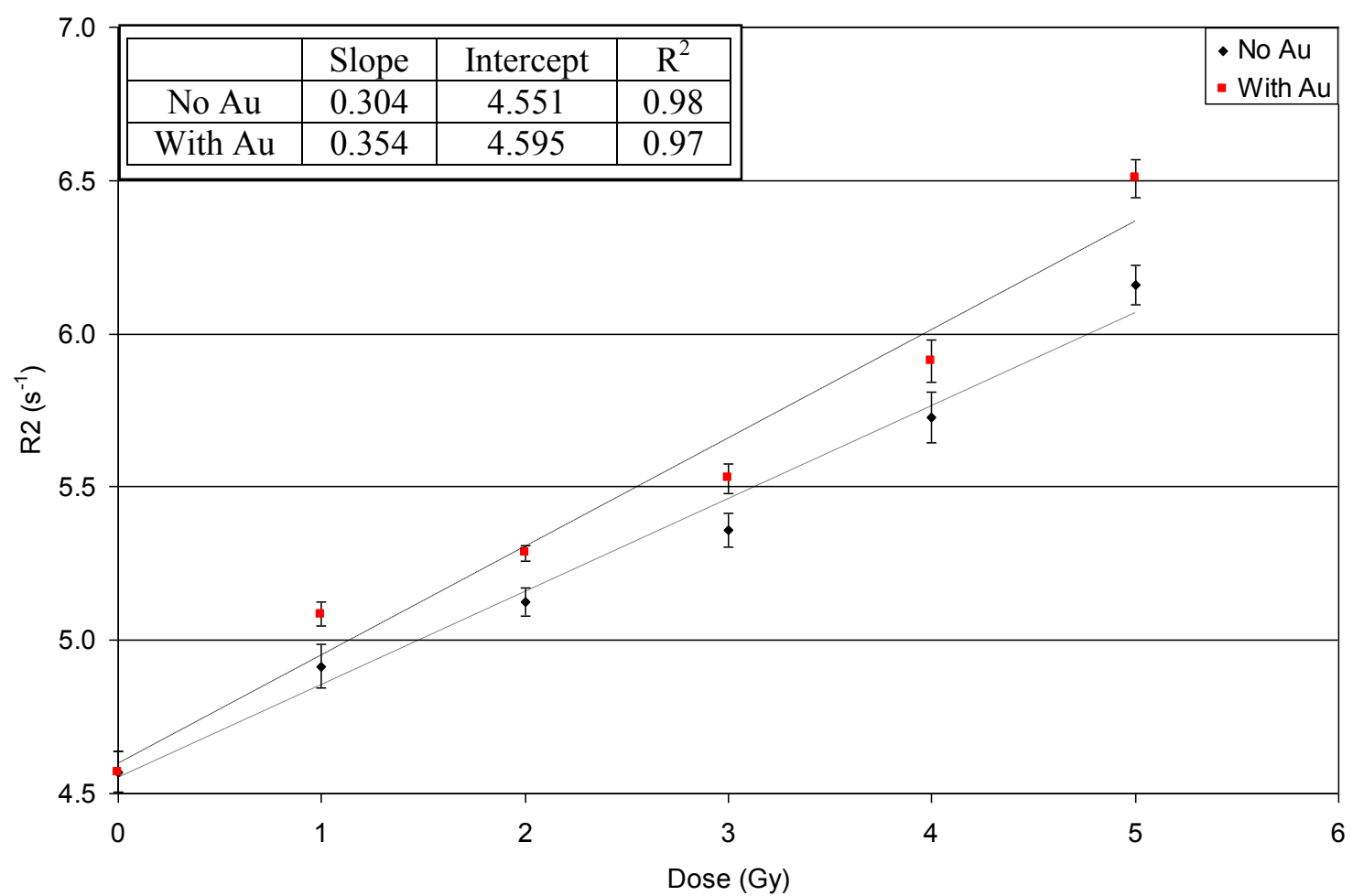

Figure 3: Relation between R2 and the dose. The red squares represent the area covered with gold foils and the black lozenges represent the area not covered with gold foils. The error bars represent the standard deviation of the R2 in the ROI.

\section{Conclusion}

The result of this study indicates the effect of dose enhancement in the area adjacent to the gold foils. Nevertheless, taking into account that difficulties mentioned above may play an important role, the experiment will be repeated using more resistant gold surfaces (i.e., thicker foils or plates) in order to assure this result and achieve a better quantification. The scanning will be performed with thinner slices, with a sequence of slices into the depth of the gels.

\section{References}

[1] Regulla D, Friedland W, Hieber L et al (2000) Spatially Limited Effects of Dose and LET Enhancement Near Tissue/Gold Interfaces at Diagnostic X Ray Qualities. Radiation Protection Dosimetry, 90, Nos 1-2, pp. 159-163

[2] Regulla D, Panzer W, Schmid E et al (2001) Detection of Elevated RBE in Human Lymphocytes Exposed to Secondary Electrons Released from X-Irradiated Metal Surfaces. Ratiation Research, 155, pp. 744-747

[3] Herold DM, Das IJ, Stobbe CC et al (2000) Gold Microspheres: a Selective Technique for Producing Biologically Effective Dose Enhancement. International Journal of Radiation Biology, 76, No 10, pp. 1357-1364

[4] Alexander P, Charlesby A, Ross M (1954) The Degradation of Solid Polymethyl-methacrylate by Ionizing Radiations. Proceedings of the Royal Society, pp. 392-404

[5] Hoecker FE, Watkins IW (1958) Radiation Polymerization Dosimetry. International Journal of Applied Radiation and Isotopes, 3, pp. 31-36

[6] Maryanski MJ, Gore JC, Schulz RJ (1992) 3-D Radiation Dosimetry by MRI: Solvent Proton Relaxation Enhancement by Radiation-Controlled Polymerisation and Cross-Linking in Gels. Proc. Intl. Soc. Mag. Reson. Med. 
[7] Maryanski MJ, Gore JC, Kennan RP et al (1993) NMR Relaxation Enhancement in Gels Polymerized and Cross-Linked by Ionizing Radiation: a New Approach to 3D Dosimetry by MRI. Magn. Reson. Imaging, 11, pp. 253-258

[8] Berg A, Ertl A, Moser E (2001) High Resolution Polymer Gel Dosimetry by Parameter Selective MR-Microimaging on a Whole Body Scanner at 3 T. Medical Physics, 28(5), pp. 833-843

[9] Bayreder C, Georg D, Moser E et al (2006) The spatial resolution in dosimetry with normoxic polymer-gels investigated with the dose modulation transfer approach. Medical Physics, 35(5), pp. 1756-1769

[10] Fong PM, Keil DC, Does MD, Gore JC (2001) Polymer Gels for Magnetic Resonance Imaging of Radiation Dose Distributions at Normal Room Atmosphere. Physics in Medicine and Biology, 46, pp. 3105-3113

[11] Baustert IC, Oldham M, Smith TAD et al (2000) Optimized MR Imaging for Polyacrylamide Gel Dosimetry. Physics in Medicine and Biology, 45, pp. 847-858

[12] McJury M, Oldham M, Cosgrove VP et al (2000) Radiation Dosimetry Using Polymer Gels: Methods and Applications. The British Journal of Radiology, 73, pp. 919-929 


\title{
DOSE SENSITIVITY ENHANCEMENT ON POLYMER GEL WITH SUSPENDED GOLD PARTICLES
}

\author{
L.C. Afonso ${ }^{1,2}$, F. Schöfer ${ }^{2}$, C. Hoeschen ${ }^{2}$, L.V.E. Caldas ${ }^{\underline{1}}$ \\ Luciana.afonso@helmholtz-muenchen.de \\ ${ }^{1}$ Institute of Energy and Nuclear Research, University of Sao Paulo, Sao Paulo, Brazil \\ ${ }^{2}$ Helmholtz Center Munich, German Research Center for Environmental Health, Neuherberg, Germany
}

The presence of high-Z materials adjacent to soft tissues, when submitted to irradiation, enhances locally the absorbed dose in these soft tissues. Such effects happen due to the outscattering of photoelectrons from the high-Z materials $[1,2,3]$. To investigate this effect, polymer gel dosimeters with suspended gold microspheres were used. This study was performed using the polymer gel dosimeter known as MAGIC [4].

The polymer gel was produced and divided into two parts. One part was uniformly mixed with gold microspheres at a concentration of $0.5 \%$ by weight and the other part contained only polymer gel. Each part was poured into test tubes, 4 samples per dose were used, in a range from 0 to $6 \mathrm{~Gy}$. The unirradiated samples were taken as control.

The samples were irradiated with X-rays generated at $150 \mathrm{kV}$, filtered with $4 \mathrm{~mm} \mathrm{Al}$ and 5 $\mathrm{mm} \mathrm{Cu}$, at a constant air kerma rate of $18.9 \mathrm{mGy} / \mathrm{min}$. All samples were read using a Bruker 9.4 T Magnetic Resonance scanner. The transversal relaxation rate R2 (measured in terms of $\mathrm{T} 2=1 / \mathrm{R} 2$ ) from each sample (minus the R2 value from the control) was plotted against the nominal delivered dose to obtain the calibration curves. The samples containing polymer gel with gold microspheres presented approximately $20 \%$ higher change of the R2 value per dose in comparison to the samples containing only polymer gel. This result indicates a dose enhancement factor of approximately $20 \%$. An analytic estimation predicted a dose enhancement factor of $30 \%$. The calculations are being refined for a closer description of the experimental parameters.

1. Regulla D, Friedland W, Hieber L et al (2000) Spatially limited effects of dose and LET enhancement near tissue/gold interfaces at diagnostic $X$ ray qualities. Radiation Protection Dosimetry, 90;1-2:159-163

2. Regulla D, Panzer W, Schmid E et al (2001) Detection of elevated RBE in human lymphocytes exposed to secondary electrons released from $\mathrm{X}$-irradiated metal surfaces. Ratiation Research, 155;744-747

3. Herold DM, Das IJ, Stobbe CC et al (2000) Gold microspheres: a selective technique for producing biologically effective dose enhancement. International Journal of Radiation Biology, 76;10:1357-1364

4. Fong PM, Keil DC, Does MD, Gore JC (2001) Polymer gels for magnetic resonance imaging of radiation dose distributions at normal room atmosphere. Physics in Medicine and Biology, 46;3105-3113

International Conference on Development and Applications of Nuclear Technologies, Krakow, Poland, 2011. 
